Marcus Rogério Oliveira dos Santos

\title{
Aplicação do Método Clássico na Resolução de Sistemas Planos Hiperestáticos
}

Dissertação apresentada à

Escola Politécnica da

Universidade de São Paulo para obtenção do titulo de Mestre em Engenharia 
Marcus Rogério Oliveira dos Santos

Engenheiro Civil - Escola Politécnica USP - 1995

\section{Aplicação do Método Clássico na Resolução de Sistemas Planos Hiperestáticos}

Dissertação apresentada à

Escola Politécnica da

Universidade de São Paulo

para obtenção do título de

Mestre em Engenharia

Orientador: Prof. Dr. Henrique de Britto Costa

SÃo PAULO 
Dedico este trabalho a meu filho, Thales, e a meu eterno amigo José Louzas. 


\section{Agradecimentos}

Tudo aquilo que conseguimos realizar, nunca fazemos sozinhos. As colaborações vêm das mais diversas direções que vão desde a orientação da linha a ser seguida no trabalho até uma palavra ou um gesto de incentivo, de apoio. Com isso, não será possível agradecer a todos aqueles que deixaram sua contribuição, mas que com toda certeza, serão sempre lembrados.

Ao Professor Henrique de Britto Costa pela valiosa orientação, pela atenção e pela paciência indispensáveis para a elaboração deste trabalho;

Aos Professores Edgard Sant'Anna de Almeida Neto e Henrique Lindenberg Neto pelos comentários realizados no exame de qualificação que contribuíram para enriquecer o tema tratado;

Ao Luiz Eduardo Cavalcante de Albuquerque, amizade praticada desde a graduação na Politécnica, pelo incentivo e pelo auxílio na resolução de alguns problemas durante o mestrado;

A Luciana Marujo Oliver, pela paciência, pelo apoio e sobretudo pelo carinho;

A meus pais, José e Lílian, pelo incentivo;

Ao Engenheiro Carlos A. Fontes pelo auxílio num dos momentos mais críticos do mestrado;

Ao Edson Sugahara, do Banco Itaú, por permitir a compatibilidade entre a pós-graduação e as minhas atividades no Banco;

A todos aqueles que, mesmo não estando mais presentes, deixaram sua contribuição, que permanecem como referências e estarão sempre em todas as minhas realizações: José Louzas, Filomena Gaccione, Luiza Gaccione Visconti, Scipione Visconti e Aristides Visconti Neto. 


\section{Resumo}

O Método Clássico é constituído por um conjunto de hipóteses relativas ao comportamento da estrutura. Dentro dessas proposições, é possível utilizar maneiras distintas de obter o campo dos esforços e o campo dos deslocamentos. A maneira mais tradicional se dá por meio dos Processos dos Esforços e dos Deslocamentos. No entanto, esses dois caminhos não encerram todas as alternativas. É neste sentido que se propõe o Processo Direto: além de ser considerado mais um procedimento de resolução de estruturas hiperestáticas nas hipóteses encerradas pelo Método Clássico, podem ser, por meio de suas equações, introduzidos os Processos dos Esforços e dos Deslocamentos. Este trabalho segue esta linha para a exposição do assunto, contendo em sua parte final, observações relativas à aplicação dos três processos. 


\section{Abstract}

The Classic Method is constituded by a set of hypothesis relative to the structural behavior. Within those propositions, it is possible to use distincts ways to obtain forces field and the displacements field. The most traditional way goes though the Forces and the Displacements Approaches. However, these two ways don't close all alternatives. Is in this line that is proposed the Direct Process: besides being considered another procedure to solve hiperestatic structures in hypothesis closed by Classic Method, one can, through its equations, being introduced the Forces and the Displacements Process. This work follows this line for a subject exposition, having in its final part, observations relatives to application of the three process. 


\section{Lista de Figuras}

Figura 1.1: Esquema de uma barra

Figura 1.2: Esquema do perfil da seção transversal de uma barra

Figura 1.3: Gráfico Esforços/Deslocamentos de um sistema de resposta linear

Figura 2.1: Graus de liberdade de um pórtico de $\mathrm{h}=7$

Figura 2.2: Exemplos de estruturas hipostáticas

Figura 2.3: Exemplos de estruturas isostáticas

Figura 2.4: Exemplos de estruturas hiperestáticas

Figura 2.5: Exemplo de estrutura para aplicação do procedimento

Figura 2.6: Nó A que une n seções

Figura 2.7: Outro exemplo de estrutura para aplicação do procedimento

Figura 2.8: Diagrama tridimensional dos trabalhos real e virtual

Figura 2.9: Diagrama tridimensional dos trabalhos real e virtual complementar

Figura 2.10: Diagrama bidimensional dos trabalhos virtual e virtual complementar

Figura 2.11: Ilustração de ações e deslocamentos correspondentes

Figura 2.12: Estrutura com carga unitária aplicada, $A_{1}=1, A_{2}=0$

Figura 2.13: Estrutura com carga unitária aplicada, $A_{1}=0, A_{2}=1$

Figura 2.14: Estrutura com deslocamento unitário imposto, $D_{1}=1, D_{2}=0$

Figura 2.15: Estrutura com deslocamento unitário imposto, $\mathrm{D}_{1}=0, \mathrm{D}_{2}=1$

Figura 2.16: Eliminação dos vínculos de extremidade da estrutura da Figura 2.11

Figura 2.17: Estrutura com rigidez infinita entre os pontos de aplicação das cargas

Figura 3.1(a): Ilustração do nó $j$ da treliça

Figura 3.1(b): Deslocamentos virtuais impostos no nó j

Figura 3.1(c): Esforços no nó j

Figura 3.2: Barra (i) da treliça

Figura 3.3: Aplicação dos deslocamentos virtuais na barra (i)

Figura 3.4: Deslocamentos virtuais aplicados no nó $\mathrm{k}$

Figura 3.5: Deslocamentos virtuais aplicados no nó 1

Figura 3.6: Treliça plana com um grau de liberdade e um grau de hiperestaticidade

Figura 3.7: Grau de liberdade da treliça

Figura 3.8: Deslocamento virtual na treliça segundo o grau de liberdade $a_{1}$

Figura 3.9: Deslocamento virtual imposto

Figura 3.10: Estrutura isostática fundamental

Figura 3.11: Treliça hiperestática

Figura 3.12: Graus de liberdade da treliça

Figura 3.13: Imposição do deslocamento virtual segundo o grau de liberdade $a_{1}$

Figura 3.14: Deslocamento virtual imposto em $\mathrm{a}_{1}$ e deformações decorrentes

Figura 3.15: Imposição do deslocamento virtual segundo o grau de liberdade $a_{2}$

Figura 3.16: Imposição do deslocamento virtual em $a_{2}$ e deformações decorrentes

Figura 3.17: Imposição do deslocamento virtual segundo o grau de liberdade $\mathrm{a}_{3}$

Figura 3.18: Imposição do deslocamento virtual em $a_{3}$ e deformações decorrentes 
Figura 3.19: Esforço virtual aplicado em substituição ao vínculo na estrutura isostática

Figura 3.20: Aplicação do esforço virtual $\delta X_{2}$

Figura 3.21: Diagrama de esforços solicitantes da treliça

Figura 4.1(a) e (b): Deslocamentos virtuais numa barra de pórtico e os esforços de extremidade

Figura 4.2: Deslocamentos impostos nas extremidades da barra (i)

Figura 4.3: Deslocamentos virtuais horizontal e vertical no nó $\mathrm{k}$

Figura 4.4: Deslocamentos virtuais horizontal e vertical no nó 1

Figura 4.5: Nó de pórtico com os esforços internos e os esforços aplicados

Figura 4.6: Viga apoiada-engastada

Figura 4.7: Grau de liberdade da viga apoiada-engastada

Figura 4.8: Esforços de extremidade da barra engastada-apoiada

Figura 4.9: Superposição de efeitos para a resolução da viga apoiada-engastada

Figura 4.10: Deslocamento virtual imposto segundo o grau de liberdade $a_{1}$

Figura 4.11: Estrutura isostática fundamental da viga apoiada-engastada

Figura 4.12: Esforço virtual aplicado sobre a estrutura isostática fundamental

Figura 4.13: Diagrama de momento fletor decorrente da ação de $\delta \mathrm{X}_{1}$

Figura 4.14: Diagrama de curvaturas reais da viga apoiada-engastada

Figura 4.15: Resultados dos casos 1 e 2 da viga apoiada-engastada

Figura 4.16: Resultado final da viga apoiada-engastada

Figura 4.17: Pórtico plano hiperestático

Figura 4.18: Graus de liberdade do pórtico plano hiperestático

Figura 4.19: Convenção de sinais dos esforços solicitantes nas barras do pórtico

Figura 4.20: Rotação virtual imposta segundo o grau de liberdade $a_{1}$

Figura 4.21: Deslocamento virtual imposto segundo o grau de liberdade $a_{2}$

Figura 4.22: Deslocamento virtual imposto segundo o grau de liberdade $a_{3}$

Figura 4.23: Rotação virtual imposta segundo o grau de liberdade $a_{4}$

Figura 4.24: Aplicação do esforço virtual $\delta X_{1}$ na estrutura isostática

Figura 4.25: Diagrama de esforço normal da estrutura isostática fundamental devido à ação de $\delta X_{1}$

Figura 4.26: Diagrama de momento fletor da estrutura isostática fundamental devido à ação de $\delta X_{1}$

Figura 4.27: Diagrama de curvaturas reais do pórtico

Figura 4.28: Aplicação do esforço virtual $\delta X_{2}$ na estrutura isostática fundamental

Figura 4.29: Diagrama de esforço normal da estrutura isostática fundamental devido à ação de $\delta X_{2}$

Figura 4.30: Diagrama de momento fletor da estrutura isostática fundamental devido à ação de $\delta \mathrm{X}_{2}$

Figura 4.31: Diagrama de esforços solicitantes do pórtico

Figura 5.1: Treliça hiperestática

Figura 5.2: Aplicação dos deslocamentos segundo os graus de liberdade da estrutura 
Figura 5.3: Pórtico plano hiperestático

Figura 5.4: Aplicação dos deslocamentos segundo os graus de liberdade da estrutura

Figura 5.5: Convenção de sinais para esforços

Figura 5.6: Ações de engastamento perfeito produzidas por deslocamentos de extremidade e o diagrama de curvatura correspondente.

Figura 5.7(a): Diagramas de curvatura e deformação axial do pórtico quando imposto o deslocamento $a_{1}$

Figura 5.7(b): Diagramas de curvatura e deformação axial do pórtico quando imposto o deslocamento $a_{2}$

Figura 5.7(c): Diagramas de curvatura e deformação axial do pórtico quando imposto o deslocamento $a_{3}$

Figura 5.7(d): Diagramas de curvatura e deformação axial do pórtico quando imposto o deslocamento $\mathbf{a}_{4}$

Figura 5.8: Obtenção dos coeficientes $\mathrm{N}_{\mathrm{i} 0}$ para os esforços na estrutura original

Figura 5.9: Aplicação do esforço unitário relativo à incógnita $X_{1}$ para obtenção dos coeficientes $\mathrm{N}_{\mathrm{il}}$

Figura 5.10: Aplicação do esforço unitário relativo à incógnita $\mathrm{X}_{2}$ para obtenção dos coeficientes $\mathrm{N}_{\mathrm{i} 2}$

Figura 5.11: Obtenção dos coeficientes para os esforços na estrutura original

Figura 5.12: Coeficientes relativos aos esforços decorrentes das cargas na estrutura original

Figura 5.13: Aplicação do esforço unitário $\mathrm{X}_{1}$ para obtenção dos coeficientes $\mathrm{N}_{\mathrm{i} 1}$

Figura 5.14: Coeficientes relativos à aplicação do esforço $\mathrm{X}_{1}$

Figura 5.15: Aplicação do esforço unitário $\mathrm{X}_{2}$ para obtenção dos coeficientes $\mathrm{N}_{\mathrm{i} 2}$

Figura 5.16: Coeficientes relativos à aplicação do esforço $\mathrm{X}_{2}$

Figura 6.1: Treliça

Figura 6.2: Estrutura isostática fundamental da treliça da Figura 6.1

Figura 6.3: Estrutura isostática fundamental resolvida para o carregamento original

Figura 6.4: Estrutura isostática fundamental resolvida para o carregamento unitário aplicado segundo $\mathrm{X}_{1}$

Figura 6.5: Estrutura isostática fundamental resolvida para o carregamento unitário aplicado segundo $\mathrm{X}_{2}$

Figura 6.6: Graus de liberdade da treliça

Figura 6.7: Estrutura bloqueada

Figura 6.8: Imposição do deslocamento unitário segundo $a_{1}$

Figura 6.9: Ampliação da região em que se impôs o deslocamento unitário

Figura 6.10: Forças atuantes no nó $\mathrm{A}$

Figura 6.11: Forças atuantes no nó $\mathrm{B}$

Figura 6.12: Imposição do deslocamento unitário segundo $a_{2}$

Figura 6.13: Ampliação da região em que se impôs o deslocamento unitário

Figura 6.14: Forças atuantes no nó $\mathrm{A}$

Figura 6.15: Forças atuantes no nó $\mathrm{B}$ 


\section{Lista de Símbolos}

\begin{tabular}{|c|c|}
\hline$A$ & Área da seção transversal \\
\hline A & Nó da estrutura \\
\hline$A^{\prime}$ & Posição final do nó A \\
\hline$A_{i}$ & Esforço externo aplicado $(i=1,2,3, \ldots)$ \\
\hline$\{A\}$ & Vetor dos esforços externos aplicados \\
\hline $\mathrm{a}$ & Dimensão linear da barra \\
\hline$\{a\}$ & Vetor deslocamentos nodais \\
\hline$\left\{a^{\prime}\right\}$ & Vetor dos deslocamentos causados pelos esforços $\mathrm{f}$ \\
\hline$\left\{a^{\prime \prime}\right\}$ & Vetor dos deslocamentos contidos por $\mathrm{f}^{0}$ \\
\hline$a_{i}$ & Grau de liberdade $i(i=1,2,3, \ldots)$ \\
\hline$\alpha$ & Ângulo formado entre uma barra e uma dada direção \\
\hline$\alpha_{i}$ & Ângulo de incidência da barra i $(\mathrm{i}=1,2,3, \ldots)$ \\
\hline$\alpha_{k}$ & Ângulo de incidência da barra no nó $\mathrm{k}$ \\
\hline$\alpha_{1}$ & Ângulo de incidência da barra no nó 1 \\
\hline$\alpha_{p}$ & Ângulo de incidência da barra $p$ \\
\hline$\alpha_{\mathrm{r}}$ & Rotação da seção transversal \\
\hline B & Nó da estrutura \\
\hline $\mathrm{b}_{1}$ & Dimensão transversal da barra \\
\hline $\mathrm{b}_{2}$ & Dimensão transversal da barra \\
\hline$b_{3}$ & Dimensão longitudinal da barra \\
\hline$\beta$ & Ângulo formado entre uma barra e uma dada direção \\
\hline $\mathrm{C}$ & Nó da estrutura \\
\hline $\mathrm{C}^{\prime}$ & Posição final do nó C \\
\hline $\mathrm{D}$ & Nó da estrutura \\
\hline D' & Posição final do nó D \\
\hline$D_{i}$ & Deslocamento da estrutura segundo a direção i $(\mathrm{i}=1,2,3, \ldots)$ \\
\hline$D_{i j}$ & Deslocamento correspondente a $A_{i}$, causado exclusivamente por $A_{j}$ \\
\hline$\{D\}$ & Vetor deslocamento da estrutura \\
\hline $\mathrm{d}$ & Deslocamento real genérico \\
\hline$d_{i}$ & Deslocamento em uma posição de equilíbrio $\mathrm{i}(\mathrm{i}=1,2,3, \ldots)$ \\
\hline $\mathrm{du}$ & Deslocamento real horizontal diferencial \\
\hline $\mathrm{dv}$ & Deslocamento real vertical diferencial \\
\hline$\delta_{\mathrm{i}}$ & Componente do vetor $\{\delta\}$ \\
\hline$\delta_{i}^{0}$ & Componente do vetor $\left\{\delta^{0}\right\}$ \\
\hline$\{\delta\}$ & $\begin{array}{l}\text { Vetor deslocamento correspondente aos esforços hiperestáticos - estrutura } \\
\text { original }\end{array}$ \\
\hline$\left\{\delta^{0}\right\}$ & $\begin{array}{l}\text { Vetor deslocamento correspondente aos esforços hiperestáticos - estrutura } \\
\text { isostática fundamental }\end{array}$ \\
\hline $\bar{\delta}_{i j}$ & Deslocamento correspondente a $f_{i}$ e devido a $f_{j}=1$, na estrutura original \\
\hline$\delta_{i j}$ & Coeficiente de flexibilidade \\
\hline$\delta a_{i}$ & Deslocamento virtual segundo o grau de liberdade $a_{i}(i=1,2,3, \ldots)$ \\
\hline
\end{tabular}




\begin{tabular}{|c|c|}
\hline $8 \mathrm{~d}$ & Deslocamento virtual genérico \\
\hline$\delta \Delta \mathrm{L}_{\mathrm{i}}$ & Variação virtual de comprimento da barra i $(\mathrm{i}=1,2,3, \ldots)$ \\
\hline$\delta \Delta p_{\mathrm{I}}$ & Deslocamento virtual relativo entre as extremidades da barra i $(\mathrm{i}=1,2,3, \ldots)$ \\
\hline$\delta e$ & Esforço virtual genérico \\
\hline$\delta \mathrm{N}_{\mathrm{i}}$ & Esforço virtual normal na barra $\mathrm{i}(\mathrm{i}=1,2,3, \ldots)$ \\
\hline$\delta \theta_{\mathrm{A}}$ & Rotação virtual do nó A \\
\hline$\delta \theta_{\mathbf{B}}$ & Rotação virtual do nó B \\
\hline$\delta \theta_{j}$ & Rotação virtual do nó j \\
\hline$\delta u_{A}$ & Deslocamento virtual horizontal aplicado ao nó A \\
\hline$\delta u_{B}$ & Deslocamento virtual horizontal aplicado ao nó B \\
\hline$\delta u_{j}$ & Deslocamento virtual horizontal imposto ao nó $\mathrm{j}$ \\
\hline$\delta u_{k}$ & Deslocamento virtual horizontal imposto ao nó $\mathrm{k}$ \\
\hline$\delta \mathrm{u}_{1}$ & Deslocamento virtual horizontal imposto ao nó 1 \\
\hline$\delta v_{A}$ & Deslocamento virtual vertical imposto ao nó A \\
\hline$\delta \mathrm{v}_{\mathrm{B}}$ & Deslocamento virtual vertical imposto ao nó B \\
\hline$\delta \mathrm{v}_{\mathrm{j}}$ & Deslocamento virtual vertical imposto ao nó j \\
\hline$\delta v_{k}$ & Deslocamento virtual vertical imposto ao nó $\mathrm{k}$ \\
\hline$\delta v_{1}$ & Deslocamento virtual vertical imposto ao nó 1 \\
\hline$\delta \mathrm{X}_{\mathrm{i}}$ & Esforço virtual $X_{i}$ aplicado segundo o grau de hiperestaticidade $\mathrm{i}(\mathrm{i}=1,2,3, \ldots)$ \\
\hline$\delta \mathrm{W}$ & Trabalho virtual \\
\hline$\delta \mathrm{W}_{\mathrm{i}}$ & Trabalho virtual realizado pelos esforços internos \\
\hline$\delta W_{i j}$ & Trabalho virtual da barra $\mathrm{j}$ realizado pelos esforços internos $(\mathrm{j}=1,2,3, \ldots)$ \\
\hline$\delta \mathrm{W}_{\mathrm{e}}$ & Trabalho virtual realizado pelos esforços externos \\
\hline$\delta \mathrm{W}^{*}$ & Trabalho virtual complementar \\
\hline$\delta W_{i}^{*}$ & Trabalho virtual complementar realizado pelos esforços internos \\
\hline$\delta \mathrm{W}_{\mathrm{ij}}{ }^{*}$ & Trabalho virtual complementar da barra $\mathrm{j}$ realizado pelos esforços internos \\
\hline$\delta \mathrm{W}_{\mathrm{e}}^{*}$ & Trabalho virtual complementar realizado pelos esforços externos \\
\hline$\Delta \mathrm{L}_{\mathrm{i}}$ & Variação do comprimento da barra i $(\mathrm{i}=1,2,3, \ldots)$ \\
\hline$\Delta \rho_{i}$ & Deslocamento relativo entre as extremidades da barra $\mathrm{i}(\mathrm{i}=1,2,3, \ldots)$ \\
\hline$E$ & Módulo de elasticidade \\
\hline $\mathrm{E}$ & Nó da estrutura \\
\hline $\mathrm{e}$ & Esforço real genérico \\
\hline$e_{i}$ & Esforço real correspondente a uma posição de equilíbrio $(\mathrm{i}=1,2,3, \ldots)$ \\
\hline$\varepsilon_{\mathrm{I}}$ & Deformação axial da barra $\mathrm{i}(\mathrm{i}=1,2,3, \ldots)$ \\
\hline $\mathrm{F}$ & Nó da estrutura \\
\hline$\underline{\underline{F}]}$ & Matriz de flexibilidade \\
\hline$[F]$ & $\begin{array}{l}\text { Matriz de flexibilidade dos elementos } \bar{\delta}_{i j} \\
\text { Vetor dos esforcos correspondentes aos decamentoc nodois }\end{array}$ \\
\hline$\{f\}$ & $\begin{array}{l}\text { Vetor dos esforços correspondentes aos deslocamentos nodais - estrutura original } \\
\text { Vetor dos esforços correspondentes aos deslocamentos nodais - estrutura }\end{array}$ \\
\hline$\left\{\mathrm{f}^{\circ}\right\}$ & $\begin{array}{l}\text { Vetor dos esforços correspondentes aos deslocamentos nodais - estrutura } \\
\text { bloqueada }\end{array}$ \\
\hline $\mathrm{f}_{\mathrm{i}}$ & Componente do vetor $\{f\}$ \\
\hline$f_{i}^{0}$ & Componente do vetor $\left\{\mathrm{f}^{0}\right\}$ \\
\hline
\end{tabular}




\begin{tabular}{|c|c|}
\hline $\mathrm{G}$ & Nó da estrutura \\
\hline $\mathrm{g}$ & Grau de hiperestaticidade \\
\hline$g_{e}$ & Grau de hiperestaticidade externo \\
\hline$g_{i}$ & Grau de hiperestaticidade interno \\
\hline $\mathrm{h}$ & Graus de liberdade da estrutura \\
\hline$I_{\mathrm{i}}$ & Momento de inércia da barra i $(\mathrm{i}=1,2,3, \ldots)$ \\
\hline $\mathrm{k}$ & Nó de extremidade da barra \\
\hline $\mathrm{k}_{\mathrm{i}}$ & Projeções do nó $\mathrm{k}(\mathrm{i}=1,2,3, \ldots)$ \\
\hline $\mathrm{k}^{\prime}$ & Posição final do nó $\mathrm{k}$ \\
\hline $\mathrm{K}_{\mathrm{ij}}$ & Coeficientes de rigidez \\
\hline$\overline{K_{i j}}$ & Esforço correspondente a $\delta_{\mathrm{I}}$ e devido a $\delta_{\mathrm{j}}=1$, na estrutura original \\
\hline$[\mathrm{K}]$ & Matriz de rigidez \\
\hline$[\bar{K}]$ & Matriz de rigidez dos elementos $\bar{K}_{i j}$ \\
\hline$\kappa$ & Curvatura \\
\hline$\kappa_{i}$ & Curvatura relativa ao momento $\mathrm{M}_{\mathrm{i}}(\mathrm{i}=1,2,3, \ldots)$ \\
\hline 1 & Nó de extremidade da barra \\
\hline$l_{i}$ & Projeções do nó $1(\mathrm{i}=1,2,3, \ldots)$ \\
\hline l' & Posição final do nó 1 \\
\hline $\mathrm{L}$ & Comprimento da barra \\
\hline $\mathrm{L}_{\mathbf{i}}$ & Comprimento da barra $\mathrm{i}$ \\
\hline $\mathrm{M}_{\mathrm{A}}$ & Momento de extremidade da viga - nó A \\
\hline $\mathrm{M}_{\mathrm{B}}$ & Momento de extremidade na viga - nó B \\
\hline $\mathrm{M}_{\mathrm{i}}$ & Momento aplicado ao nó $\mathrm{j}$ \\
\hline $\mathrm{M}_{\mathrm{ij}}$ & $\begin{array}{l}\text { Coeficiente relativo ao momento da barra i correspondente à incógnita } \\
\text { hiperestática } j\end{array}$ \\
\hline $\mathrm{m}$ & Número de barras \\
\hline $\mathrm{N}$ & Esforço normal \\
\hline $\mathrm{N}_{\mathrm{i}}$ & Esforço normal na barra i $(\mathrm{i}=1,2,3, \ldots)$ \\
\hline$N_{p}$ & Esforço normal na barra $\mathrm{p}$ \\
\hline $\mathrm{N}_{\mathrm{ij}}$ & $\begin{array}{l}\text { Coeficiente relativo ao esforço normal da barra i correspondente à incógnita } \\
\text { hiperestática } \mathrm{j}\end{array}$ \\
\hline $\mathrm{n}$ & número de nós \\
\hline $\mathbf{P}$ & Carga concentrada aplicada \\
\hline$P_{j}$ & Carga concentrada aplicada no nó j \\
\hline $\mathrm{P}_{\mathrm{xj}}$ & Projeção horizontal da carga $P_{i}$ \\
\hline $\mathrm{P}_{\mathrm{yj}}$ & Projeção vertical da carga $P_{j}$ \\
\hline $\mathrm{r}$ & Número de reações vinculares \\
\hline$u_{j}$ & Deslocamento real horizontal do nó $\mathrm{j}$ \\
\hline $\mathrm{V}_{\mathrm{i}}$ & Esforço transversal de extremidade na barra i $(i=1,2,3, \ldots)$ \\
\hline $\mathrm{V}_{\mathrm{A}}$ & Esforço transversal de extremidade da barra - nó A \\
\hline $\mathrm{V}_{\mathrm{Ai}}$ & $\begin{array}{l}\text { Esforço transversal de extremidade da barra no nó } A \text { devido ao efeito } i \\
(i=1,2,3, \ldots)\end{array}$ \\
\hline $\mathrm{V}_{\mathrm{B}}$ & Esforço transversal de extremidade da barra - nó B \\
\hline $\mathrm{V}_{\mathrm{Bi}}$ & Esforço transversal de extremidade da barra no nó B devido ao efeito i \\
\hline
\end{tabular}




\begin{tabular}{|c|l|}
\hline$v_{j}$ & Deslocamento real vertical do nó $\mathrm{j}$ \\
\hline$X_{j}$ & Esforço horizontal aplicado ao nó $\mathrm{j}$ \\
\hline$\{\mathrm{X}\}$ & Vetor dos esforços hiperestáticos \\
\hline$\left\{\mathrm{X}^{\prime}\right\}$ & Vetor dos esforços que produzem os deslocamentos $\delta$ \\
\hline$\left\{\mathrm{X}^{\prime \prime}\right\}$ & Vetor dos esforços que neutralizam os deslocamentos $\delta^{0}$ \\
\hline$Y_{j}$ & Esforço vertical aplicado ao nó $\mathrm{j}$ \\
\hline$Y_{\mathrm{i}}$ & Esforço atuante na barra $\mathrm{i}(\mathrm{i}=1,2,3, \ldots)$ \\
\hline $\mathrm{Y}_{\mathrm{ij}}$ & Coeficiente relativo à barra i em relação à incógnita hiperestática $\mathrm{j}$ \\
\hline $\mathrm{W}$ & Trabalho real \\
\hline
\end{tabular}




\section{E R R A T A}

Eliminar parágrafo na página 16 :

"No diagrama proposto... pela área amarela." 


\section{Índice}

1. Introdução 4

2. Conceitos Estruturais Fundamentais 9

2.1 Introdução 9

2.2 Estruturas Planas Indeterminadas 9

2.2.1 Grau de Liberdade (h) 9

2.2.2 Grau de Hiperestaticidade $(\mathrm{g}) \quad 10$

2.2.2.1 Procedimento para Determinação do Grau de Hiperestaticidade 12

$\begin{array}{lll}2.3 & \text { Trabalho Virtual } & 14\end{array}$

2.4 Ações e Deslocamentos Correspondentes 16

$\begin{array}{ll}2.5 & \text { Princípio da Superposição de Efeitos } \\ 2.6 & 17\end{array}$

$\begin{array}{lll}2.6 & \text { Coeficientes de Flexibilidade }\left(\delta_{i j}\right) & 18\end{array}$

$\begin{array}{lll}2.7 & \text { Coeficientes de Rigidez }\left(\mathrm{K}_{\mathrm{ij}}\right) & 19\end{array}$

$2.8 \quad$ Relação entre as Matrizes [K]e [F] 20

$\begin{array}{lll}2.9 & \text { Algumas Propriedades de }[\mathrm{K}] \mathrm{e}[\mathrm{F}] & 21\end{array}$

2.10 Condições de Existência das Matrizes [F] e [K] 21

$\begin{array}{lll}2.10 .1 & \text { Matriz }[\mathrm{F}] & 21\end{array}$

$\begin{array}{lll}2.10 .2 & \text { Matriz }[\mathrm{K}] & 22\end{array}$

3. O Processo Direto Aplicado à Resolução de Treliças Planas Hiperestáticas

$\begin{array}{lll}3.1 & \text { Introdução } & 24\end{array}$

3.2 O Teorema dos Deslocamentos Virtuais Aplicado a uma Treliça Plana 24

$\begin{array}{lll}3.3 & \text { O Teorema dos Esforços Virtuais Aplicado a uma Treliça Plana } 30\end{array}$

3.4 Aplicação do Processo Direto a um Sistema Estrutural com $\mathrm{g}=\mathrm{h}=\mathrm{l}$

3.5 Aplicação do Processo Direto a uma Treliça Plana Hiperestática 35 


\section{O Processo Direto Aplicado a Resolução dos Pórticos Planos}

Hiperestáticos

4.1 Introdução

4.2 O Teorema dos Deslocamentos Virtuais Aplicado a um Pórtico Plano

4.3 O Teorema dos Esforços Virtuais Aplicado a um Pórtico Plano 52

4.4 Aplicação do Processo Direto a um Sistema Estrutural com $\mathrm{g}=\mathrm{h}=1$

4.5 Aplicação do Processo Direto a um Pórtico Plano Hiperestático 56

5. Introdução aos Processos dos Esforços e dos Deslocamentos

5.3.1 O Processo dos Deslocamentos - Treliça 70

5.3.2 O Processo dos Deslocamentos - Pórtico 74

$5.4 \quad$ O Processo dos Esforços $\quad 80$

5.5 Introdução ao Processo dos Esforços 80

5.5.1 O Processo dos Esforços - Treliça 81

5.5.2 O Processo dos Esforços - Pórtico 86

6. Comparação Entre o Processo dos Esforços e o Processo dos Deslocamentos

6.2 Quadro Comparativo Entre o Processo dos Esforços e dos Deslocamentos

6.4 Ilustração da Aplicação dos Processos dos Esforços e dos 
6.4.2 Resolução da Treliça pelo Processo dos

7. Observações Finais

112

7.1 Introdução

112

7.2 Análises e Conclusões

112

8. Bibliografia

115 


\section{Capítulo 1}

\section{Introdução}

"O objetivo da Análise Estrutural é encontrar tensões resultantes, deslocamentos $e$ reações de apoio de vários tipos de estrutura, especialmente aquelas que são estaticamente indeterminadas ". " Para cumprir tal compromisso, é necessária a utilização de um Método. Segundo o Professor Telemaco van Langendonck ${ }^{2}$, o Método deve estar baseado na escolha de hipóteses fundamentais convenientemente escolhidas. Já o termo Processo refere-se a uma simples marcha de cálculo por meio da qual será resolvido o problema, seguindo um determinado Método. Qualquer que seja o Processo escolhido, os resultados obtidos dentro do mesmo Método serão os mesmos. Por outro lado, alterando qualquer hipótese, os resultados a serem obtidos serão diferentes.

O tema a ser tratado é a aplićação do Método Clássico na resolução de estruturas reticuladas planas hiperestáticas, especificamente pórticos e treliças. Sendo assim, apresenta-se o Processo Direto e posteriormente ele é comparado com os Processos dos Esforços e dos Deslocamentos. O Processo Direto foi anteriormente apresentado por Costa e Diogo em treliças ${ }^{3}$ e pórticos ${ }^{4}$ planos hiperestáticos. Esses sistemas estruturais são freqüentemente encontrados na prática da engenharia e vêm sendo resolvidos por meio dos processos tradicionais, dos Esforços e dos Deslocamentos.

Constitui objetivo deste trabalho a aplicação dos Processos Direto, dos Esforços e dos Deslocamentos, para os sistemas estruturais mencionados, destacando os aspectos relevantes decorrentes da formulação e da aplicação de cada processo. É importante destacar que, assim como as formulações tradicionais, a aplicação do Processo Direto pode ser estendida a outros tipos de estruturas, tais como placas, chapas e cascas, porém tal situação encontra-se fora da linha a ser desenvolvida neste trabalho. Esse processo pode ser considerado como "misto", pelo fato de se trabalhar, em um mesmo sistema linear que conduz à solução da estrutura, com equações de compatibilidade e de equilíbrio separadas umas das outras, enquanto nos Processos dos Esforços tem-se o sistema linear formado somente por equações de compatibilidade, estando o equilibrio implícito nas mesmas. No Processo dos Deslocamentos, analogamente, tem-se o sistema linear formado somente por equações de equilíbrio, estando a compatibilidade implícita.

\footnotetext{
${ }^{1}$ Timoshenko, S. P. Gere, J. Mecânica dos Sólidos. Vol. II, p. 332.

${ }^{2}$ Langendonck, T. H. M. Van. Considerações sobre o Método Clássico de Resolução das Estruturas Hiperestáticas

${ }^{3}$ Costa, H.B; Diogo, L.A. C. Considerações sobre o Emprego do Teorema dos Trabalhos Virtuais na Resolução de Estruturas Hiperestáticas: Treliças.

${ }^{4}$ Costa, H.B; Diogo, L.A. C. Considerações sobre o Emprego do Teorema dos Traballos Virtuais na Resolução de Estruturas Hiperestáticas: Pórticos
} 
São denominadas estruturas reticuladas planas aquelas formadas por barras e nós e ainda que tenham os vetores das forças no mesmo plano que contém a estrutura e os vetores momento perpendiculares ao mesmo. Entende-se por barra um ente linear, no qual duas dimensões, $b_{1}$ e $b_{2}$, possuem mesma ordem de grandeza e ambas são bem inferiores a uma terceira, $b_{3}$, conforme ilustra a figura 1.1 .

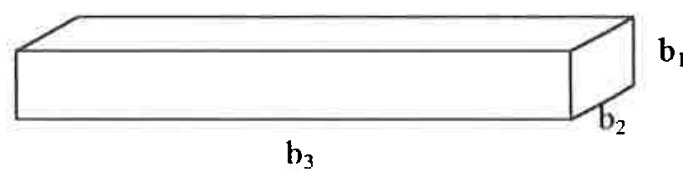

Figura 1.1: Esquema de uma barra

Entende-se por nós como sendo os pontos de intersecção dos eixos das barras, como também os pontos de apoio das mesmas e ainda as suas extremidades livres.

O Método Clássico está baseado nas seguintes hipóteses:

\section{- Equilíbrio;}

- $\quad$ Linearidade fisica e geométrica;

- Continuidade da estrutura.

A primeira hipótese implica afirmar que todas as estruturas analisadas estão em equilibrio estático de forças e de momentos.

A linearidade fisica significa que o material aqui estudado segue a Lei de Hooke, ou seja, verifica-se a proporcionalidade entre tensões e deformações. Já a linearidade geométrica equivale afirmar que não se verificam efeitos de segunda ordem, não havendo influência dos deslocamentos na determinação dos esforços solicitantes, podendo estes serem calculados em relação à posição indeformada da estrutura.

A continuidade caracteriza-se pela ausência de pontos angulosos na linha elástica de cada barra. Afirma-se ainda que se conservam constantes os ângulos entre as tangentes às linhas elásticas nos nós.

Além dessas hipóteses, há duas considerações a serem feitas com relação a este trabalho:

- $\quad$ Modelo de barra de Bernoulli-Euler;

- Carregamento estático.

A Teoria de Barra de Bernoulli-Euler considera a barra como sendo um ente unidimensional. Assim, as forças de volume e superfície são reduzidas ao seu eixo longitudinal. Desta maneira, as equações são restritas ao domínio definido por esse mesmo eixo e as condições de contorno a pontos do mesmo. As hipóteses básicas desse modelo são as seguintes:

1) A seção transversal da barra possui um eixo de simetria; 
2) Seções originariamente planas e perpendiculares ao eixo da barra permanecem planas (hipótese de Navier) e perpendiculares à tangente ao eixo da barra após a deformação;

3) Não ocorre deformação no plano da seção transversal;

4) Considerando pequenos deslocamentos, pequenas deformações e rotações, $u m$ elemento $d x$ de linha sofre translações $u(x)$ na direção $x$ e $\mathrm{v}(\mathrm{x})$ na direção y e ainda, rotação $\frac{d v}{d x}$ no plano xy.

5) O carregamento externo atua no plano de simetria.

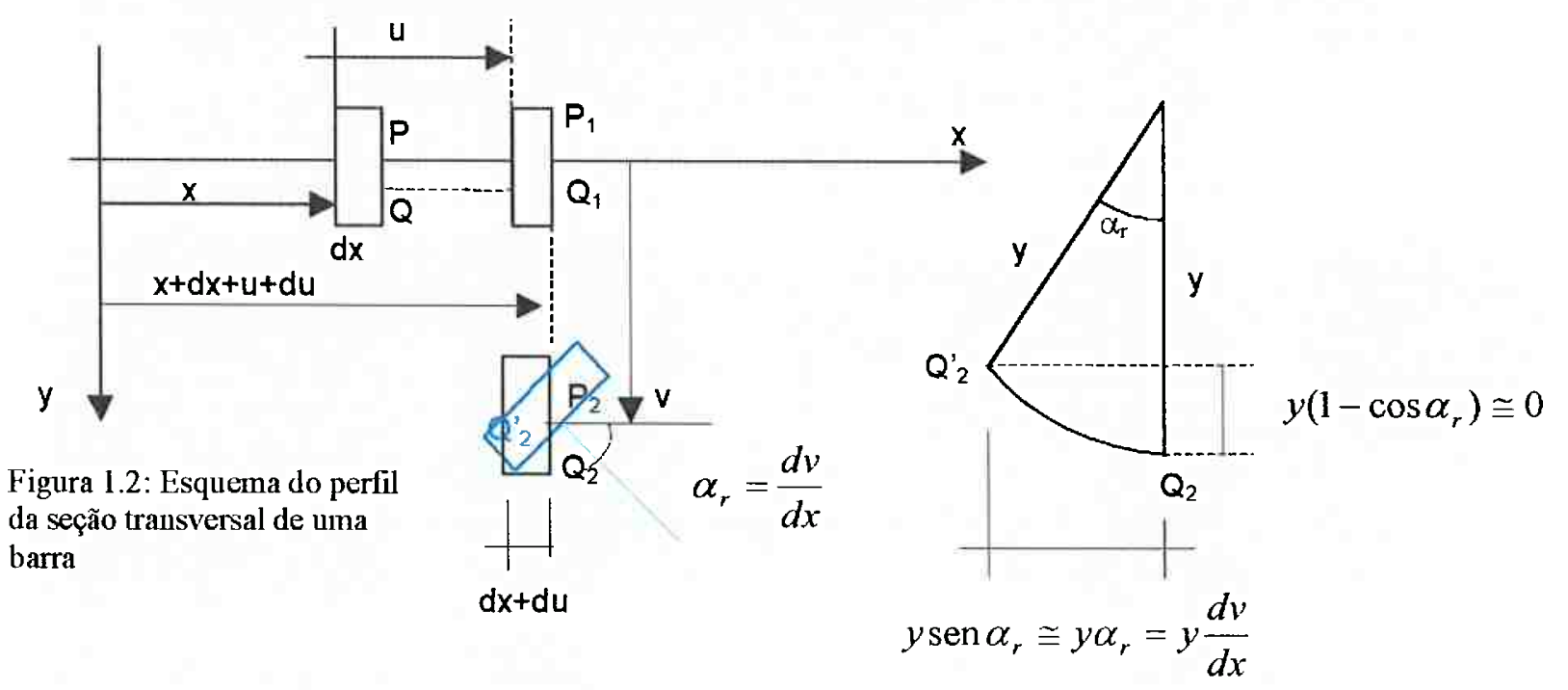

O carregamento estático, em um sistema de resposta linear, apresenta o seguinte diagrama esforços/deslocamentos:

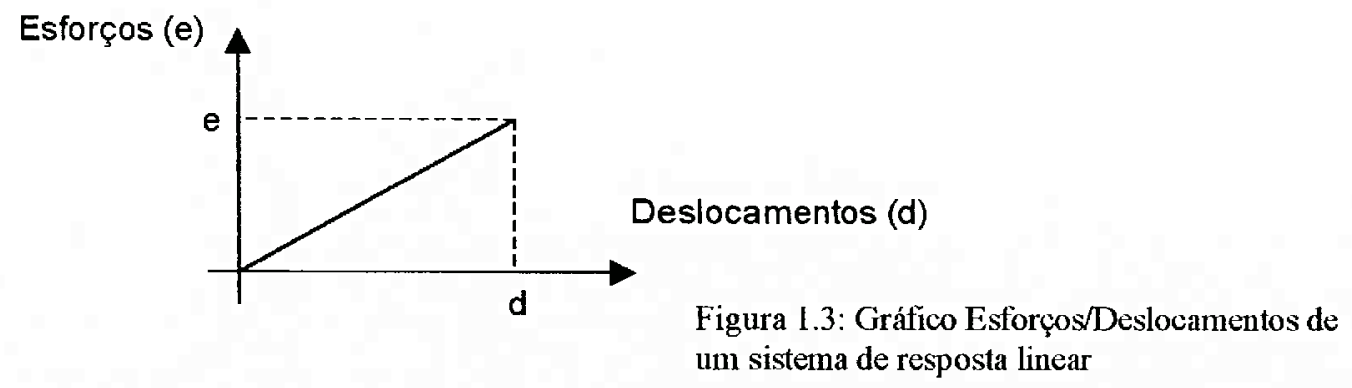

O trabalho realizado pelos esforços reais é dado pela área sob o diagrama linear, ou seja:

$$
W=\frac{1}{2} e d
$$

São exemplos de outros Métodos, o Método de Segunda Ordem, no qual não se verifica a superposição de efeitos e o Método das Rótulas Plásticas, em que além 
de não se aplicar a superposição de efeitos, não se verifica a proporcionalidade entre tensões e deformações e a continuidade da linha elástica.

Com as hipóteses do Método Clássico, é possível obter equações que relacionam esforços, denominadas equações de equilibrio, e as equações que relacionam deslocamentos, denominadas equações de compatibilidade. E importante observar que as equações de equilíbrio podem, com auxílio das equações constitutivas, estar escritas em função dos deslocamentos, mas que traduzem o equilíbrio em uma determinada região da estrutura, ou dela própria. O mesmo se aplica às equações de compatibilidade: através das equações constitutivas, aquelas podem estar escritas em função dos esforços, mas que traduzem a compatibilidade de deslocamentos em uma determinada região da estrutura.

O Processo Direto, neste trabalho, caracteriza-se pela aplicação do Teorema dos Deslocamentos Virtuais tantas vezes quantos forem os graus de liberdade ${ }^{5} \mathrm{da}$ estrutura. Cada aplicação do Teorema implica a obtenção de uma equação de equilíbrio. Posteriormente, aplica-se o Teorema dos Esforços Virtuais tantas vezes quantas forem as incógnitas hiperestáticas da estrutura. Cada aplicação desse teorema implica a obtenção de uma equação de compatibilidade. Em cada equação dessa natureza, é inserida a Lei de Hooke, tendo-se então as equações de compatibilidade escritas em função dos esforços. As equações obtidas por meio da aplicação dos Teoremas dos Esforços e Deslocamentos Virtuais constituem um sistema linear de ordem $\mathrm{MxM}$, onde $\mathrm{M}$ é a soma do número de graus de liberdade da estrutura com o respectivo número de incógnitas hiperestáticas. A solução desse sistema fornece os esforços solicitantes atuantes na estrutura em análise.

No Capítulo 2 deste trabalho, é feita a exposição de conceitos fundamentais para o desenvolvimento do Processo Direto, bem como para a comparação dos Processos dos Esforços e dos Deslocamentos: são definidos os conceitos de grau de liberdade, grau de hiperestaticidade interno, externo e total, assim como as respectivas determinações. Ainda nesta linha, são apresentados os conceitos de deslocamentos cinematicamente admissiveis, esforços estaticamente admissíveis, trabalho virtual, rigidez, flexibilidade e ainda menciona-se o Princípio da Superposição de Efeitos. São introduzidos os conceitos de matrizes de rigidez e flexibilidade, bem como suas relações.

No Capítulo 3, o Processo Direto é aplicado na resolução de treliças hiperestáticas planas. A teoria se desenvolve sobre treliças com cargas nodais, havendo consequentemente apenas a ocorrência de esforços normais nas barras. São apresentados os enunciados dos Teoremas dos Deslocamentos e dos Esforços Virtuais e a aplicação da sistemática desenvolvida a dois exemplos.

s ver p.9. 
O Capítulo 4 segue o mesmo roteiro do Capítulo 3 , porém a aplicação do Processo Direto se dá em pórticos planos hiperestáticos. São apresentadas as aplicações do processo em duas estruturas, uma viga apoiada-engastada submetida a carga fora dos nós e um pórtico submetido a um carregamento nodal.

No Capítulo 5, é feita a introdução dos Processos dos Esforços e dos Deslocamentos. Isto se faz a partir dos exemplos, treliça e pórtico, apresentados nos Capítulos 3 e 4, respectivamente.

No Capítulo 6, é feita uma análise comparativa entre o Processo dos Esforços e dos Deslocamentos, ressaltando a dualidade existente entre os dois. Utiliza-se uma treliça para a ilustração das matrizes e dos vetores utilizados nos dois processos. São observados os aspectos sob a forma de um quadro comparativo a fim de tornar o trabalho mais prático e mais didático. Segue-se ainda a resolução de uma treliça pelos dois processos.

No Capítulo 7, é realizada uma análise crítica e as respectivas conclusões a respeito da aplicação do Processo Direto e suas relações com os Processos dos Esforços e dos Deslocamentos. 


\section{Capítulo 2}

\section{Conceitos Estruturais Fundamentais}

\subsection{Introdução}

Antes de iniciarmos o Processo Direto será necessário introduzirmos alguns conceitos fundamentais para o desenvolvimento deste trabalho. A aplicação do Processo Direto depende da visualização do número de graus de liberdade, assim como da determinação do grau de hiperestaticidade. Indo mais além, torna-se importante a definição de trabalho virtual, bem como dos deslocamentos cinematicamente admissíveis e dos esforços estaticamente admissíveis para enunciarmos os Teoremas dos Deslocamentos e dos Esforços Virtuais. São apresentados os conceitos de ações e deslocamentos correspondentes, flexibilidade, rigidez e de suas respectivas matrizes, que são de fundamental importância no estabelecimento dos Processos dos Esforços e dos Deslocamentos.

\subsection{Estruturas Planas Indeterminadas}

Segundo Gere ${ }^{1}$, as estruturas são denominadas cinematicamente indeterminadas quando são desconhecidos alguns deslocamentos nodais da estrutura e estaticamente indeterminadas quando os esforços solicitantes não podem ser determinados somente por meio das equações de equilíbrio.

\subsubsection{Grau de Liberdade (h)}

Segundo Lindenberg ${ }^{2}$, dá-se o nome de graus de liberdade de um sistema material ao menor número de parâmetros necessários para definir a posição deste sólido em relação a um determinado referencial. A cada nó de uma estrutura plana correspondem três graus

\footnotetext{
${ }^{1}$ Gere, J.T; Weaver Jr, W. Análise de Estruturas Reticuladas

${ }^{2}$ Lindenberg N.,H. Introdução à Mecânica das Estruturas. p. 25.
} 
de liberdade: dois deslocamentos e uma rotação. Para facilitar a compreensão do conceito, a Figura 2.1 ilustra um pórtico com seus graus de liberdade:

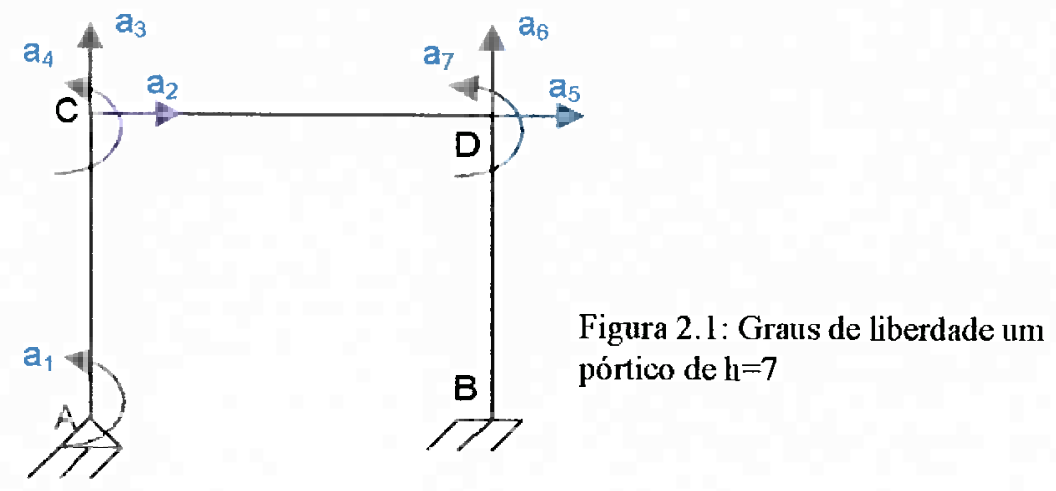

Os deslocamentos, $a_{2}, a_{3}, a_{5}$ e $a_{6}$ e as rotações $a_{1}, a_{4}$, e $a_{7}$ não são conhecidos, portanto $\mathrm{h}=7$, ao passo que os deslocamentos verticais e horizontais dos apoios A e B são nulos, assim como a rotação do apoio B.

Os sentidos positivos para os graus de liberdade adotados para este trabalho são os mesmos desta figura.

\subsubsection{Grau de Hiperestaticidade (g)}

Para estudarmos a estaticidade de uma estrutura é necessário verificar se sua vinculação é suficiente para mantê-la em equilíbrio, devendo ser examinado se há impedimento quanto aos movimentos que a estrutura pode realizar no plano. Como se tem três movimentos a impedir no plano, deve-se utilizar apoios que restrinjam pelo menos três componentes de movimento da estrutura, apoios que introduzam pelo menos três vínculos no sistema. Com relação à estaticidade, as estruturas podem ser classificadas em:

Estruturas Hipostáticas: são aquelas que podem apresentar movimento de corpo rígido. Basta haver apenas um carregamento que faça uma estrutura apresentar movimento de corpo rígido para que ela seja considerada hipostática. Abaixo, são mostrados exemplos de estruturas hipostáticas.
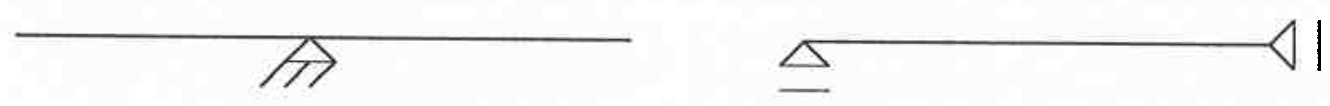

Figura 2.2: Exemplos de estruturas hipostáticas 
Estruturas Isostáticas: são denominadas isostáticas as estruturas cujos vínculos impedem que ela se movimente, mas que passe a poder se movimentar se algum de seus vínculos for suprimido. Exemplos são mostrados na Figura 2.3:
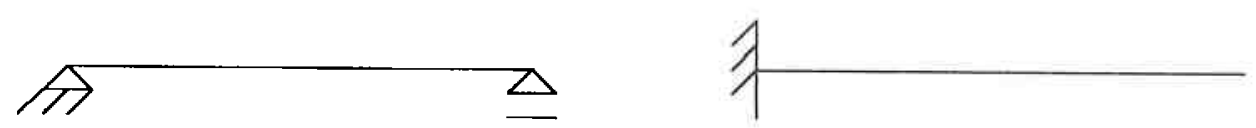

Figura 2.3: Exemplos de estruturas isostáticas

Estruturas Hiperestáticas: são todas as estruturas que não apresentam movimento e que podem ter vínculos suprimidos sem que se tornem hipostáticas. São exemplos de estruturas hiperestáticas.
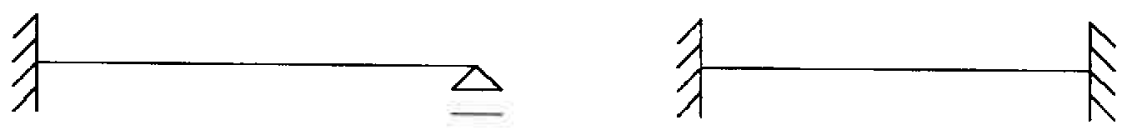

Figura 2.4: Exemplos de estruturas hiperestáticas

Para Lindenberg ${ }^{3}$, dá-se o nome de grau de hiperestaticidade de uma estrutura hiperestática ao número máximo de vínculos da estrutura que podem ser suprimidos sem que ela se torne hipostática.

O grau de hiperestaticidade ( $\mathrm{g}$ ), também chamado de grau de indeterminação estática é um conceito que relaciona os vínculos e a geometria da estrutura. $O$ grau de hiperestaticidade de uma estrutura é determinado pela soma dos graus interno e externo. O grau de hiperestaticidade externo ( $\mathrm{g}_{\mathrm{e}}$ ), para problemas planos, é dado pela expressão:

$$
g_{e}=r-3
$$

onde r é o número de reações vinculares.

Se tivéssemos o problema no espaço, a expressão (2.1) ficaria: $g_{e}=r-6$

O grau de hiperestaticidade interno $\left(\mathrm{g}_{\mathrm{i}}\right)$ é o grau de hiperestaticidade da estrutura liberada, isto é, da estrutura original sem os vínculos externos.

O grau de hiperestaticidade total da estrutura ( $\mathrm{g}$ ) é dado pela soma dos graus interno e externo, podendo-se escrever:

$$
g=g_{i}+g_{e}
$$

Chama-se estrutura isostática fundamental, a uma estrutura derivada da original (hiperestática), suprimindo os vínculos, tal que $\mathrm{g}=0$.

A determinação dos parâmetros, $g_{i}$ e $g_{c}$, constitui tema do item que segue.

\footnotetext{
${ }^{3}$ Lindenberg N.,H. Introdução à Mecânica das Estruturas. p.30.
} 


\subsubsection{Procedimento para Determinação do Grau de Hiperestaticidade}

Considere a estrutura da Figura 2.5. Inicialmente, deve-se determinar o grau de hiperestaticidade externo.

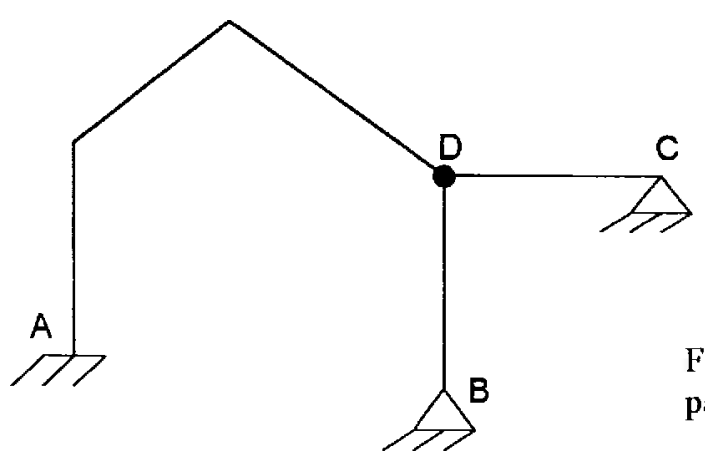

Figura 2.5: Exemplo de estrutura para aplicação do procedimento.

Como se trata de estrutura plana:

$$
g_{e}=r-3=4
$$

Para cada articulação existente na estrutura, deve-se considerar o número de seções que a respectiva articulação une. Para melhor compreensão, deve ser observada a Figura 2.6:

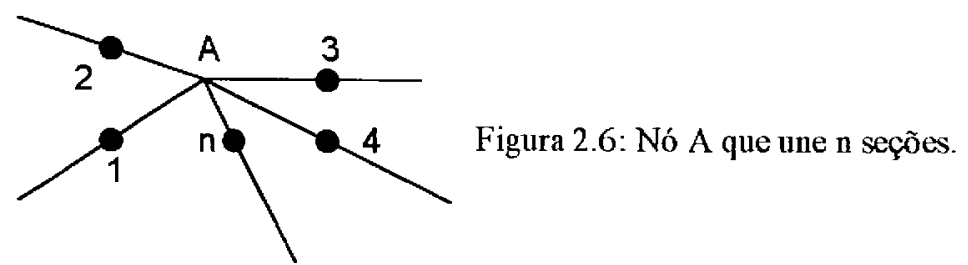

Considere a articulação $\mathrm{A}$, que une $\mathrm{n}$ seções. A quantidade de articulações a ser considerada na determinação da hiperestaticidade é n-1. A justificativa é que a articulação A da Figura 2.6 libera n-1 vínculos.

No exemplo em questão, na Figura 2.5, há um nó articulado, com três seções unidas por ele. Como não há regiões fechadas, não há outras considerações a serem feitas, então obtém-se o grau de hiperestaticidade interno da estrutura:

$$
g_{i}=-2
$$

O sinal negativo indica que a estrutura liberada é duas vezes hipostática. 
O grau de hiperestaticidade total da estrutura é dado por:

$$
g=g_{e}+g_{i}=2
$$

As considerações relativas às regiões fechadas podem ser melhor visualizadas no próximo exemplo, que é a estrutura da Figura 2.7.

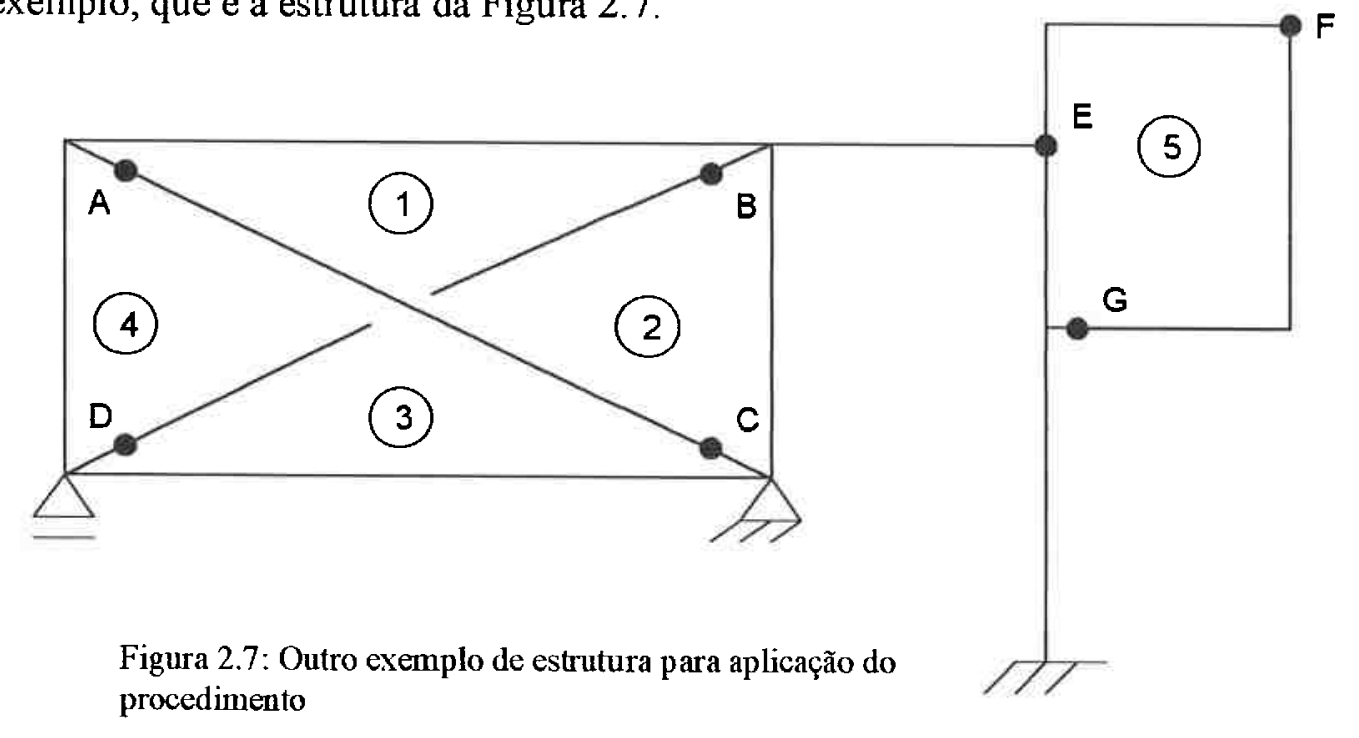

Determinação do grau de hiperestaticidade externo:

$$
r=6 \text {, então: } \quad g_{e}=3
$$

Determinação do grau de hiperestaticidade interno:

Como há cinco regiões fechadas, cada uma contribui com três incógnitas hiperestáticas, então deve-se considerar a quantidade quinze, resultante da contribuição das regiões fechadas no cálculo do $g_{i}$.

O próximo passo é a consideração do cruzamento das barras no cálculo do grau de hiperestaticidade interno. Deve-se analisar a quantidade e o tipo, ou seja, o número de cruzamentos e quantos vínculos são excluídos para cada um deles. Neste caso, há apenas um cruzamento (barras $\mathrm{AC}$ e $\mathrm{BD}$ ), não havendo contato entre elas, o que indica a exclusão de três vínculos. Então a quantidade a ser considerada decorrente do cruzamento das barras é -3 .

Analogamente ao exemplo anterior, deve-se considerar o efeito relativo aos nós articulados. Os nós A, B, C, D, F e G têm duas seções ligadas a ele, enquanto o nó E possui três. Então, a quantidade a ser considerada em virtude da existência dos nós articulados é -8 . 
Com as considerações feitas anteriormente, o grau de hiperestaticidade interno é dado pela somatória das quantidades consideradas no seu cálculo, então:

$$
\begin{aligned}
& g_{i}=15-3-8 \quad \text {, ou seja: } \\
& g_{i}=4
\end{aligned}
$$

O grau de hiperestaticidade total é dado por:

$$
g=g_{e}+g_{i}=7
$$

\subsection{Trabalho Virtual}

O conceito de Trabalho Virtual é de extrema importância, pois a sua utilização vai nos permitir obter as equações de equilíbrio e compatibilidade no Processo Direto. $\mathrm{O}$ termo virtual significa ser em essência, ou efeito, mas não realmente, não havendo necessariamente um significado físico associado a ele. $O$ uso do conceito de trabalho virtual para resolver problemas de sistemas mecânicos pode ser observado em trabalhos anteriores ao de Newton. A primeira formulação geral do Princípio dos Deslocamentos Virtuais é creditada a Jean Bernoulli (1667-1748).

O Trabalho Virtual é definido como o produto escalar entre um deslocamento virtual e um esforço real, ou o contrário, um deslocamento real com um esforço virtual. A notação utilizada é a letra grega $\delta$ : assim, uma força virtual $F$ será designada por $\delta \mathrm{F}$ e um deslocamento virtual d será designado por $\delta \mathrm{d}$.

Vale mencionar que o esforço real constitui um caso particular do virtual, pois este é arbitrário, podendo ocorrer em qualquer direção. Os esforços reais quando aplicados na estrutura causam deslocamentos e deformações reais. Esta relação de causa e efeito não se verifica entre deslocamentos reais e esforços virtuais e entre deslocamentos virtuais e esforços reais. 
Para tornar clara a diferença entre o trabalho virtual e o trabalho real, realizado por um esforço real por meio de um deslocamento real, pode-se recorrer ao diagrama tridimensional mostrado por Laursen ${ }^{4}$ da figura seguinte:

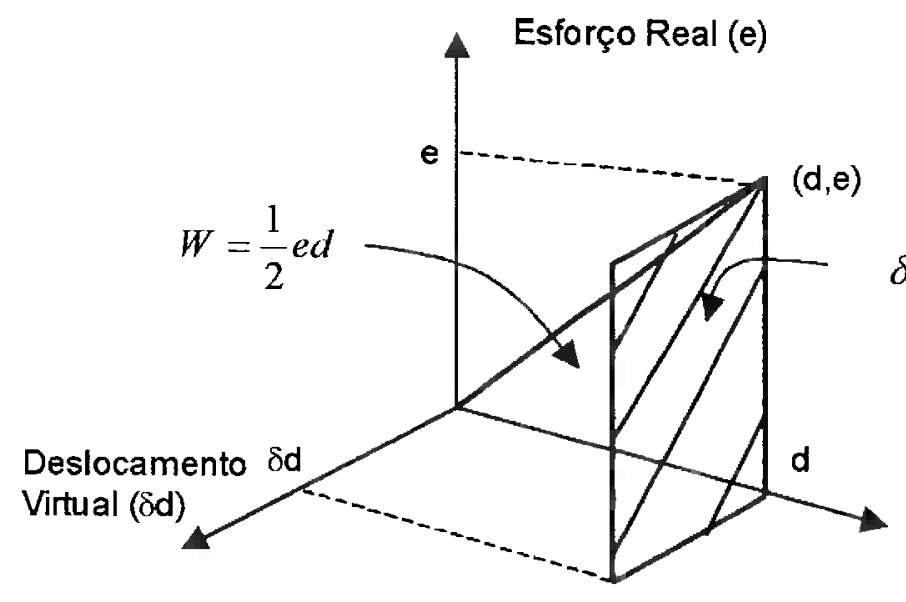

$\delta W=e \delta d$

Deslocamento

Real (d)

Figura 2.8: Diagrama tridimensional dos trabalhos real e virtual

Os esforços e os deslocamentos reais são mostrados nos dois eixos: para um esforço dado, e, corresponde um deslocamento, d, ambos reais, através da relação linear que há entre eles. Este ponto representa uma posição de equilíbrio do sistema elástico. Se o ponto de aplicação do esforço, e, é submetido a um deslocamento virtual, $\delta \mathrm{d}$, o trabalho virtual realizado pelo esforço, e, é a área do retângulo hachurado, fazendo com que o fator $1 / 2$ não seja incluído em seu cálculo.

As mesmas considerações podem ser feitas para os esforços virtuais:

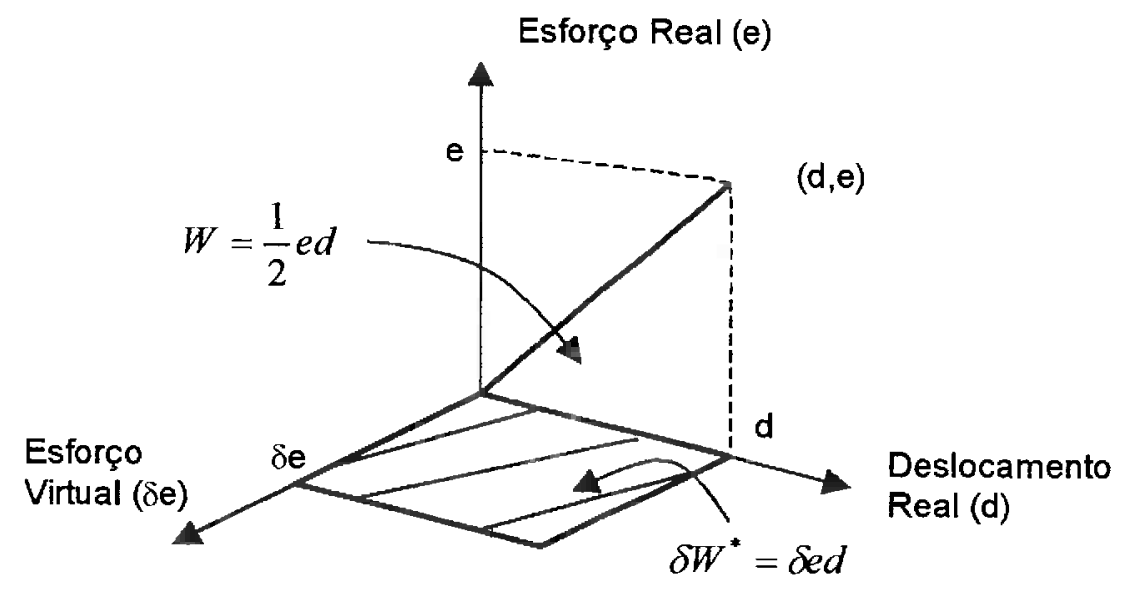

Figura 2.9: Diagrama tridimensional dos traballos real e virtual complementar

No diagrama anterior, o trabalho virtual é dado pela área da região hachurada. Os diagramas mostrados por Laursen, no entanto, não deixam claro o fato do deslocamento

\footnotetext{
${ }^{4}$ Laursen, H. I. Structural Analysis. p. 191
} 
real ser um caso particular do deslocamento virtual. Isto se torna nitido à medida que se observa o diagrama seguinte:

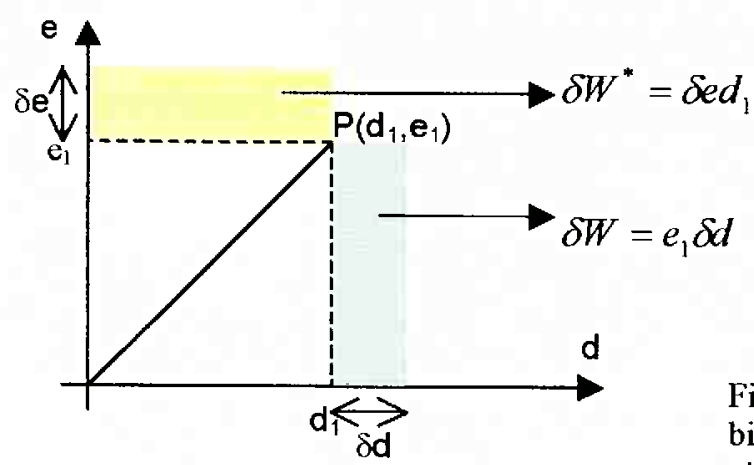

Figura 2.10: Diagrama bidimensional dos trabalhos virtual e virtual complementar

No diagrama proposto por Almeida ${ }^{5}$, além de ser possivel a visualização, também permite analisar, no mesmo diagrama, os trabalhos virtuais e os trabalhos virtuais complementares. P é uma posição de equilíbrio alcançada pelo sistema estrutural. Podese aplicar um deslocamento virtual, $\delta \mathrm{d}$, obtendo-se o trabalho virtual dado pela área cinza. Ou então, pode-se aplicar um esforço virtual, $\delta$ e, obtendo-se o trabalho virtual complementar, dado pela área amarela.

Os Teoremas dos Deslocamentos e dos Esforços Virtuais são enunciados no Capítulo 3. Para o estabelecimento desses teoremas é necessária a introdução de dois conceitos:

\section{Deslocamentos Cinematicamente Admissíveis:}

São deslocamentos cinematicamente admissiveis (ou compativeis) qualquer campo de deslocamentos com deformações compativeis que sejam contínuos e que tenham as respectivas derivadas continuas e que ainda satisfaçam as condiçôes de contorno cinemáticas.

\section{Esforços Estaticamente Admissíveis:}

São esforços estaticamente admissiveis qualquer sistema de esforços (externos $e$ internos) aplicados sobre a estrutura, definidos arbitrariamente e que sejam autoequilibrados.

\subsection{Ações e Deslocamentos Correspondentes}

É comum tratarmos com ações e deslocamentos que se correspondem uns aos outros. "Ações e deslocamentos são ditos correspondentes, quando são de mesma natureza e estão localizados no mesmo ponto e na mesma direção. Assim, o deslocamento correspondente a uma força concentrada é uma translação da estrutura no ponto onde atua a força e na direção da mesma, ainda que o deslocamento não seja necessariamente

\footnotetext{
${ }^{5}$ Almeida N., E. S.
} 
causado por essa mesma força. Além disso, considera-se deslocamento correspondente positivo, se ele tiver o mesmo sentido do esforço correspondente. No caso de um binário, o deslocamento correspondente é uma rotação no ponto onde o binário está aplicado, sendo considerado positivo quando tem o mesmo sentido que o binário". A Figura 2.11 auxilia a compreensão dos conceitos expostos neste item:

A estrutura está submetida aos esforços externos $A_{1}$ e $A_{2}$, apresentando os deslocamentos $\mathrm{D}_{1}$ e $\mathrm{D}_{2}$

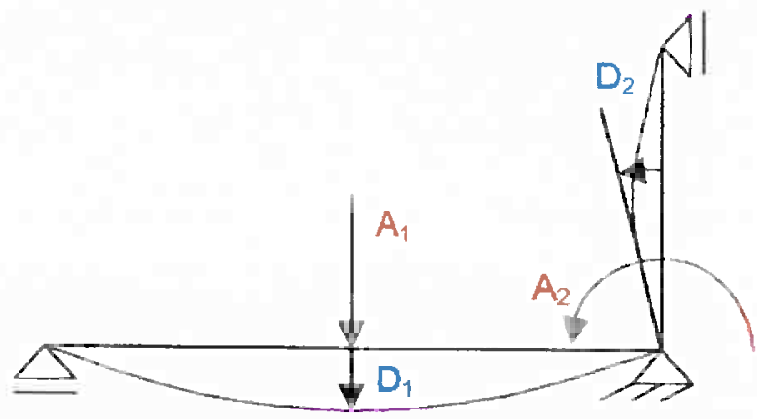

Figura 2.11: Ilustração de ações e deslocamentos correspondentes

Observando a figura anterior, conclui-se:

$A_{1}$ e $D_{1}$ são correspondentes

$\mathrm{A}_{2}$ e $\mathrm{D}_{2}$ são correspondentes.

\subsection{Princípio da Superposição de Efeitos}

O Princípio da Superposição estabelece que o efeito produzido por várias ações pode ser obtido por meio da soma de cada efeito correspondente a cada uma das ações. Essas causas podem ter natureza diversa: podem ser esforços aplicados, deslocamentos impostos, variações de temperatura.

O Princípio da Superposição de Efeitos tem como requisitos as linearidades física e geométrica. Esses requisitos encaixam-se perfeitamente nas hipóteses do Método Clássico. Este Princípio será fundamental no estabelecimento dos Processos Direto, dos Esforços e dos Deslocamentos. 


\subsection{Coeficientes de Flexibilidade $\left(\delta_{\mathrm{ij}}\right)$}

Analisando a estrutura da figura 2.11, observa-se a aplicação de dois esforços, $A_{1}$ e $A_{2}$, que são correspondentes aos deslocamentos $D_{1}$ e $D_{2}$, respectivamente, conforme foi visto no item 2.4. Tanto o deslocamento $D_{1}$ quanto o $D_{2}$ têm parcelas relativas aos efeitos de $A_{1}$ e $A_{2}$, ou seja, através do Princípio da Superposição, tem-se:

$$
\begin{aligned}
& D_{1}=D_{11}+D_{12} \\
& D_{2}=D_{21}+D_{22}
\end{aligned}
$$

Onde $D_{i j}$ é o deslocamento correspondente a $A_{i}$ causado exclusivamente por $A_{j}$.

Pode-se escrever os deslocamentos em função dos esforços, fazendo-se:

$$
D_{i j}=\delta_{i j} A_{j}
$$

Então, $\delta_{i j}$ será o deslocamento correspondente a $A_{i}$ causado por um $A_{j}$ unitário e os demais esforços nulos. Sendo assim, os termos de (2.3) podem ser escritos da seguinte forma:

$$
\begin{aligned}
& D_{1}=\delta_{11} A_{1}+\delta_{12} A_{2} \\
& D_{2}=\delta_{21} A_{1}+\delta_{22} A_{2}
\end{aligned}
$$

A expressão (2.5) pode ser escrita em notação matricial, como é mostrado a seguir:

$$
\{D\}=[F]\{A\}
$$

onde: $\{D\}=\left\{\begin{array}{l}D_{1} \\ D_{2}\end{array}\right\},\{A\}=\left\{\begin{array}{l}A_{1} \\ A_{2}\end{array}\right\}$ e $[F]=\left[\begin{array}{ll}\delta_{11} & \delta_{12} \\ \delta_{21} & \delta_{22}\end{array}\right]$.

[F] é denominada matriz de flexibilidade. A seguir é apresentado seu significado físico.

Para a obtenção da Matriz de Flexibilidade, deve ser observado o sistema linear dado por (2.5) e as Figura 2.14 e 2.15.

Estabelecendo $A_{1}=1$ e $A_{2}=0$, obtém-se $D_{1}=\delta_{11}$ e $D_{2}=\delta_{21}$.

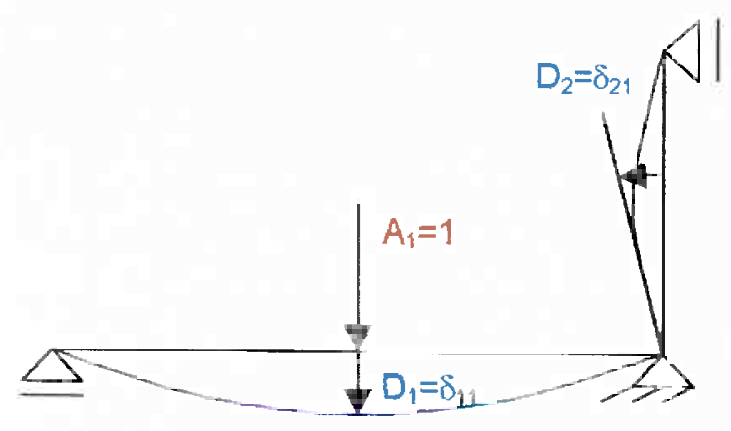


Assim, determina-se a primeira coluna da Matriz de Flexibilidade. A seguir, atribuem-se os valores $A_{1}=0$ e $A_{2}=1$, obtendo-se $D_{1}=\delta_{12}$ e $D_{2}=\delta_{22}$.

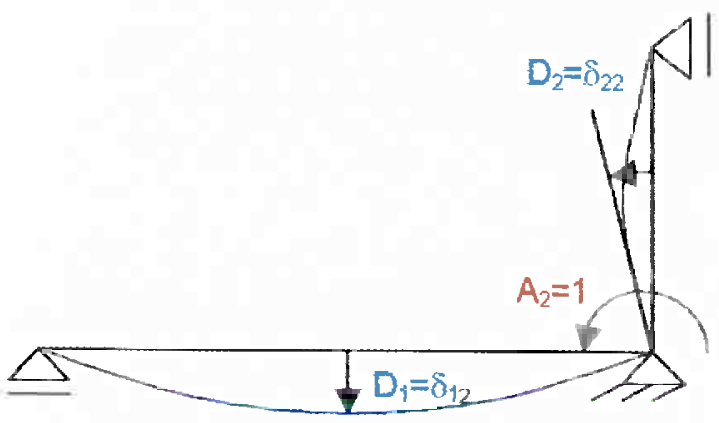

Figura 2.13: Estrutura com carga unitária aplicada, $A_{1}=0$ e $A_{2}=1$

Assim, obtém-se a segunda coluna da Matriz de Flexibilidade.

\subsection{Coeficientes de Rigidez $\left(K_{\mathrm{ij}}\right)$}

Os esforços também podem ser escritos em função dos deslocamentos, o que equivale a inverter o sistema (2.6). Então, tem-se:

$$
\begin{aligned}
& A_{1}=K_{11} D_{1}+K_{12} D_{2} \\
& A_{2}=K_{21} D_{1}+K_{22} D_{2}
\end{aligned}
$$

Escrevendo (2.7) em notação matricial:

$$
\{A\}=[K]\{D\}
$$

Onde: $A=\left\{\begin{array}{l}A_{1} \\ A_{2}\end{array}\right\}, D=\left\{\begin{array}{l}D_{1} \\ D_{2}\end{array}\right\}$ e $K=\left[\begin{array}{ll}K_{11} & K_{12} \\ K_{21} & K_{22}\end{array}\right]$

[K] é denominada matriz de rigidez e seu significado fisico é apresentado a seguir.

Para se obter os coeficientes de rigidez, deve-se observar o sistema linear dado em (2.7). Atribuindo os valores $D_{1}=1$ e $D_{2}=0$, obtém-se $A_{1}=K_{11}$ e $A_{2}=K_{21}$.

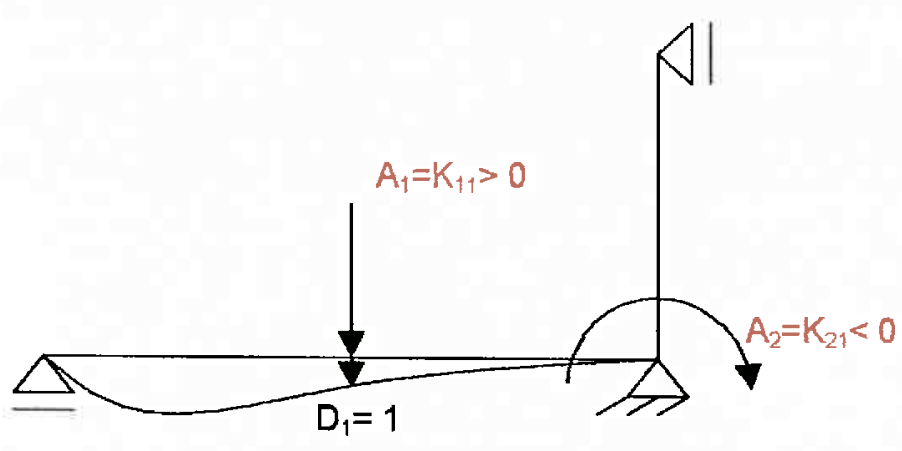

19
Figura 2.14: Estrutura com deslocamento unitário imposto, $\mathrm{D}_{1}=1 \mathrm{e}$ $\mathrm{D}_{2}=0$ 
Assim obtém-se a primeira coluna da Matriz de Rigidez. A seguir, atribuem-se os valores $\mathrm{D}_{1}=0$ e $\mathrm{D}_{2}=1$, obtendo-se $\mathrm{A}_{1}=\mathrm{K}_{12}$ e $\mathrm{A}_{2}=\mathrm{K}_{22}$.

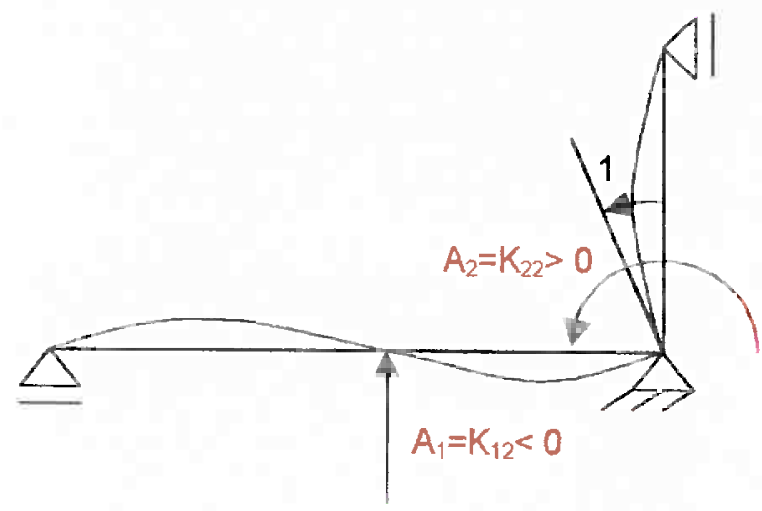

Figura 2.15: Estrutura com

deslocamento unitário imposto, $\mathrm{D}_{1}=0 \mathrm{e}$ $\mathrm{D}_{2}=1$

Assim obtém-se a segunda coluna da Matriz de Rigidez.

Então, podem ser extraídas as seguintes conclusões:

- $K_{j i}$ representa o esforço externo ativo, correspondente a $D_{j}$, que provoca $D_{j}=1$, na hipótese de se ter $D_{k}=0$, para $k \neq j$.

$-K_{i j}$ representa o esforço externo reativo, correspondente a $D_{i}$, que surge devido à aplicação de $K_{\mathrm{j} j}$, quando se tem $\mathrm{D}_{\mathrm{k}}=0$, para $\mathrm{k} \neq \mathrm{j}$.

\subsection{Relação entre as Matrizes [K] e [F]}

Sabe-se que:

$$
\{D\}=[F]\{A\}
$$

Então:

$$
\{A\}=[F]^{-1}\{D\}
$$

Comparando com $\{A\}=[K]\{D\}$, conclui-se:

$$
[F]^{-1}=[K]
$$

ou:

$$
[K]^{-1}=[F]
$$

As matrizes $[\mathrm{K}]$ e $[\mathrm{F}]$ são a inversa uma da outra, sempre que se referirem à mesma estrutura e ao mesmo conjunto $\left(A_{i}, D_{i}\right)$ de ações e deslocamentos correspondentes. Nos Processos dos Esforços (matriz $[\mathrm{F}]$ ) e dos Deslocamentos (matriz [K]), isto nunca se verificará. $\mathrm{O}$ motivo é que, na mesma estrutura, os conjuntos de ações e deslocamentos nunca podem ser os mesmos para os dois processos. Resta dizer que, no exemplo apresentado, $[\mathrm{F}]$ não pode se referir ao Processo dos Esforços, porque a estrutura 
apresentada não é isostática. Por outro lado, $[\mathrm{K}]$ não pode estar ligada ao Processo dos Deslocamentos, porque $\mathrm{D}_{1}$ não é deslocamento nodal.

\subsection{Algumas Propriedades de $[\mathrm{K}]$ e $[\mathrm{F}]$}

Se as ações $A_{1}$ e $A_{2}$ aumentam proporcionalmente e gradualmente (carregamentos estáticos - ver Capítulo 1), desde zero até seus valores prescritos, o trabalho por elas realizado será:

$$
W=\frac{1}{2}\left(A_{1} D_{1}+A_{2} D_{2}\right)=\frac{1}{2}\{A\}^{T}\{D\}=\frac{1}{2}\{A\}^{T}[F]\{A\}
$$

Por outro lado:

$$
W=\frac{1}{2}\{D\}^{T}\{A\}
$$

Mas de $\{D\}=[F]\{A\}$ vem: $\{D\}^{T}=\{A\}^{T}[F]^{T}$

Donde: $W=\frac{1}{2}\{D\}^{T}\{A\}=\frac{1}{2}\{A\}^{T}[F]^{T}\{A\}$

Comparando (2.12) e (2.14), conclui-se:

$$
[F]=[F]^{T}
$$

Ou seja, $[\mathrm{F}]$ é simétrica $\left(\delta_{i j}=\delta_{j i}\right)$. Conseqüentemente, como $[K]=[F]^{-1},[\mathrm{~K}]$ também será simétrica, pois a inversa de uma matriz simétrica também é simétrica.

\subsection{Condições de Existência das Matrizes [F] e [K]}

\subsubsection{Matriz $[\mathbf{F}]$}

Se as ações $A_{1}$ e $A_{2}$ não são independentes entre si, a matriz [F] perde o sentido e deixa de existir. Além disso, [K] fica singular e não pode ser invertida. Essa é a contrapartida matemática do fato físico de, dados $A_{1}$ e $A_{2}$, não ficarem definidos de maneira unívoca, os deslocamentos $\mathrm{D}_{1}$ e $\mathrm{D}_{2}$, pois, como se sabe, $\{D\}=[K]^{-1}\{A\}$. 
No exemplo apresentado nos itens anteriores, se forem eliminados os dois vínculos extremos, tem-se:

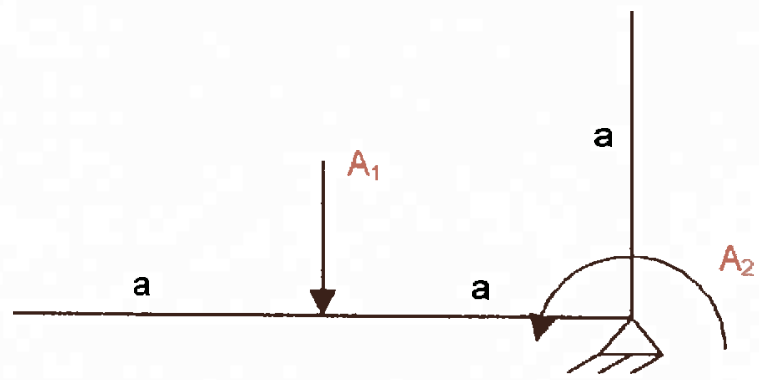

Figura 2.16: Eliminação dos vínculos de extremidade da estrutura da Figura 2.11

Neste caso, $A_{1}$ e $A_{2}$ estão ligados entre si pela condição estática (equilíbrio).

$$
A_{2}+a A_{1}=0
$$

Portanto $[\mathrm{F}]$ não existe e $[\mathrm{K}]$ é singular.

\subsubsection{Matriz [K]}

Se existe alguma relação pré-fixada entre $D_{1}$ e $D_{2}$, então $[K]$ não existe e [F] é singular.

$O$ fato do determinante de $[F]$ ser igual a zero, significa que, dados $D_{1}$ e $D_{2}$, não ficam definidos, de maneira unívoca, as ações $\mathrm{A}_{1}$ e $\mathrm{A}_{2}$, pois, como se sabe, $\{A\}=[F]^{-1}[D]$.

No exemplo apresentado anteriormente, considere que o trecho da barra entre os pontos de aplicação de $A_{1}$ e $A_{2}$ é infinitamente rígido $(E I=\infty)$.

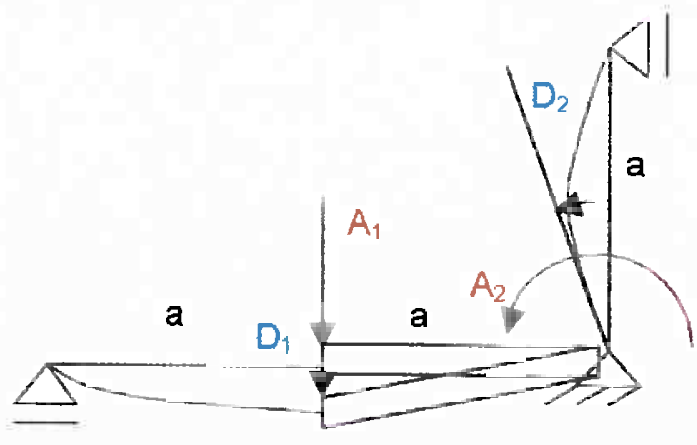

Figura 2.17: Estrutura com rigidez infinita entre os pontos de aplicação das cargas

No caso acima, $D_{1}$ e $D_{2}$ estão ligados entre si pela condição cinemática (compatibilidade).

$$
D_{1}=a D_{2}
$$


Portanto [K] não existe e [F] é singular. 


\section{Capítulo 3}

\section{O Processo Direto Aplicado à Resolução de Treliças Planas Hiperestáticas}

\subsection{Introdução}

Uma treliça plana é idealizada como um sistema de barras existentes num plano e ligadas entre si por articulações. Todas as forças aplicadas atuam no plano da estrutura. As cargas consistem em forças concentradas aplicadas aos nós, o que dará como resultado forças axiais de tração e compressão.

Ressalta-se que as equações de equilibrio são obtidas através da aplicação do Teorema dos Deslocamentos Virtuais, embora elas possam ser obtidas através das equações de equilíbrio dos nós nas direções dos graus de liberdade. As equações de compatibilidade são obtidas através da aplicação do Teorema dos Esforços Virtuais e nelas são inseridas as equações constitutivas. As equações de compatibilidade e de equilibrio formarão um sistema linear cuja solução fornece os esforços na estrutura.

\subsection{O Teorema dos Deslocamentos Virtuais Aplicado a uma Treliça Plana}

a) Obtenção das expressões dos trabalhos virtua is realizados pelos esforços internos e externos

Considere-se uma treliça plana constituída por m barras e n nós. Conforme a figura 3.1a, tem-se um nó genérico, $\mathrm{j}$, dessa mesma treliça: 
(a)

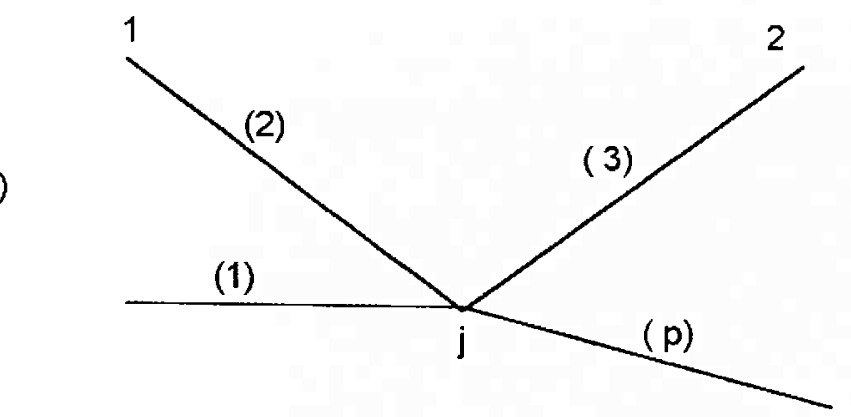

(b)
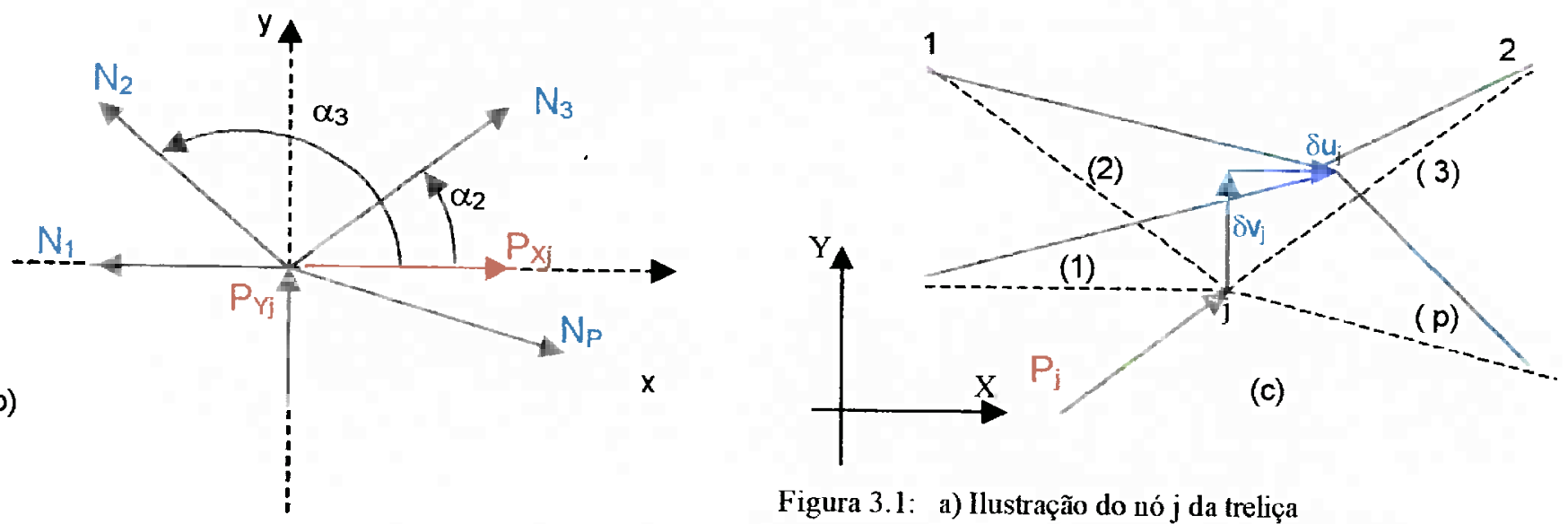

Figura 3.1: a) llustração do nó j da treliça

nó $\mathrm{j} \quad$ b) Deslocamentos vif̧os no nó $\mathrm{j}$

Onde: $\quad N_{P}$ é a força normal na barra $p$ que converge ao nó $\mathrm{j}$, segundo o ângulo $\alpha_{P}$.

$P_{x j}, \quad P_{y j}$ são as projeções $d a$ força $P_{j}$, segundo os eixos $x$ e $y$, respectivamente.

$\delta u_{j}$ e $\delta v_{j}$ são os deslocamentos virtuais horizontal e vertical, respectivamente

Para esse mesmo nó, tem-se as equações de equilibrio:

$$
\begin{aligned}
& \sum\left(N_{P} \cos \alpha_{P}\right)+P_{X j}=0 \\
& \sum\left(N_{P} \operatorname{sen} \alpha_{P}\right)+P_{Y j}=0
\end{aligned}
$$

Os esforços relativos ao nó j podem ser visualizados na Figura 3.1-b:

Impondo-se os deslocamentos virtuais horizontal e vertical, $\delta u_{j}$ e $\delta v_{j}$, (ver Figura 3.1 - c), nos $\mathrm{n}$ nós da treliça, sendo os mesmos cinematicamente admissiveis, o trabalho virtual dos esforços extemos para a estrutura é dado por: 


$$
\delta W_{e}=\sum_{j=1}^{n}\left(P_{X j} \delta \imath_{j}+P_{Y j} \delta v_{j}\right)
$$

A imposição dos deslocamentos virtuais nos n nós da estrutura causa deformações virtuais nas barras que estão ligadas aos nós. Como são consideradas apenas cargas concentradas aplicadas aos nós e as barras são biarticuladas, as deformações resultantes nas barras da treliça serão apenas as axiais. Então, o trabalho virtual dos esforços internos na estrutura é dado por:

$$
\delta W_{i}=\sum_{i=1}^{m} N_{i} \delta\left(\Delta L_{i}\right)
$$

Onde: $\quad \delta\left(\Delta \mathrm{L}_{\mathrm{i}}\right)$ é a variação de comprimento virtual da barra $\mathrm{i}$, que corresponde aos deslocamentos virtuais $\delta u_{j}$ e $\delta v_{j}$

$\mathrm{N}_{\mathrm{i}}$ é a força normal na barra $\mathrm{i}$

\section{b) Estabelecimento da compatibilidade entre deslocamentos e as variações de comprimento}

Observando a barra ( i ) da treliça, formada pelos nós k e l. Atribui-se o sinal positivo ao esforço real que constitui a incógnita, neste caso, a força normal de tração, conforme a Figura 3.2.

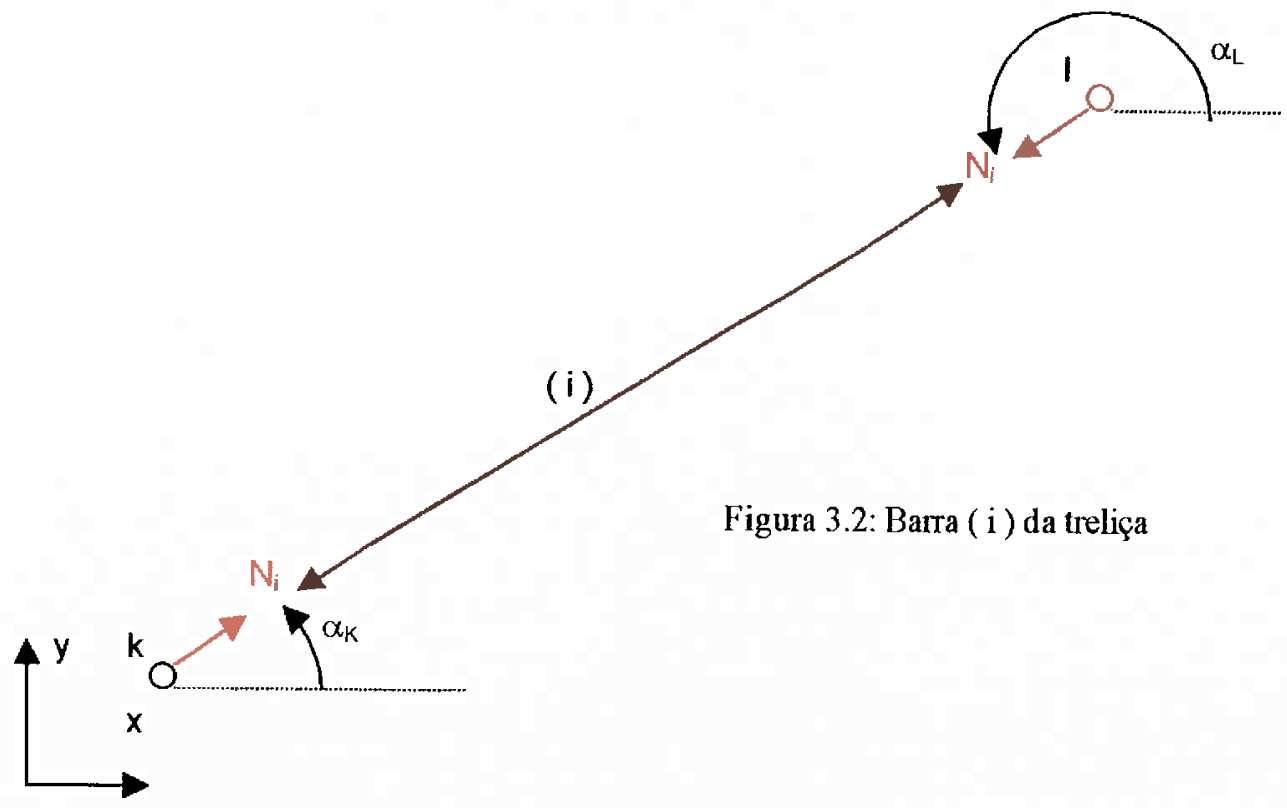

Nessa mesma barra, são impostos nas extremidades os mesmos deslocamentos virtuais aplicados nos nós, $\delta u_{j}$ e $\delta v_{j}$, conforme a Figura 3.3: 


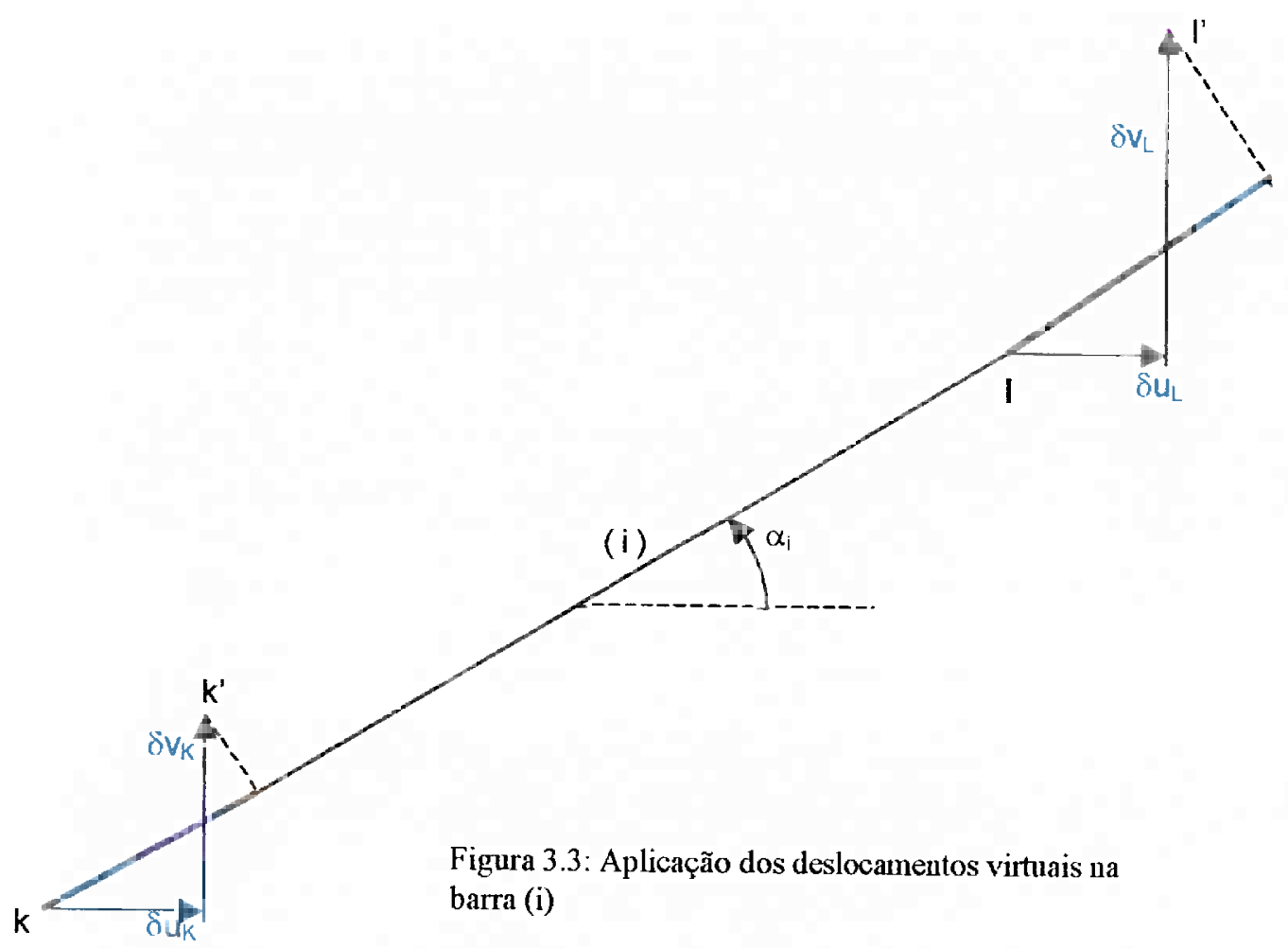

A seguir, são obtidas as relações entre os deslocamentos aplicados nos nós e as deformações decorrentes dos mesmos.

Inicia-se a análise pelo nó $\mathrm{k}$ através da Figura 3.4.

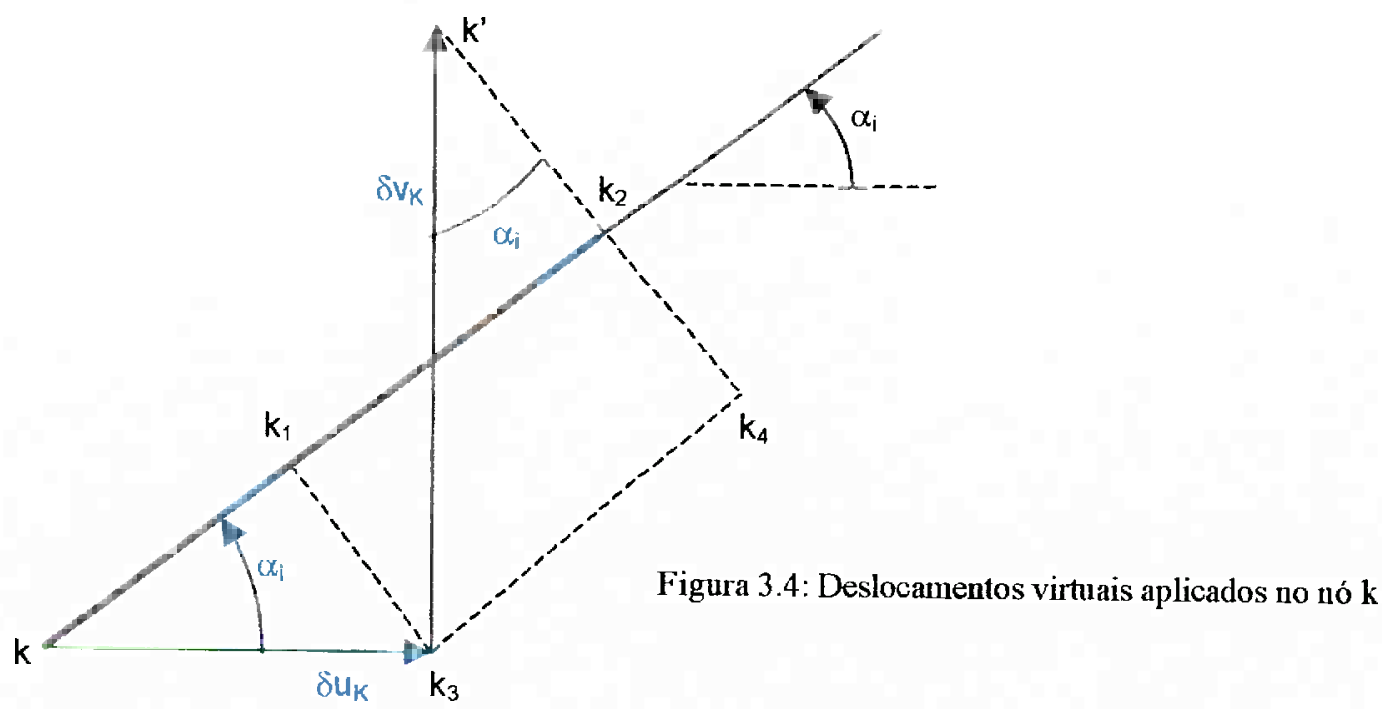


Os deslocamentos virtuais são impostos no nó $\mathrm{k}$ no sentido positivo, conforme o sistema de referência na Figura 3.2. Conclui-se:

$$
k k_{1}=\delta u_{k} \cos \alpha_{i}
$$

$\mathrm{Na}$ expressão acima, $\mathrm{kk}_{1}$ indica o encurtamento virtual da barra (i) em decorrência da imposição do deslocamento virtual $\delta u_{K}$.

$$
k_{1} k_{2}=\delta v_{k} \operatorname{sen} \alpha_{i}
$$

$\mathrm{Na}$ expressão acima, $\mathrm{k}_{1} \mathrm{k}_{2}$ indica o encurtamento virtual da barra (i) em virtude da imposição do deslocamento virtual $\delta v_{\mathrm{k}}$. Sendo assim, a deformação axial virtual resultante, $\mathrm{kk}_{2}$, da imposição dos dois deslocamentos, $\delta u_{k}$ e $\delta v_{k}$, é dada pela equação abaixo:

$$
k k_{2}=k k_{1}+k_{1} k_{2}=\delta i_{k} \cos \alpha_{i}+\delta v_{k} \operatorname{sen} \alpha_{i}
$$

Analogamente, são impostos os deslocamentos virtuais no nó $1, \delta u_{1} \mathrm{e} \delta \mathrm{v}_{1}$.

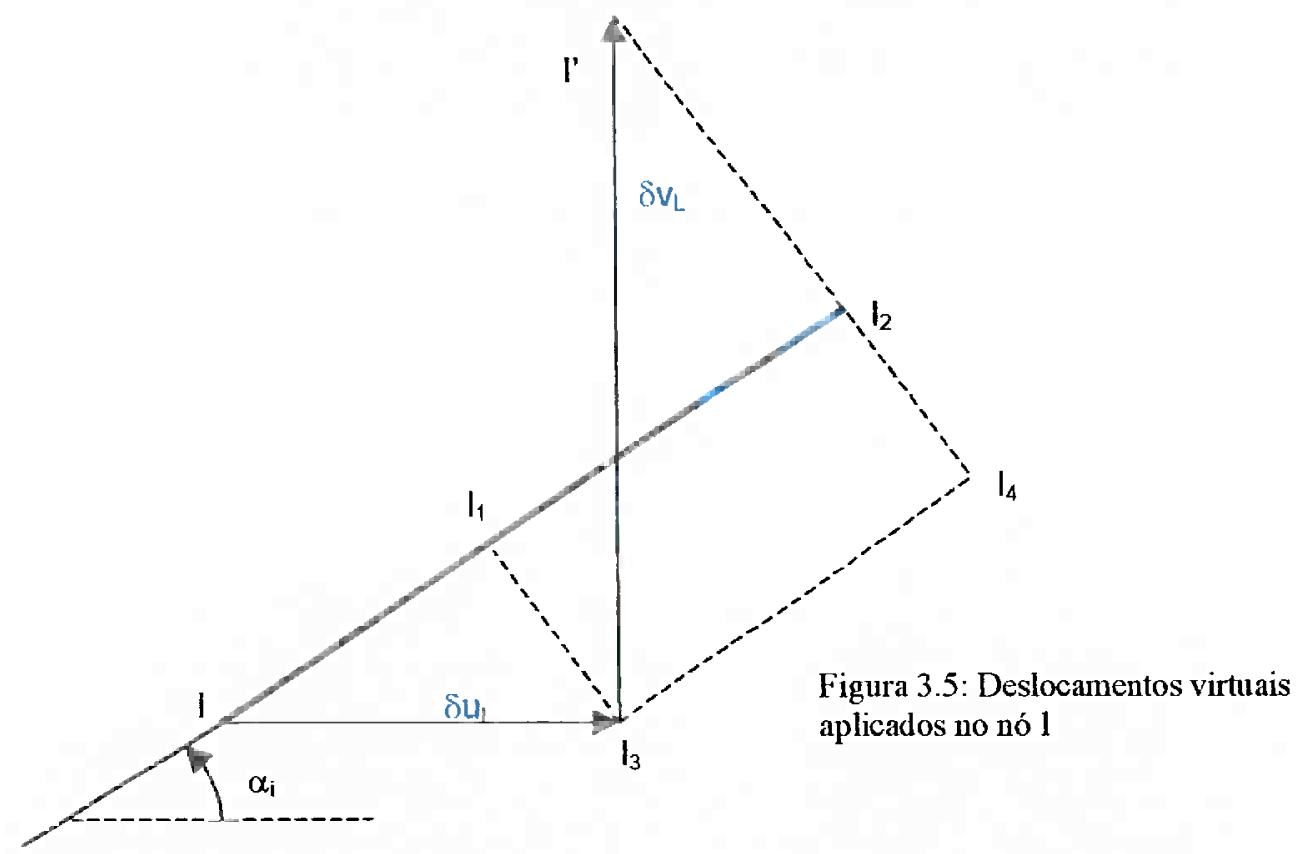

O alongamento virtual da barra devido ao deslocamento virtual horizontal, $\delta u_{1}$, é dado por:

$$
l_{1}=\delta u_{l} \cos \alpha_{i}
$$


O alongamento virtual da barra devido ao deslocamento virtual vertical, $\delta v_{l}$, é dado por:

$$
l_{1} l_{2}=\delta v_{1} \operatorname{sen} \alpha_{i}
$$

O alongamento virtual total, $11_{2}$, decorrente da soma da imposição dos deslocamentos aplicados ao nó $1, \delta u_{1}$ e $\delta v_{1}$, é dado por:

$$
l_{2}=l_{1}+l_{1} l_{2}=\delta u_{l} \cos \alpha_{i}+\delta v_{l} \operatorname{sen} \alpha_{i}
$$

A deformação axial virtual total da barra (i) é dada por:

$$
\delta\left(\Delta U_{i}\right)=l_{2}-k k_{2}
$$

$\mathrm{Na}$ expressão acima, nota-se que o sinal negativo atribuído ao termo $\mathrm{kk}_{2}$ deve-se ao fato da barra (i) ter sofrido encurtamento. É atribuido o sinal negativo à variação de comprimento virtual quando a mesma caracterizar encurtamento.

Substituindo as equações (3.7) e (3.10) na equação (3.11), chega-se a:

$$
\delta\left(\Delta L_{i}\right)=-\delta u_{k} \cos \alpha_{i}-\delta v_{k} \operatorname{sen} \alpha_{i}+\delta u_{l} \cos \alpha \alpha_{i}+\delta v_{l} \operatorname{sen} \alpha_{i}
$$

Como $\alpha_{i}=\alpha_{k}$ e $\alpha_{l}=\alpha_{i}+\pi$, afirma-se que: $\operatorname{sen} \alpha_{i}=-\operatorname{sen} \alpha_{1}, \cos \alpha_{i}=-\cos \alpha_{1}, \quad \operatorname{sen} \alpha_{l}=-\operatorname{sen} \alpha_{k}$ e $\cos \alpha_{\mathrm{I}}=-\cos \alpha_{\mathrm{k}}$, então a equação (3.12) toma a seguinte forma:

$$
\delta\left(\Delta L_{i}\right)=-\delta u_{k} \cos \alpha_{k}-\delta v_{k} \operatorname{sen} \alpha_{k}-\delta u_{l} \cos \alpha_{l}-\delta v_{l} \operatorname{sen} \alpha_{l}
$$

Inserindo a equação (3.13) em (3.4), chega-se a:

$$
\delta W_{i}=\sum_{i=1}^{m} N_{i}\left(-\delta u_{k} \cos \alpha_{k}-\delta v_{k} \operatorname{sen} \alpha_{k}-\delta u_{l} \cos \alpha_{l}-\delta v_{l} \operatorname{sen} \alpha_{l}\right)
$$

A expressão (3.14) está escrita para as $m$ barras da treliça. Sendo assim, pode-se escrever as quatro componentes para cada uma das $m$ barras e agrupá-las de acordo com a incidência em cada um dos $n$ nós. Colocando os deslocamentos em evidência, chega-se a:

$$
\delta W_{i}=\sum_{i=1}^{m} N_{i} \delta\left(\Delta_{i}\right)=\sum_{i=1}^{n}\left\{\left[-\sum\left(N_{P} \cos \alpha_{P}\right) \delta u_{j}\right]+\left[-\sum\left(N_{P} \operatorname{sen} \alpha_{P}\right) \delta v_{j}\right]\right\}
$$


Utilizando as equações de equilíbrio, (3.1) e (3.2) e substituindo em (3.15) tem-se:

$$
\delta W_{i}=\sum_{i=1}^{m} N_{i} \delta\left(\Delta L_{i}\right)=\sum_{i=1}^{n}\left(P_{X j} \delta u_{j}+P_{Y j} \delta v_{j}\right)=\delta W_{e}
$$

Vale a observação de que não existe relação de causa e efeito entre grandezas do mesmo termo, ou seja, $\delta(\Delta L)$ não é causado por $N$.

A expressão (3.16) é equivalente à seguinte:

$$
\delta W_{i}=\delta W_{e}
$$

A igualdade entre o trabalho virtual dos esforços internos com o trabalho virtual dos esforços externos só se verifica quando houver equilíbrio. Sendo assim, pode-se enunciar o Teorema dos Deslocamentos Virtuais:

"Se uma estrutura está em equilíbrio, então o trabalho virtual realizado pelos esforços internos é igual ao trabalho virtual realizado pelos esforços externos, para qualquer sistema de deslocamentos e deformaçöes compativeis e vice-versa".

\subsection{O Teorema dos Esforços Virtuais Aplicado a uma Treliça Plana}

No item anterior, verificou-se que na imposição de deslocamentos virtuais nos graus de liberdade da estrutura, a igualdade entre o trabalho virtual dos esforços internos e o trabalho virtual dos esforços externos implica equilíbrio nas direções dos deslocamentos impostos.

Neste item, o trabalho virtual a ser considerado é o produto escalar entre o deslocamento real e o esforço virtual. Este produto recebe a denominação de "Trabalho Virtual Complementar" e sua notação é dada por " $\delta W_{i}{ }^{*}$ ", quando for realizado pelos esforços internos $\mathrm{e}, " \delta \mathrm{W}_{\mathrm{e}}{ }^{*}$ ", quando for realizado pelos esforços externos.

Na dedução do Teorema dos Deslocamentos Virtuais, para se chegar a igualdade expressa em (3.16), observou-se a compatibilidade entre os deslocamentos e as variações de comprimento virtuais (ver Figuras 3.5 e 3.6) e o equilíbrio dos esforços reais (ver equações (3.1) e (3.2)). A dedução do Teorema dos Esforços Virtuais é análoga à dedução do Teorema dos Deslocamentos Virtuais: estabelecendo a compatibilidade entre os deslocamentos e as variações de comprimento reais na estrutura e aplicando um sistema de esforços virtuais estaticamente admissíveis, chega-se a igualdade da expressão (3.18) 


$$
\delta W_{i}^{*}=\sum_{i=1}^{m} \delta N_{i} \Delta L_{i}=\sum_{i=1}^{n}\left(\delta P_{X j} u_{j}+\delta P_{Y j} v_{j}\right)=\delta W_{e}^{*}
$$

ou seja:

$$
\delta W_{i}^{*}=\delta W_{e}^{*}
$$

Sendo assim, pode-se enunciar o Teorema dos Esforços Virtuais:

"Em uma estrutura, para qualquer sistema de esforços virtuais estaticamente admissiveis, se o trabalho virtual complementar realizado pelos esforços internos for igual ao trabalho virtual complementar realizado pelos esforços externos, então as deformações e os deslocamentos são cinematicamente admissiveis e vice-versa".

\subsection{Aplicação do Processo Direto a um Sistema Estrutural com $\mathrm{g}=\mathrm{h}=1$}

Considere a treliça da Figura 3.6. .A estrutura possui um grau de liberdade e é uma vez hiperestática e será resolvida pelo Processo Direto.

$$
\begin{aligned}
& \\
& L_{1}=L_{3}=5 \mathrm{~m} \\
& L_{2}=4 \mathrm{~m} \\
& E A=10^{3} \mathrm{kN}
\end{aligned}
$$

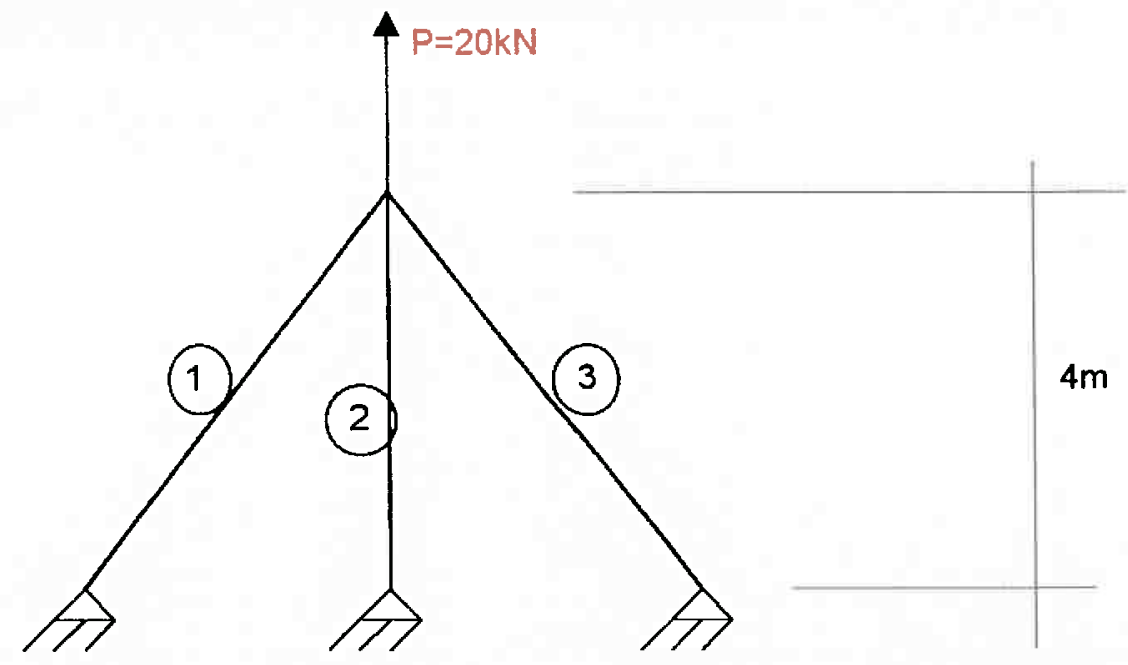

Figura 3.6 : Treliça plana com um

\begin{tabular}{l|l|}
$3 \mathrm{~m}$ & $3 \mathrm{~m}$ \\
\hline &
\end{tabular}
grau de liberdade e um grau de hiperestaticidade. 
Nesta estrutura só podem ocorrer esforços normais, então pressupõe-se que todos os esforços sejam de tração. A Figura 3.7 exibe o grau de liberdade da estrutura.

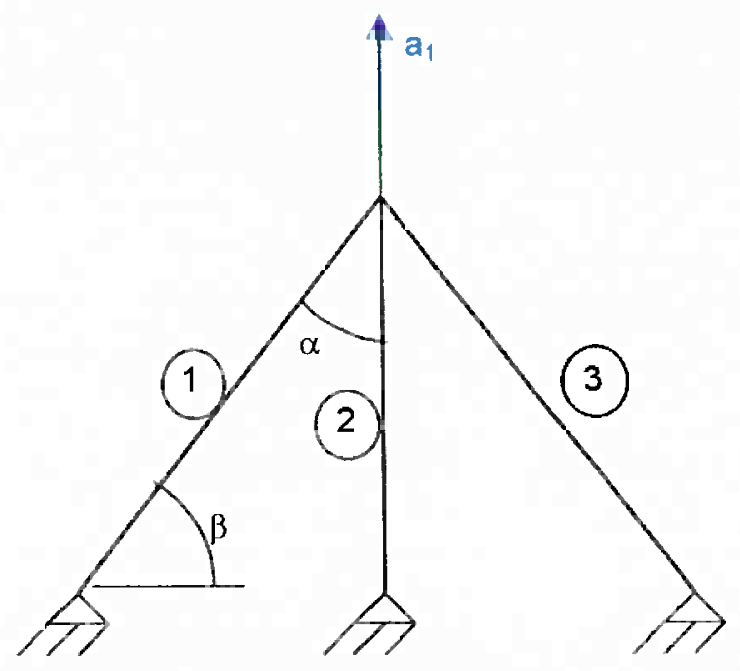

Figura 3.7 : Grau de liberdade da treliça.

Para a obtenção da equação de equilíbrio, deve-se aplicar o Teorema dos Deslocamentos Virtuais, impondo o deslocamento virtual segundo o grau de liberdade da estrutura.

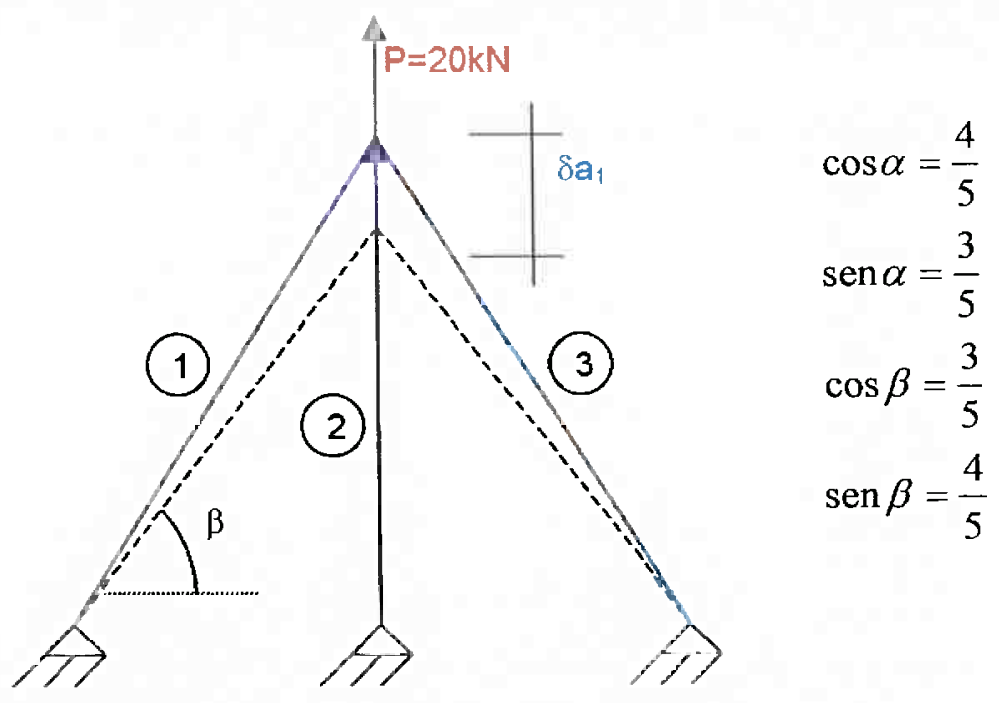

Figura 3.8 : Deslocamento virtual na treliça segundo o grau de liberdade $a_{1}$.

O trabalho virtual dos esforços internos é dado por:

$\delta W_{i}=N_{1} \delta\left(\Delta L_{1}\right)+N_{2} \delta\left(\Delta L_{2}\right)+N_{3} \delta\left(\Delta L_{3}\right)$ 
A Figura 3.9 ilustra a relação entre o deslocamento e a variação de comprimento virtual :

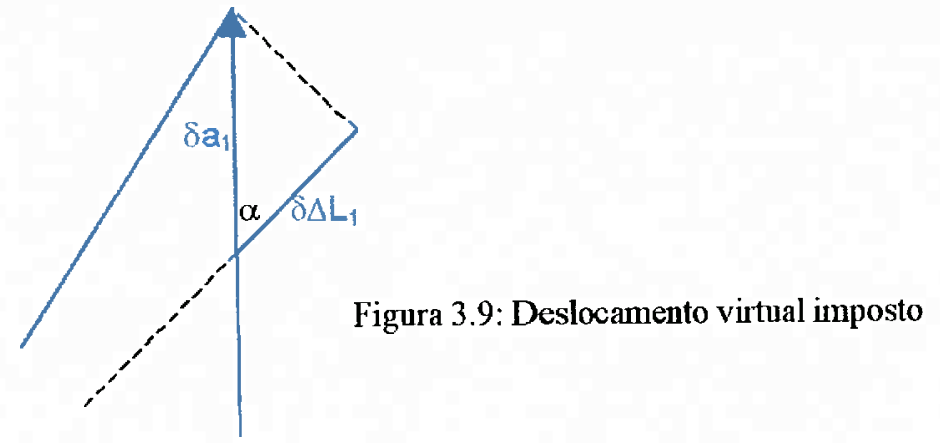

Por simetria, $\delta \Delta \mathrm{L}_{1}=\delta \Delta \mathrm{L}_{3}$ e $\mathrm{N}_{1}=\mathrm{N}_{3}$, então a equação (3.20) toma a seguinte forma:

$\delta W_{i}=\frac{8}{5} N_{1} \delta a_{1}+N_{2} \delta a_{1}$

O trabalho virtual realizado pelos esforços externos é dado por:

$\delta W_{e}=20 \delta a_{1}$

Fazendo:

$\delta W_{e}=\delta W_{i}$

Obtém-se a equação de equilíbrio:

$8 N_{1}+5 N_{2}=100$

A seguir, deve-se obter uma equação de compatibilidade, utilizando o Teorema dos Esforços Virtuais. Para tanto é necessário obter uma estrutura isostática fundamental, como mostra a Figura 3.10:

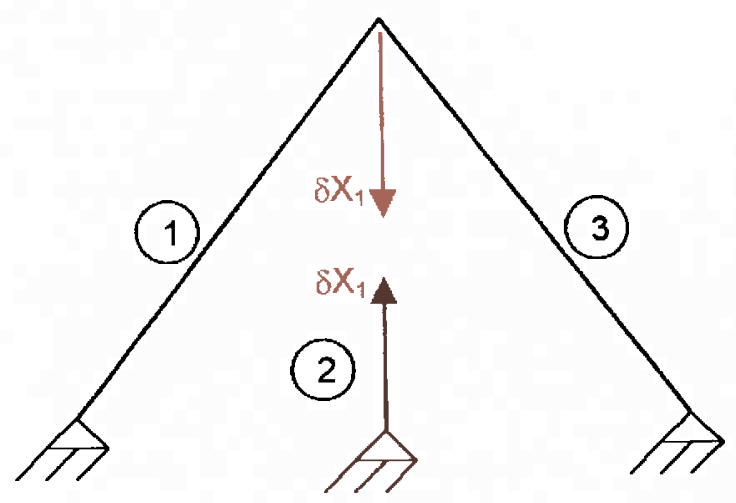

Figura 3.10 : Estrutura isostática fundamental 
Resolvendo a treliça, obtém-se:

$\delta N_{1}=\delta N_{3}=-\frac{5}{8} \delta X_{1}$

$\delta N_{2}=\delta X_{1}$

O trabalho virtual complementar dos esforços internos é dado por:

$\delta W_{i}^{*}=\delta N_{1} \Delta L_{1}+\delta N_{2} \Delta L_{2}+\delta N_{3} \Delta L_{3}$

Substituindo as equações (3.25) e (3.26) em (3.27), obtém-se:

$\delta W_{i}^{*}=-\frac{5}{4} \delta X_{1} \Delta L_{1}+\delta X_{1} \Delta L_{2}$

Como não há nenhum deslocamento imposto, o trabalho virtual complementar realizado pelos esforços externos é dado por:

$\delta W_{e}^{*}=0$

Pelo Teorema dos Esforços Virtuais:

$\delta W_{i}^{*}=\delta W_{e}^{*}$

Assim, obtém-se a seguinte equação de compatibilidade:

$-\frac{5}{4} \Delta L_{1}+\Delta L_{2}=0$

Inserindo as equações constitutivas, $\Delta L_{i}=\frac{N_{i} L_{i}}{E A}$, para $\mathrm{i}=1,2$, na equação de compatibilidade, tem-se:

$-25 N_{1}+16 N_{2}=0$

As equações (3.24) e (3.33) formam o seguinte sistema linear:

$\left[\begin{array}{cc}-25 & 16 \\ 8 & 5\end{array}\right]\left\{\begin{array}{l}N_{1} \\ N_{2}\end{array}\right\}=\left\{\begin{array}{c}0 \\ 100\end{array}\right\}$ 
De onde se obtém:

$N_{1}=6,324 k N$

$N_{2}=9,881 k N$

\subsection{Aplicação do Processo Direto a uma Treliça Plana Hiperestática}

A seguir, o Processo Direto é aplicado à treliça plana hiperestática da Figura 3.11, onde $\mathrm{L}_{1}=\mathrm{L}_{2}=\mathrm{L}_{4}=\mathrm{L}_{5}=5 \mathrm{~m} ; \mathrm{L}_{3}=6 \mathrm{~m}$ e $F A=10^{3} \mathrm{kN}$

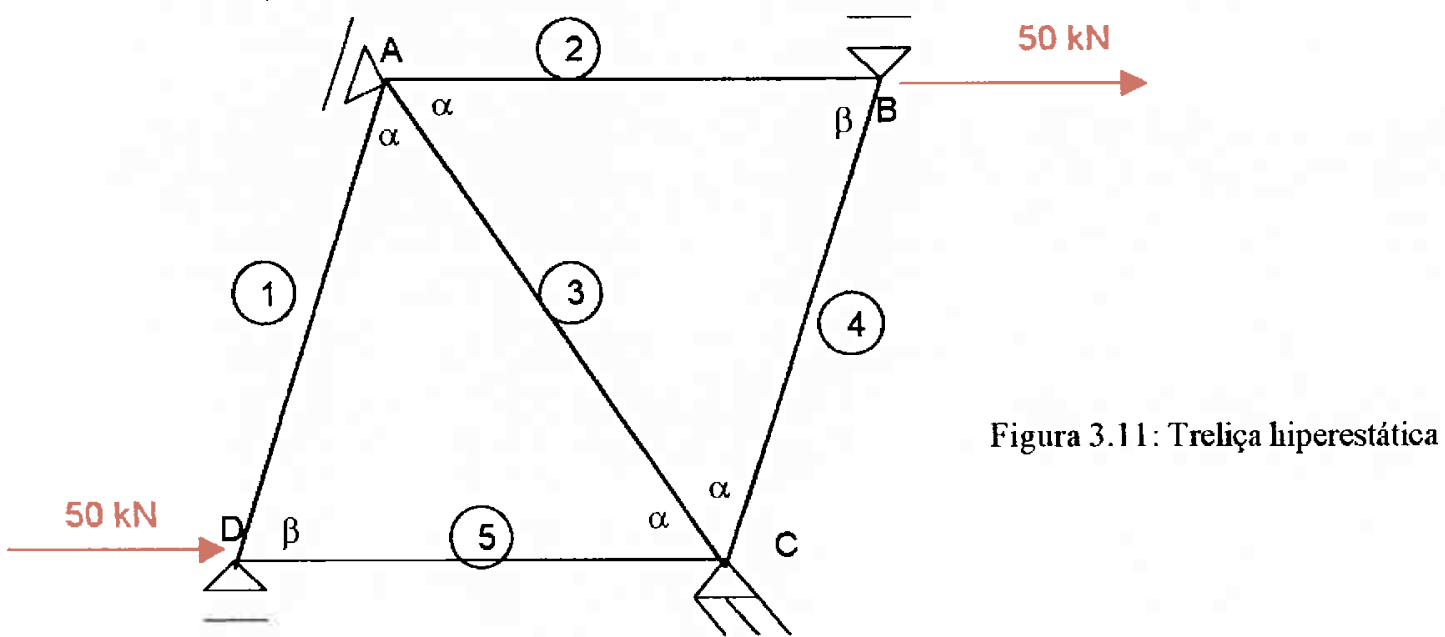

PASSO 1: Serão obtidas as equações de equilíbrio através da aplicação do Teorema dos Deslocamentos Virtuais. Percebe-se que essas equações podem ser facilmente obtidas através do equilibrio dos nós da treliça, o que constitui um procedimento mais prático. No entanto, optou-se pela utilização do teorema para a ilustração do seu uso. Os deslocamentos virtuais são, a princípio, arbitrários, mas eles são aplicados segundo as direções e os respectivos sentidos dos graus de liberdade da estrutura, o que permite qualificá-los como cinematicamente admissiveis.

São identificados os graus de liberdade da estrutura, conforme mostra a Figura 3.12:

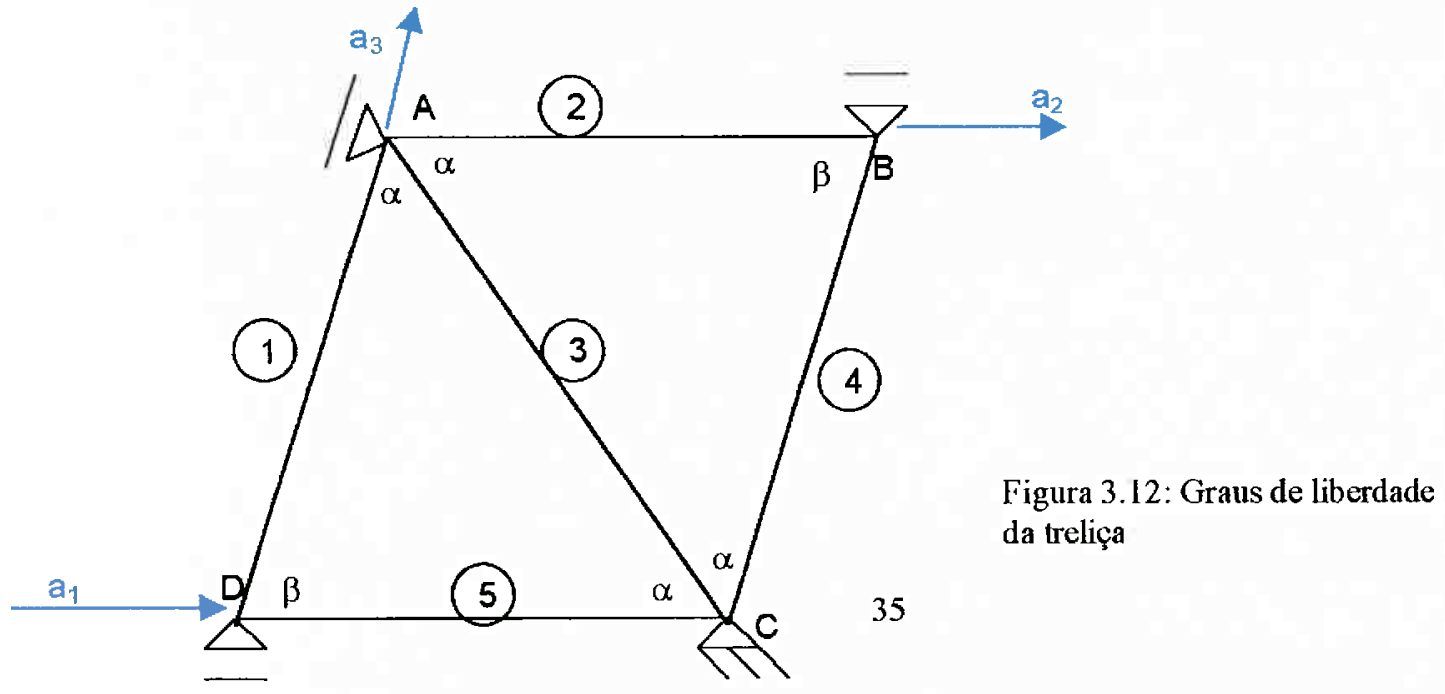


Neste caso, a treliça possui $h=3$, então são aplicados três sistemas virtuais. Antes de aplicar os deslocamentos virtuais nos graus de liberdade da estrutura, admite-se que as incógnitas são todas positivas. Os deslocamentos virtuais impostos são positivos, conforme dedução mostrada no item 3.2.

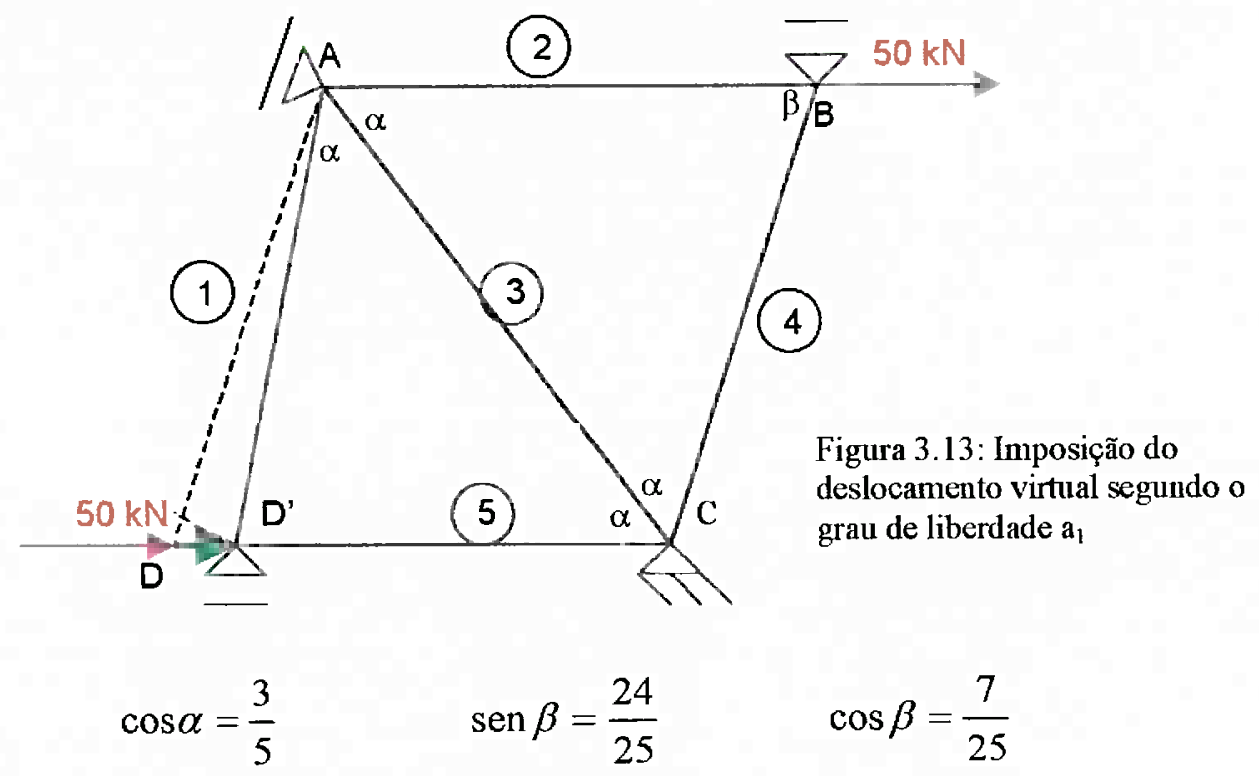

Ampliando a figura 3.13 na região da imposição do deslocamento virtual, tem-se:

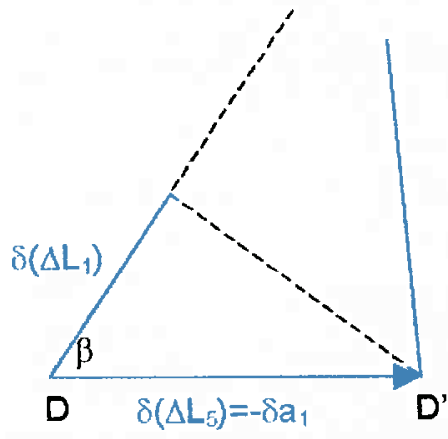

Figura 3.14: Deslocamento virtual imposto em $a_{1}$ e deformações decorrentes

A barra 1 sofre encurtamento, então a deformação virtual é negativa:

$\delta\left(\Delta_{1}\right)=-\frac{7}{25} \delta a_{1}$

$\delta a_{1}=-\delta\left(\Delta L_{5}\right)$

Como apenas as barras 1 e 5 sofrem deformação, a expressão do trabalho virtual dos esforços internos se apresenta da seguinte maneira:

$\delta W_{i}=N_{1} \delta\left(\Delta_{1}\right)+N_{5} \delta\left(\Delta L_{5}\right)$ 
Escreve-se a expressão do trabalho virtual dos esforços externos:

$\delta W_{e}=50 \delta a_{1}$

Como o deslocamento imposto é cinematicamente admissível, podem ser igualados os trabalhos virtuais dos esforços internos e externos. Tal igualdade fornece a equação de equilibrio no nó considerado e na direção do deslocamento.

$\delta W_{e}=\delta W_{i}$

Substituindo (3.36) e (3.37) em (3.38), tem-se:

$-7 N_{1}-25 N_{5}=1250$

Pode-se verificar facilmente que a expressão (3.39) constitui a equação de equilibrio do nó $\mathrm{D}$ na direção horizontal.

Impondo o deslocamento virtual segundo o grau de liberdade $a_{2}$, tem-se:

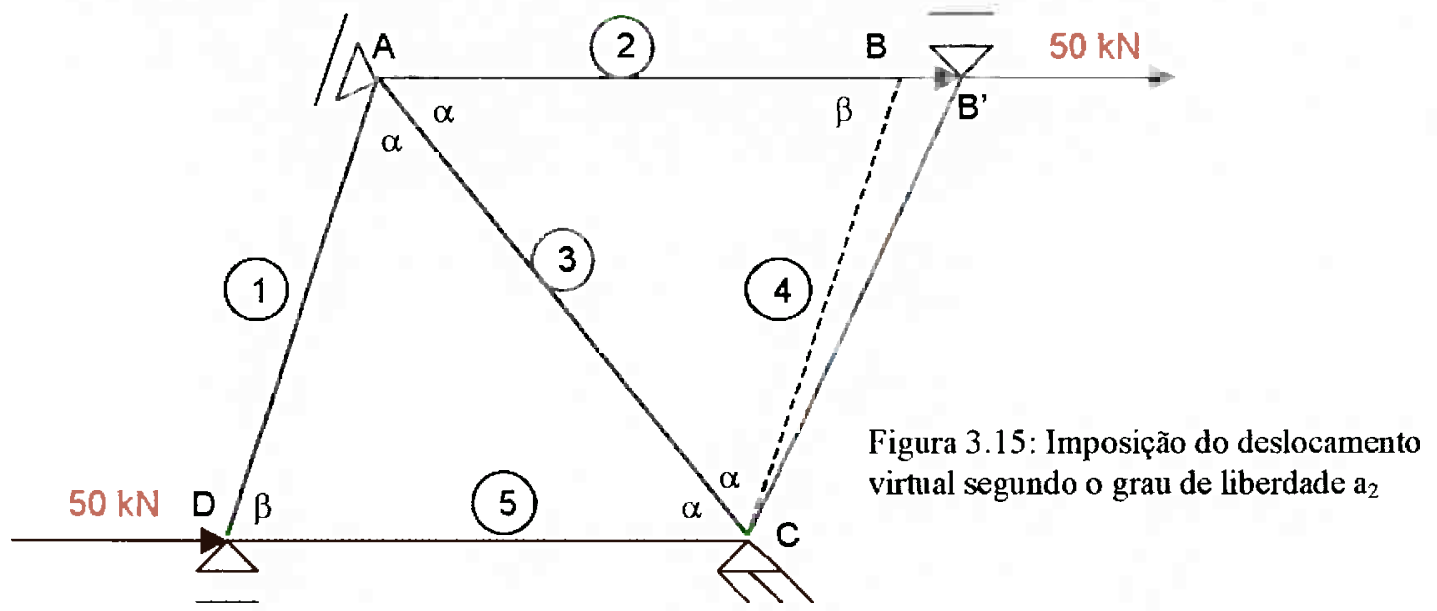

Ampliando a Figura 3.15 na região da imposição do deslocamento virtual:

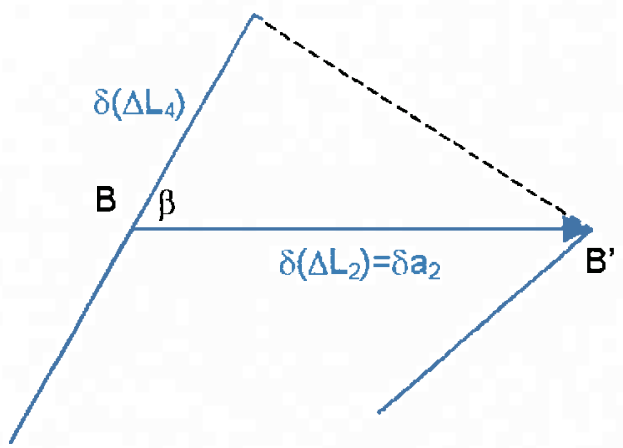

Figura 3.16: Imposição do deslocamento virtual em $\mathbf{a}_{2}$ e deformações decorrentes 
Como há alongamento das barras 2 e 4 , a deformação virtual tem sinal positivo.

$\delta\left(\Delta L_{4}\right)=\frac{7}{25} \delta a_{2}$

$\delta\left(\Delta L_{2}\right)=\delta a_{2}$

A expressão do trabalho virtual dos esforços internos é:

$\delta W_{i}=N_{4} \delta\left(\Delta L_{4}\right)+N_{2} \delta\left(\Delta L_{2}\right)$

A expressão do trabalho virtual dos esforços externos é:

$\delta W_{e}=50 \delta a_{2}$

Novamente, a igualdade entre o trabalho virtual dos esforços externos e internos implica o equilíbrio do nó B, na direção horizontal. Então:

$\delta W_{e}=\delta W_{i}$

Substituindo (3.42) e (3.43) em (3.44), chega-se a:

$25 N_{2}+7 N_{4}=1250$

A expressão (3.45) constitui a equação de equilibrio do nó B na direção horizontal.

Impondo o deslocamento virtual, $\delta a_{3}$, segundo o grau de liberdade $a_{3}$, tem-se:

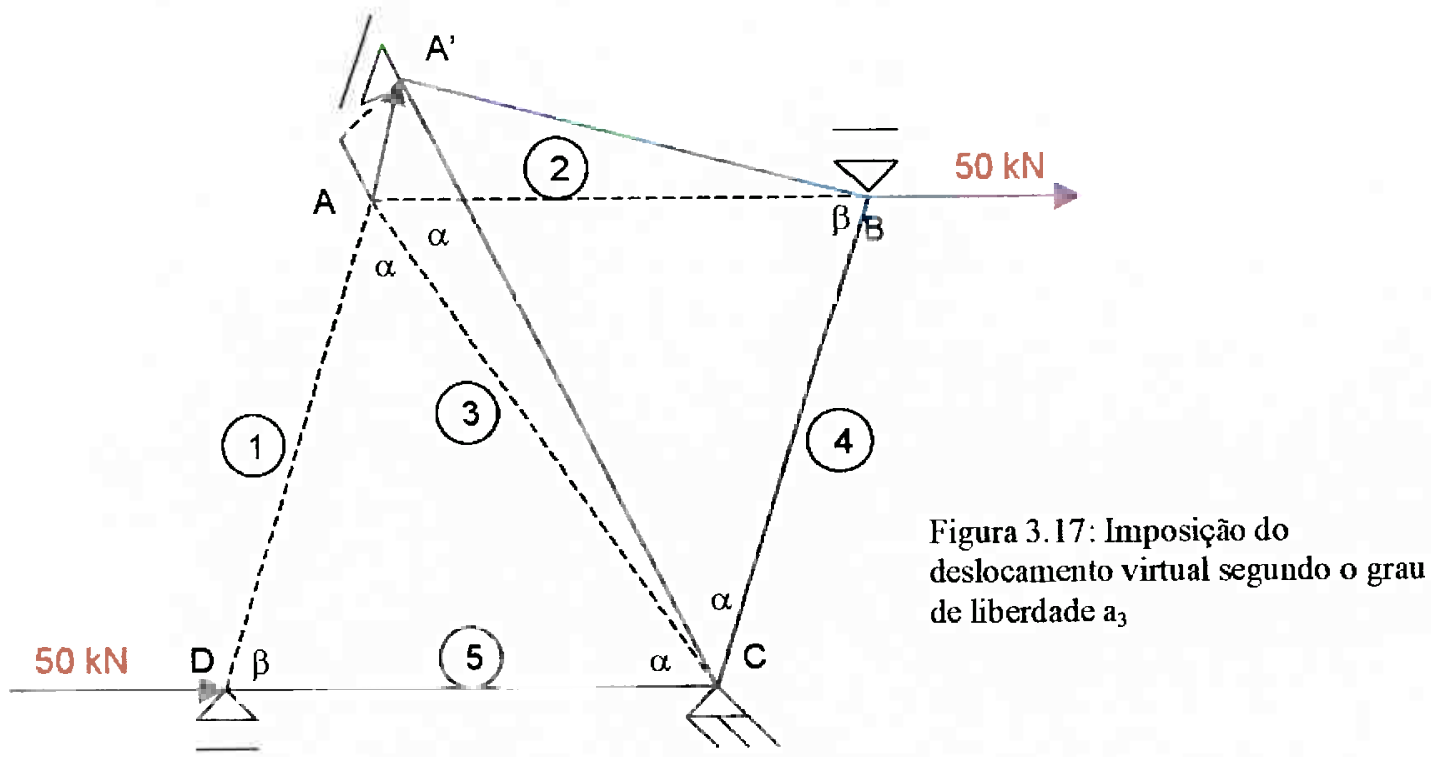


Ampliando a Figura 3.17 na região de imposição do deslocamento virtual, tem-se:

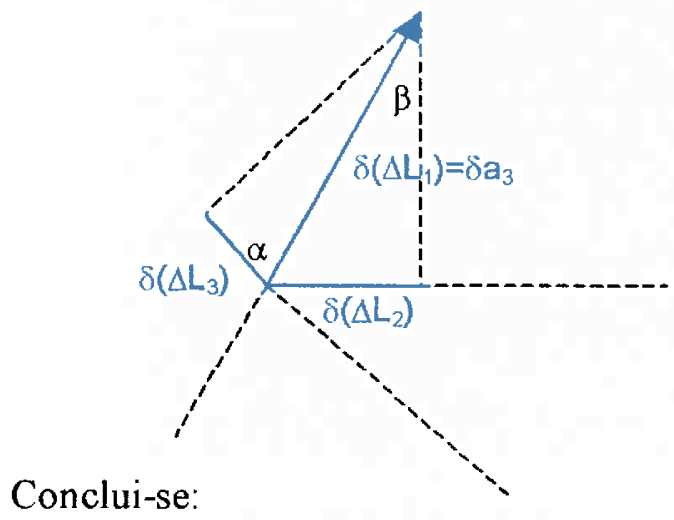

Figura 3.18: Imposição do deslocamento virtual em $a_{3}$ e deformações decorrentes

$\delta\left(\Delta L_{2}\right)=-\frac{7}{25} \delta a_{3}$

O sinal negativo indica o encurtamento na barra 2. Já as barras 1 e 3 serão alongadas, implicando sinal positivo nas suas variações de comprimento.

$\delta\left(\Delta L_{3}\right)=\frac{3}{5} \delta a_{3}$

$\delta\left(\Delta L_{1}\right)=\delta a_{3}$

A expressão do trabalho virtual dos esforços internos é:

$\delta W_{i}=N_{1} \delta\left(\Delta L_{1}\right)+N_{2} \delta\left(L_{2}\right)+N_{3} \delta\left(\Delta_{3}\right)$

Como não há nenhum esforço externo real correspondente ao deslocamento virtual imposto, então:

$\delta W_{e}=0$

Igualando os trabalhos virtuais realizados pelos esforços internos e externos, obtém-se a equação de equilíbrio na direção da barra 1 , então:

$\delta W_{i}=\delta W_{e}$

Substituindo (3.49) e (3.50) em (3.51), obtém-se:

$25 N_{1}-7 N_{2}+15 N_{3}=0$ 
A expressão (3.52) constitui a equação de equilíbrio do nó A, segundo a direção da barra 1 .

PASSO 2: Uma vez obtidas as três equações de equilíbrio, é necessário obter as equações de compatibilidade. Como $\mathrm{g}=2$, serão obtidas duas equações dessa natureza. É necessário escolher uma estrutura isostática fundamental. Vale mencionar que essa escolha pode conduzir a uma resolução mais simples ou mais complexa. Os esforços virtuais são aplicados segundo a direção dos vínculos subtraídos. Esses vínculos podem ser internos ( ver Figura 3.19 ) ou externos ( ver Figura 3.20). Nas equações de compatibilidade, são introduzidas as equações constitutivas, obtendo-se equações de compatibilidade escritas em função dos esforços.

Abaixo, encontra-se uma estrutura isostática fundamental, na qual será aplicada a força relativa ao vínculo subtraído. Admite-se que os deslocamentos reais são todos positivos e admite-se esforços de tração nas barras da treliça.

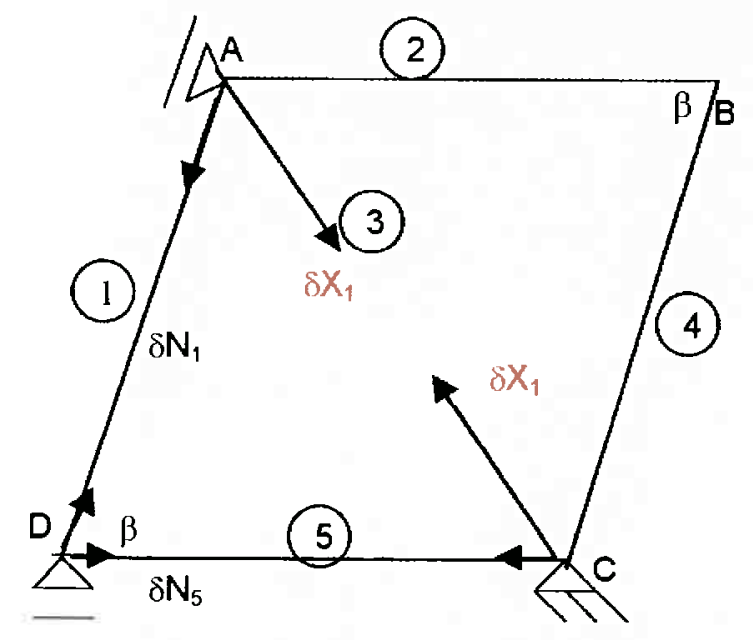

Figura 3.19: Esforço virtual aplicado em substituição ao vínculo na estrutura isostática fundamental

Segundo o equilíbrio do nó A, obtém-se:

$$
\delta N_{1}=-\frac{3}{5} \delta X_{1}
$$

$\mathrm{O}$ esforço $\delta \mathrm{N}_{1}$ é negativo, o que representa compressão do esforço virtual na barra 1.

Segundo o equilíbrio do nó D, obtém-se:

$$
\delta N_{5}=\frac{21}{125} \delta X_{1}
$$

O trabalho virtual complementar dos esforços internos é dado pela expressão abaixo:

$$
\delta W_{i}^{*}=\delta N_{1} \Delta L_{1}+\delta N_{3} \Delta L_{3}+\delta N_{5} \Delta L_{5}
$$


O trabalho virtual complementar dos esforços externos é dado por:

$\delta W_{e}^{*}=0$

Então, tem-se:

$\delta W_{i}^{*}=\delta W_{e}^{*}$

$\mathrm{O}$ trabalho virtual realizado por $\delta \mathrm{X}_{1}$ é nulo. A igualdade expressa em (3.57) equivale afirmar que não há deslocamento relativo entre as faces do corte da barra 3 .

Substituindo (3.55) e (3.56) em (3.57), obtém-se:

$-75 \Delta L_{1}+125 \Delta L_{3}+21 \Delta L_{5}=0$

Pela Lei de Hooke:

$\Delta L_{i}=\frac{N_{i} L_{i}}{E_{i} A_{i}}$

Onde $\mathrm{L}_{1}=\mathrm{L}_{5}=5 \mathrm{~m}, \mathrm{~L}_{3}=6 \mathrm{~m} \mathrm{e} E_{1} A_{1}=E_{3} A_{3}=E_{5} A_{5}=10^{3}$

Substituindo a Lei de Hooke e seus respectivos valores em (3.58), obtém-se:

$-75 N_{1}+150 N_{3}+21 N_{5}=0$

A expressão (3.59) indica a equação de compatibilidade (3.58) escrita em função dos esforços

Aplicando ainda o esforço virtual correspondente à subtração do vínculo do nó B e ainda, mantendo a mesma convenção do início do passo 2 .

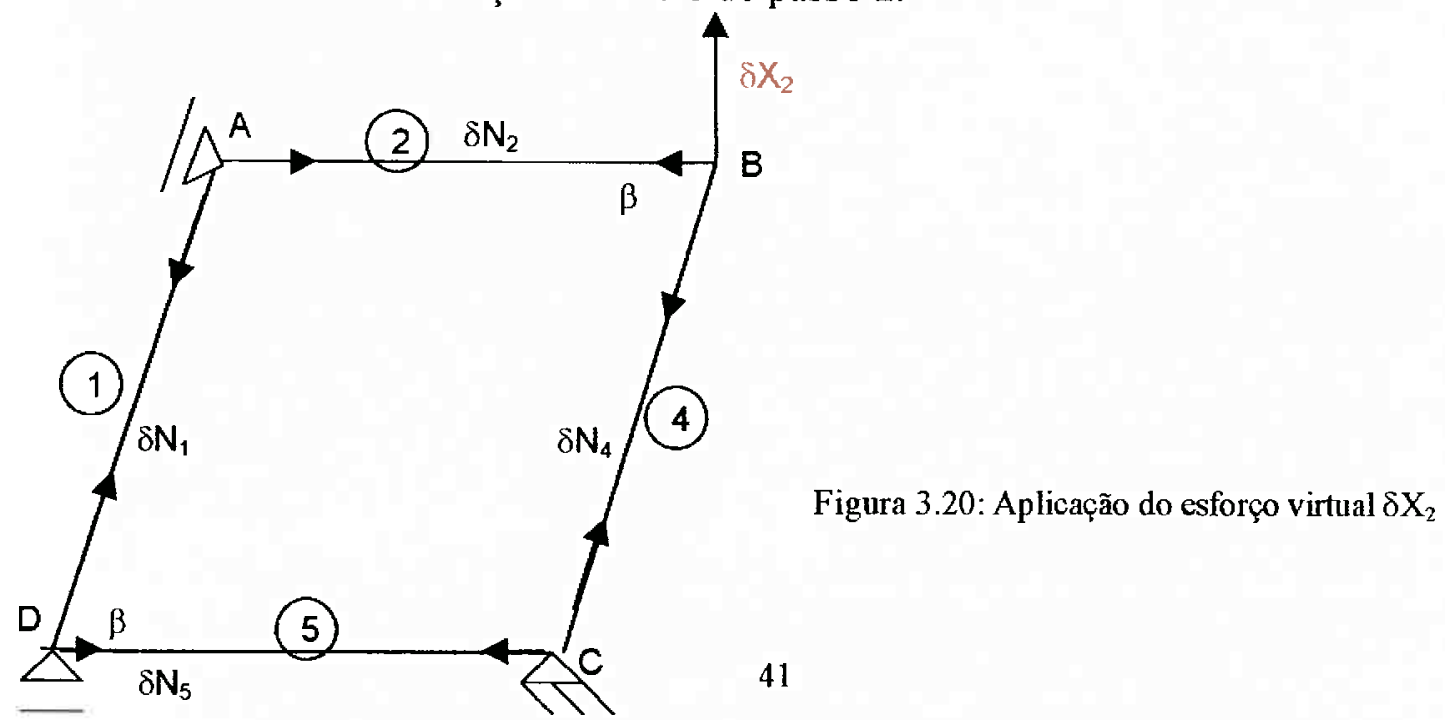


Segundo o equilíbrio do nó B, obtém-se:

$\delta N_{4}=\frac{25}{24} \delta X_{2}$

$\delta N_{2}=-\frac{7}{24} \delta X_{2}$

Segundo o equilíbrio do nó A, tem-se:

$\delta N_{1}=-\frac{49}{600} \delta X_{2}$

$\delta N_{5}=\frac{343}{15000} \delta X_{2}$

Pode-se facilmente perceber a compressão nas barras 1 e 2 . A seguir, tem-se a expressão do trabalho virtual complementar dos esforços internos, obtida pela somatória dos produtos dos esforços virtuais com as variações de comprimentos reais:

$\delta W_{i}^{*}=\delta N_{1} \Delta L_{1}+\delta N_{2} \Delta I_{2}+\delta N_{4} \Delta L_{4}+\delta N_{5} \Delta L_{5}$

A expressão do trabalho virtual complementar dos esforços externos, é dada por:

$$
\delta W_{e}^{*}=0
$$

O trabalho virtual dos esforços externos é nulo pelo fato de não haver recalque de apoio no ponto e na direção em que foi aplicado o esforço virtual.

A igualdade entre os trabalhos virtuais complementares dos esforços internos e externos implica na equação de compatibilidade que indica o deslocamento vertical do nó B como sendo nulo, então:

$\delta W_{e}^{*}=\delta W_{i}^{*}$

Substituindo (3.64) e (3.65) em (3.66), tem-se:

$-\frac{49}{600} \Delta L_{1}-\frac{7}{24} \Delta L_{2}+\frac{25}{24} \Delta L_{4}+\frac{343}{15000} \Delta L_{5}=0$ 
Novamente, substituindo pela Lei de Hooke, chega-se a equação de compatibilidade escrita em função dos esforços solicitantes da treliça:

$-1225 N_{1}-4375 N_{2}+15625 N_{4}+343 N_{5}=0$

As equações (3.39), (3.45), (3.52), (3.59) e (3.68) formam o seguinte sistema linear:

$\left[\begin{array}{ccccc}-7 & 0 & 0 & 0 & -25 \\ 0 & 25 & 0 & 7 & 0 \\ 25 & -7 & 15 & 0 & 0 \\ -75 & 0 & 150 & 0 & 21 \\ -1225 & -4375 & 0 & 15625 & 343\end{array}\right]\left\{\begin{array}{l}N_{1} \\ N_{2} \\ N_{3} \\ N_{4} \\ N_{5}\end{array}\right\}=\left\{\begin{array}{c}1250 \\ 1250 \\ 0 \\ 0 \\ 0\end{array}\right\}$

Resolvendo o sistema linear, obtém-se:

$$
\begin{aligned}
& N_{1}=6,545 \mathrm{kN} \\
& N_{2}=45,936 \mathrm{kN} \\
& N_{3}=10,529 \mathrm{kN} \\
& N_{4}=14,513 \mathrm{kN} \\
& N_{5}=-51,832 \mathrm{kN}
\end{aligned}
$$$$
\text { Diagrama de Esforços Normais }
$$

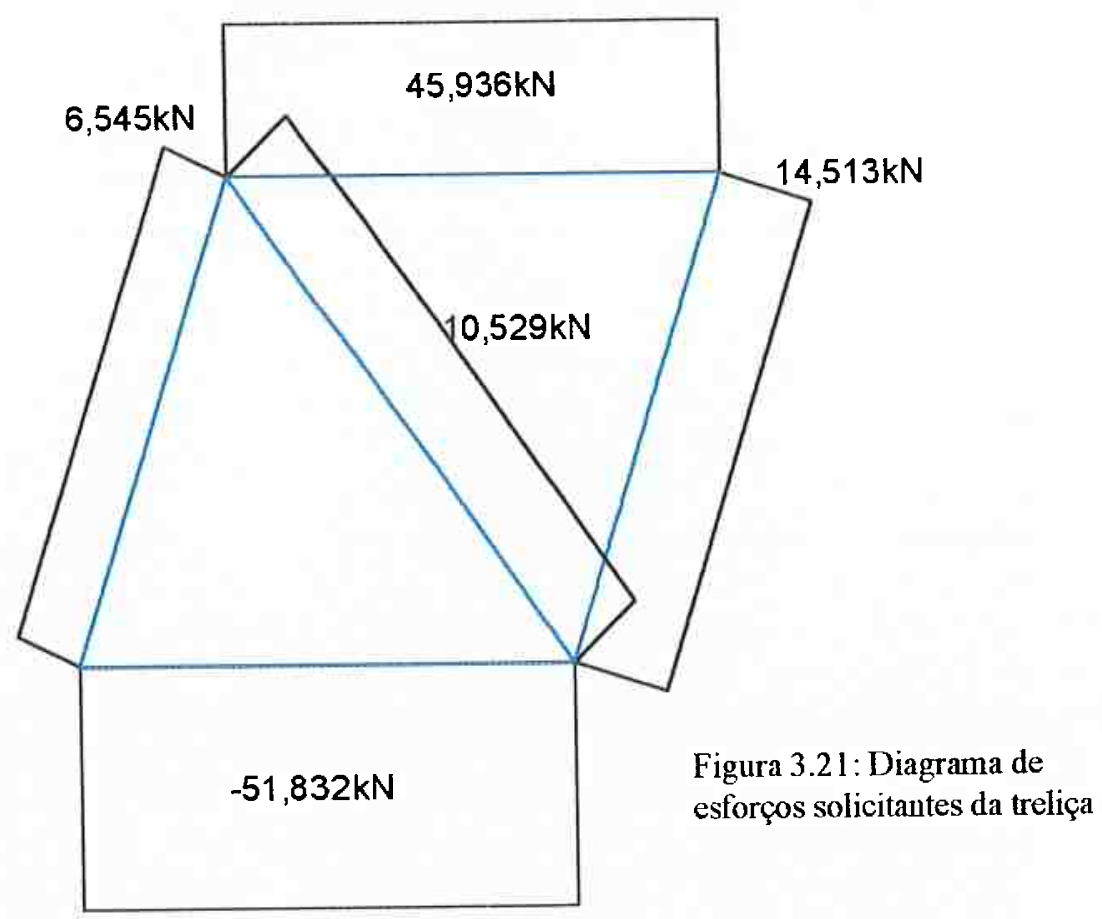




\section{Capítulo 4}

\section{O Processo Direto Aplicado à Resolução dos Pórticos Planos Hiperestáticos}

\subsection{Introdução}

Neste capítulo, são apresentados conceitos análogos aos que foram aplicados às treliças. Os pórticos, porém, apresentam uma maior variedade de esforços solicitantes em relação à treliça: além do esforço normal, apresentam também o esforço cortante e o momento fletor. A teoria é desenvolvida para pórticos somente com cargas nodais. As equações de equilíbrio são obtidas através da aplicação do Teorema dos Deslocamentos Virtuais e as equações de compatibilidade são obtidas através da aplicação do Teorema dos Esforços Virtuais. As equações constitutivas são inseridas nas equações de compatibilidade. Estas, juntamente com as equações de equilíbrio, vão fornecer um sistema linear, cuja solução fornece os esforços solicitantes na estrutura.

Utiliza-se ainda um procedimento alternativo daquele apresentado por Costa e Diogo ${ }^{1}$, que obtiveram as expressões dos trabalhos virtuais realizados pelos esforços internos na aplicação do Teorema dos Deslocamentos Virtuais por meio da integração dos diagramas de curvatura, $\kappa$, com os diagramas de momentos fletores e dos diagramas de deformação axial, $\varepsilon$, com os diagramas de esforço normal, relativos a um mesmo deslocamento virtual e a uma mesma barra, enquanto neste trabalho, essas expressões foram obtidas multiplicando-se os deslocamentos virtuais de extremidade de barra decorrentes da imposição do deslocamento virtual segundo o grau de liberdade, pelos esforços reais de extremidade correspondentes aos mesmos.

\footnotetext{
${ }^{1}$ Costa, H.B; Diogo, L.A.C. Considerações sobre o Emprego do Teorema dos Trabalhos Virtuais na Resolução de Estruturas Hiperestáticas: Pórticos.
} 


\subsection{O Teorema dos Deslocamentos Virtuais Aplicado a um Pórtico Plano}

\section{a) Obtenção das expressões dos trabalhos virtuais realizados pelos esforços internos e externos}

Considere uma barra $\mathrm{AB}$ de um pórtico plano, no seu sistema local, conforme a figura 4.1-a:

A convenção de sinais dos esforços solicitantes é utilizada ao longo do desenvolvimento da teoria e também na resolução do exemplo prático. São considerados positivos:

- o esforço normal de tração;

- a força cortante no sentido horário;

- o momento fletor que comprime as fibras superiores da viga.

Impondo a essa barra um campo de deslocamentos virtuais, $\delta v=\delta v(x)$, conforme figura 4.1-b:

(a)

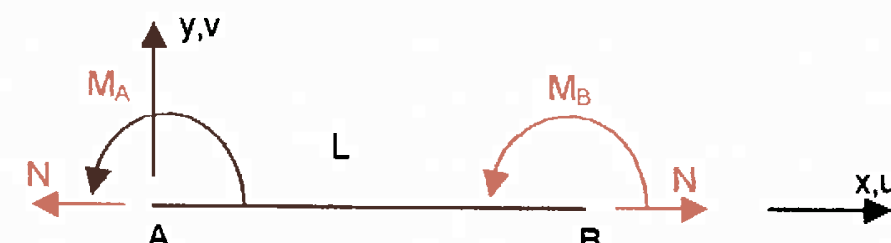

(b)

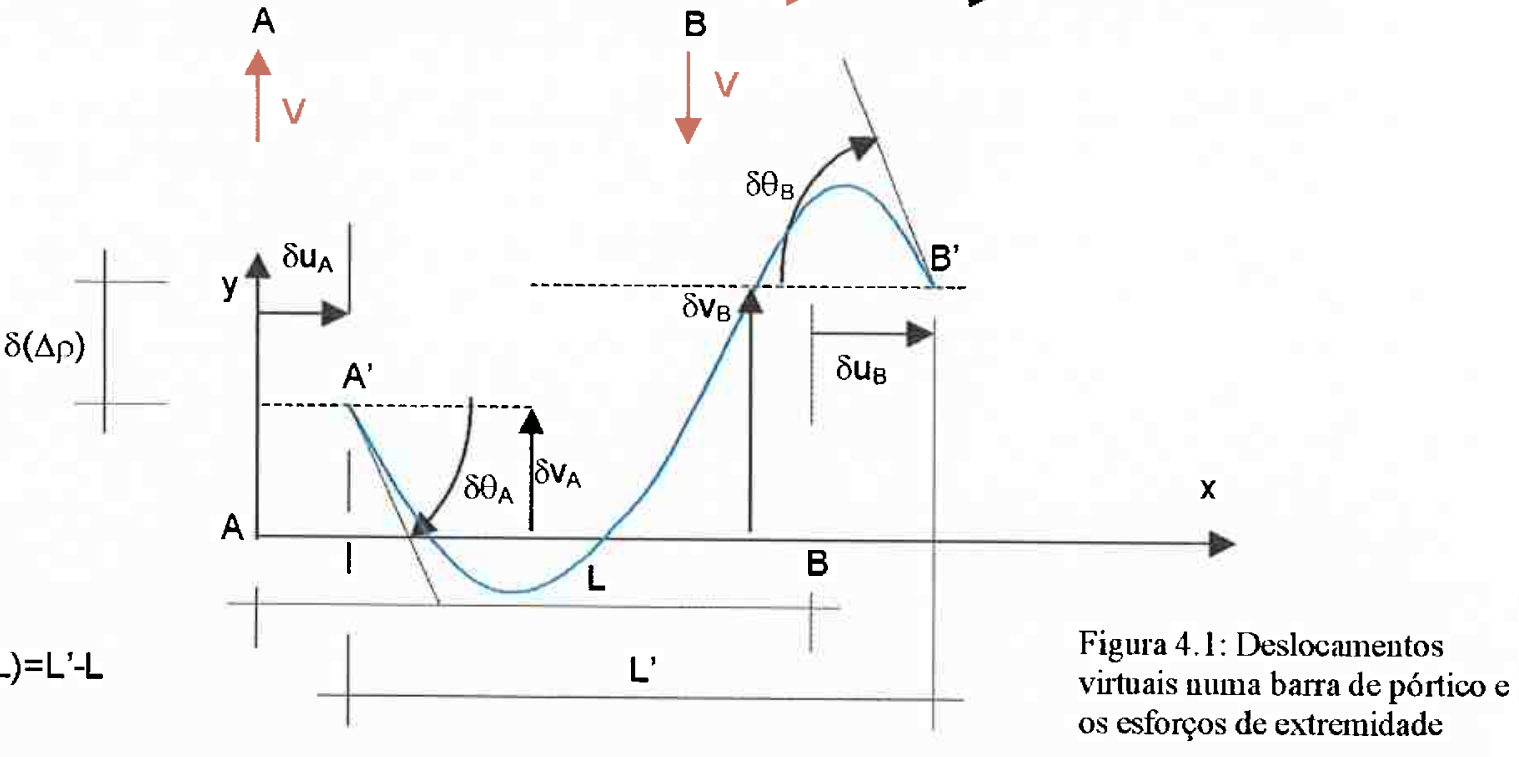

Desprezando as deformações por força cortante, o trabalho virtual dos esforços internos é dado por:

$$
\delta W_{i}=\int_{A B} M d(\delta \theta)=\int_{0}^{L} M \frac{d(\delta \theta)}{d x} d x=\int_{0}^{L} M \frac{d^{2}(\delta v)}{d x^{2}} d x
$$


Integrando por partes, obtém-se:

$$
\int_{0}^{L} M \frac{d^{2}(\delta v)}{d x^{2}} d x=[M \delta \theta]_{0}^{L}-\int_{0}^{L} \frac{d M}{d x} \frac{d(\delta v)}{d x} d x
$$

Substituindo (4.2) em (4.1), chega-se a:

$$
\delta W_{i}=[M \delta \theta]_{0}^{L}-\int_{0}^{L} \frac{d M}{d x} \frac{d(\delta v)}{d x} d x
$$

Integrando novamente por partes, obtém-se:

$$
\int_{0}^{L} \frac{d M}{d x} \frac{d(\delta v)}{d x} d x=[V \delta v]_{0}^{L}-\int_{0}^{L} \frac{d^{2} M}{d x^{2}} \delta v d x
$$

Como a barra de pórtico está sujeita apenas a esforços de extremidade, pode-se concluir que:

$$
\frac{d^{2} M}{d x^{2}}=p=0
$$

Então:

$$
\int_{0}^{L} \frac{d M}{d x} \frac{d(\delta v)}{d x} d x=[V \delta v]_{0}^{L}
$$

Substituindo (4.6) em (4.3), tem-se:

$$
\delta W_{i}=[M \delta \theta]_{0}^{L}-[V \delta v]_{0}^{L}
$$

Reescrevendo a expressão (4.7), obtém-se:

$$
\delta W_{i}=M_{B} \delta \theta_{B}+M_{A} \delta \theta_{A}-V \delta v_{B}+V \delta v_{A}
$$

$O$ sinal positivo da parcela $M_{A} \delta \theta_{A}$ deve-se ao fato de o momento fletor, $M_{A}$, tracionar as fibras superiores, sendo o mesmo negativo em relação à convenção de sinais adotada.

Denominando:

$$
\delta \Delta \rho=\delta v_{B}-\delta v_{A}
$$


Como o deslocamento virtual relativo, a expressão (4.8) transforma-se em:

$$
\delta W_{i}=M_{B} \delta \theta_{B}+M_{A} \delta \theta_{A}-V \delta(\Delta \rho)
$$

Pode-se notar na expressão acima que a convenção de sinais para o deslocamento virtual relativo é contrária à convenção adotada para a força cortante, ou seja, o deslocamento é positivo no sentido anti-horário.

Até o presente momento, não foi considerado o efeito devido às deformações por força normal. Isto pode ser feito adicionando à expressão (4.10), o termo relativo ao trabalho virtual realizado por esses mesmos esforços, que encontra-se explícito na expressão (4.11):

$$
\delta W_{i}=N \delta(\Delta L)+M_{B} \delta \theta_{B}+M_{A} \delta \theta_{A}-V \delta(\Delta \rho)
$$

Onde:

$$
\delta(\Delta L)=\delta u_{B}-\delta u_{A}
$$

Pode-se notar na expressão (4.12) que o alongamento é traduzido pelo sinal positivo.

\section{b) Estabelecimento da compatibilidade entre os deslocamentos e as variações de comprimento das barras}

Considerando um pórtico plano de n nós e $m$ barras, toma-se uma barra genérica (i), com nós $k$ e 1 nas extremidades. Serão impostos deslocamentos nodais virtuais $\delta u_{k}, \delta v_{k}, \delta u_{l}$, $\delta v_{1}$, conforme mostra a figura (4.3) e $\delta \theta_{k}$ e $\delta \theta_{1}$. Sendo assim, a expressão do trabalho virtual dos esforços internos para a estrutura é dada por:

$$
\delta W_{i}=\sum_{i=1}^{m}\left(N_{i} \delta\left(\Delta U_{i}\right)-V_{i} \delta\left(\Delta \rho_{i}\right)+M_{i}^{k} \delta \theta_{k}+M_{i}^{l} \delta \theta_{l}\right)
$$



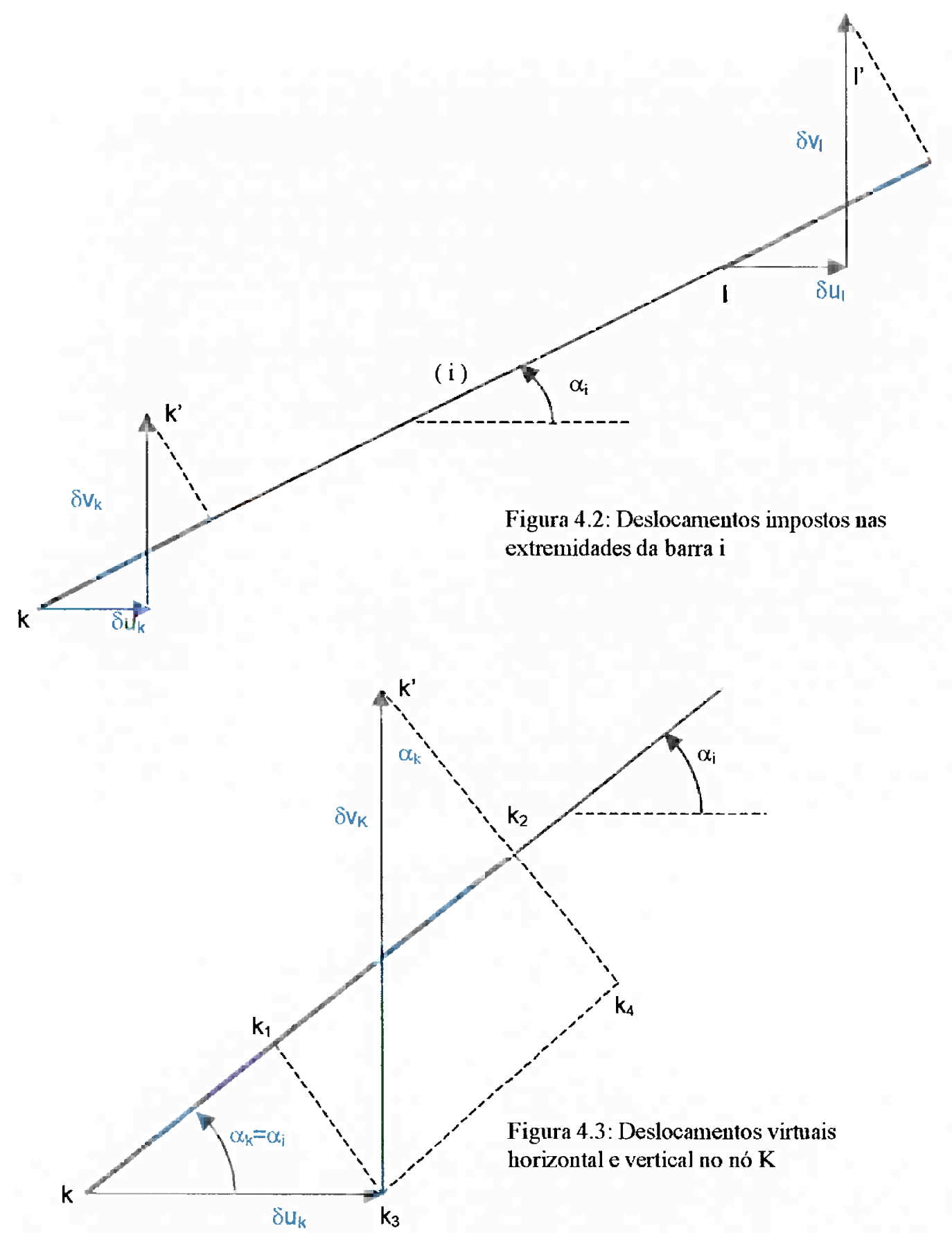

Pode-se concluir na direção do eixo da barra i:

$$
\begin{aligned}
& k k_{1}=\delta u_{k} \cos \alpha_{i} \\
& k_{1} k_{2}=\delta v_{k} \operatorname{sen} \alpha_{i} \\
& k k_{2}=k k_{1}+k_{1} k_{2}=\delta t_{k} \cos \alpha_{i}+\delta v_{k} \operatorname{sen} \alpha_{i}
\end{aligned}
$$


Na direção perpendicular ao eixo da barra i, conclui-se:

$$
\begin{aligned}
& k_{1} k_{3}=\delta u_{k} \operatorname{sen} \alpha_{i} \\
& k^{\prime} k_{4}=\delta v_{k} \cos \alpha_{i} \\
& k^{\prime} k_{2}=k^{\prime} k_{4}-k_{1} k_{3}=\delta v_{k} \cos \alpha_{i}-\delta u_{k} \operatorname{sen} \alpha_{i}
\end{aligned}
$$

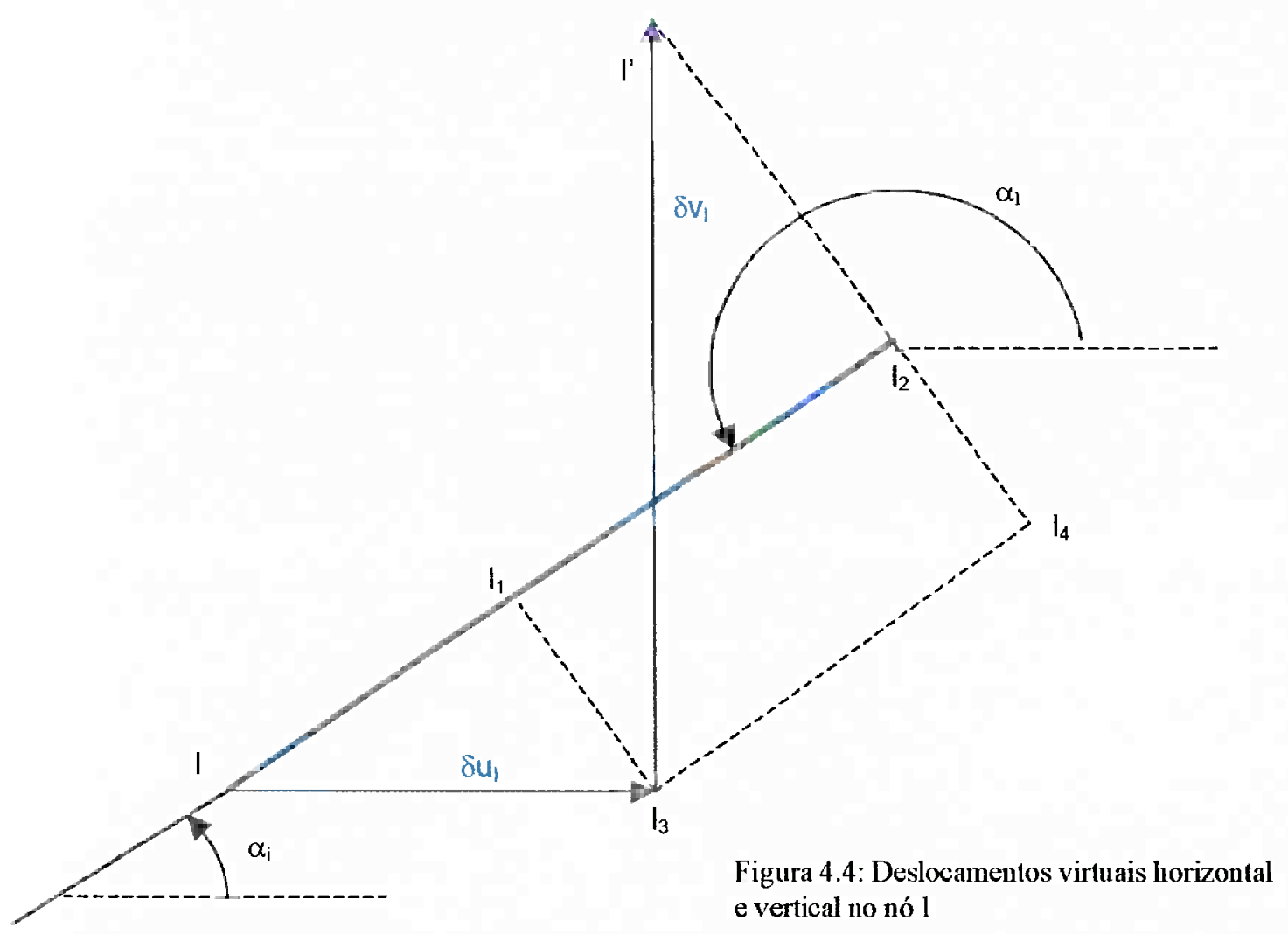

Pode-se concluir na direção do eixo da barra i:

$$
\begin{aligned}
& l_{1}=\delta u_{l} \cos \alpha_{i} \\
& l_{1} l_{2}=\delta v_{l} \operatorname{sen} \alpha_{i} \\
& l_{2}=l_{1}+l_{1} l_{2}=\delta u_{l} \cos \alpha_{i}+\delta v_{l} \operatorname{sen} \alpha_{i}
\end{aligned}
$$


Na direção perpendicular ao eixo da barra, conclui-se:

$$
\begin{aligned}
& l_{1} l_{3}=\delta u_{l} \operatorname{sen} \alpha_{i} \\
& l^{\prime} l_{4}=\delta v_{l} \cos \alpha_{i} \\
& l^{\prime} l_{2}=l^{\prime} l_{4}-l_{1} l_{3}=\delta v_{l} \cos \alpha_{i}-\delta u_{l} \operatorname{sen} \alpha_{i}
\end{aligned}
$$

A variação virtual do comprimento da barra i é dada por:

$$
\delta\left(\Delta_{i}\right)=l l_{2}-k k_{2}
$$

Pode-se perceber na expressão (4.26) que ao encurtamento é atribuído o sinal negativo. Substituindo as expressões (4.16) e (4.22) em (4.26) obtém-se as variações virtuais de comprimento em componentes dos deslocamentos virtuais aplicados:

$$
\delta\left(\Delta L_{i}\right)=\delta u_{l} \cos _{i}+\delta v_{l} \operatorname{sen} \alpha_{i}-\delta u_{k} \cos \alpha_{i}-\delta v_{k} \operatorname{sen} \alpha_{i}
$$

O deslocamento relativo entre as extremidades da barra (i) é dado por:

$$
\delta(\Delta \rho)=l^{\prime} l_{2}-k^{\prime} k_{2}
$$

Nota-se na expressão (4.28), que ao deslocamento relativo é atribuído o sinal positivo quando o mesmo ocorre em sentido anti-horário. Substituindo (4.19) e (4.25) em (4.28), obtém-se a expressão do deslocamento virtual relativo em função dos deslocamentos virtuais aplicados.

$$
\delta(\Delta \rho)=\delta v_{l} \cos \alpha_{i}-\delta u_{l} \operatorname{sen} \alpha_{i}-\left(\delta v_{k} \cos \alpha_{i}-\delta u_{k} \operatorname{sen} \alpha_{i}\right)
$$

A expressão do trabalho virtual dos esforços internos para o pórtico é obtida através da substituição de (4.27) e (4.29) em (4.13). Sabendo que $\alpha_{i}=\alpha_{k}$ e $\alpha_{1}=\alpha_{i}$ $+\pi$, tem-se: $\operatorname{sen} \alpha_{i}=-\operatorname{sen} \alpha_{1}, \cos \alpha_{i}=-\cos \alpha_{1}, \operatorname{sen} \alpha_{1}=-\operatorname{sen} \alpha_{k}$ e $\cos \alpha_{1}=-\cos \alpha_{k}$, então:

$\delta W_{i}=\sum_{i=1}^{m}\left(-N_{i} \delta u_{k} \cos \alpha_{k}-N_{i} \delta u_{l} \cos \alpha_{l}-N_{i} \delta v_{k} \operatorname{sen} \alpha_{k}-N_{i} \delta v_{l} \operatorname{sen} \alpha_{l}-V_{i} \delta u_{k} \operatorname{sen} \alpha_{k}-\right.$

$\left.V_{i} \delta u_{l} \operatorname{sen} \alpha_{l}+V_{i} \delta v_{k} \cos \alpha_{k}+V_{i} \delta v_{l} \cos \alpha_{l}+M_{i}^{k} \delta \theta_{k}+M_{i}^{l} \delta \theta_{l}\right)$

Assim como ilustrou-se no item 3.2, através da escrita da expressão (4.30) para cada uma das m barras do pórtico, verificando os deslocamentos cinematicamente admissíveis e reagrupando os termos restantes $e$ ainda colocando os 
deslocamentos virtuais em evidência, a expressão (4.30) pode ser escrita também para os $\mathrm{n}$ nós do pórtico.

$\delta W_{i}=\sum_{j=1}^{n}\left[\left(-\sum N_{p} \cos \alpha_{p}\right) \delta u_{j}+\left(-\sum N_{p} \operatorname{sen} \alpha_{p}\right) \delta v_{j}+\left(-\sum V_{p} \operatorname{sen} \alpha_{p}\right) \delta u_{j}+\left(\sum V_{p} \cos \alpha_{p}\right) \delta v_{j}+\right.$

$\left.\left(M_{p}\right) \delta \theta_{j}\right]$

Tem-se na Figura 4.5 a ilustração de um nó genérico j, no qual $N_{p}, V_{p}$ e $M_{p}$ são os esforços nas $p$ barras que convergem no nó $\mathrm{j}$ e $\mathrm{X}_{\mathrm{j}}, \mathrm{Y}_{\mathrm{j}}$ e $\mathrm{M}_{\mathrm{j}}$, as forças horizontal, vertical e o momento, respectivamente aplicado a esse mesmo nó.

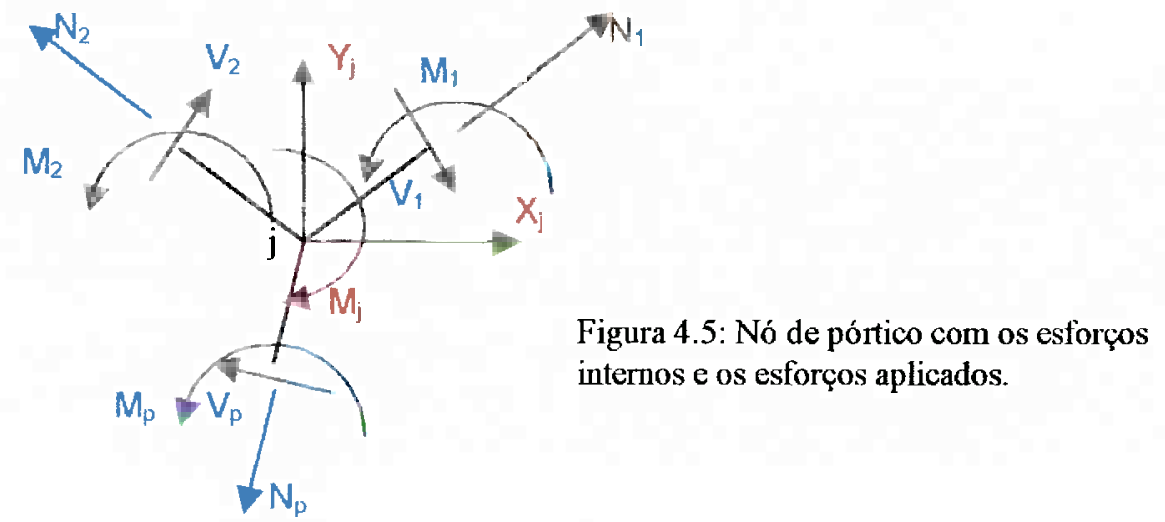

As equações de equilíbrio para o nó acima são as seguintes:

$\sum\left(N_{p} \cos \alpha_{p}+V_{p} \operatorname{sen} \alpha_{p}\right)+X_{j}=0$

$\sum\left(N_{p} \operatorname{sen} \alpha_{p}-V_{p} \cos \alpha_{p}\right)+Y_{j}=0$

$\sum\left(M_{p}\right)-M_{j}=0$

Substituindo as equações (4.32), (4.33) e (4.34) na expressão (4.31), obtém-se o trabalho virtual dos esforços externos:

$\delta W_{e}=\sum_{j=1}^{n}\left(X_{j} \delta u_{j}+Y_{j} \delta v_{j}+M_{j} \delta \theta_{j}\right)$

Estando os esforços nodais externos $\mathrm{X}_{\mathrm{j}}, \mathrm{Y}_{\mathrm{j}}$ e $\mathrm{M}_{\mathrm{j}}$ em equilíbrio com os esforços $\mathrm{N}_{\mathrm{i}}$, $V_{i}, M_{i}^{k}$ e $M_{i}^{l}$ e as grandezas virtuais $\delta\left(\Delta \mathrm{L}_{i}\right), \delta(\Delta \rho), \delta \theta_{k}$ e $\delta \theta_{1}$ compativeis com os 
os deslocamentos virtuais $\delta u_{\mathrm{j}}, \delta v_{\mathrm{j}}, \delta \theta_{\mathrm{j}}$, conclui-se o Teorema dos Deslocamentos Virtuais, dado por:

$\sum_{i=1}^{m}\left[N_{i} \delta\left(\Delta L_{i}\right)-V_{i} \delta\left(\Delta \rho_{i}\right)+M_{i}^{k} \delta \theta_{k}+M_{i}^{l} \delta \theta_{l}\right]=\sum_{j=1}^{n}\left[X_{j} \delta u_{j}+Y_{j} \delta v_{j}+M_{j} \delta \theta_{j}\right]$

Da mesma maneira que se concluiu no Capítulo 3, que a igualdade imediatamente acima implica equilibrio da estrutura, ou seja:

$$
\delta W_{e}=\delta W_{i}
$$

\subsection{O Teorema dos Esforços Virtuais Aplicado a um Pórtico Plano}

Analogamente ao item 3.3 , tendo sido estabelecidos a compatibilidade entre deformações e deslocamentos reais e o equilibrio entre os esforços virtuais, a igualdade expressa em (4.38) será verificada.

$\sum_{i=1}^{m}\left[\delta N_{i} \Delta L_{i}-\delta V_{i} \Delta \rho_{i}+\delta M_{i}^{k} \theta_{k}+\delta M_{i}^{l} \theta_{l}\right]=\sum_{j=1}^{n}\left(\delta X_{j} u_{j}+\delta Y_{j} v_{j}+\delta M_{j} \theta_{j}\right)$

ou seja:

$\delta W_{i}^{*}=\delta W_{e}^{*}$

\subsection{Aplicação do Processo Direto a um Sistema Estrutural com $\mathrm{g}=\mathrm{h}=1$}

Considere a viga apoiada engastada.

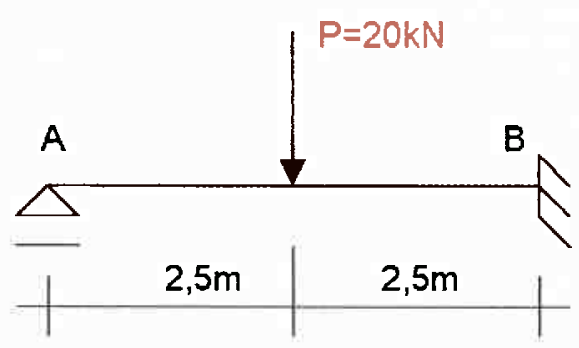

Figura 4.6: Viga apoiada engastada 
A estrutura é uma vez hiperestática e possui um grau de liberdade, conforme pode ser visto na Figura 4.7.

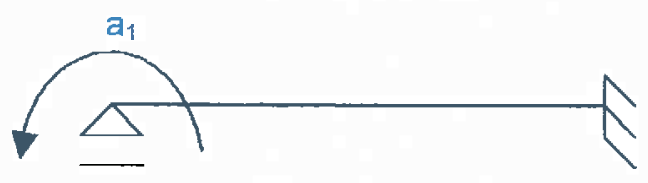

Figura 4.7: Grau de liberdade da viga apoiada - engastada

Os esforços internos estão representados na figura 4.8 .

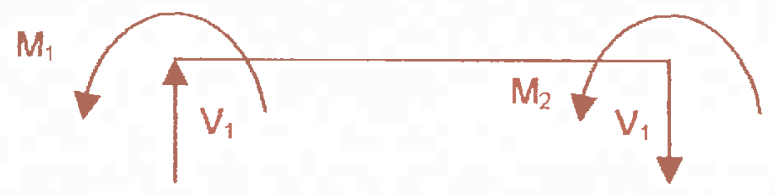

Figura 4.8: Esforços de extremidade da barra apoiada - engastada

A teoria foi desenvolvida para cargas aplicadas aos nós da estrutura. Então deve ser utilizado o Princípio da Superposição dos Efeitos, considerando o resultado final como a soma dos resultados dos dois casos da Figura 4.9.

CASO 1

CASO 2
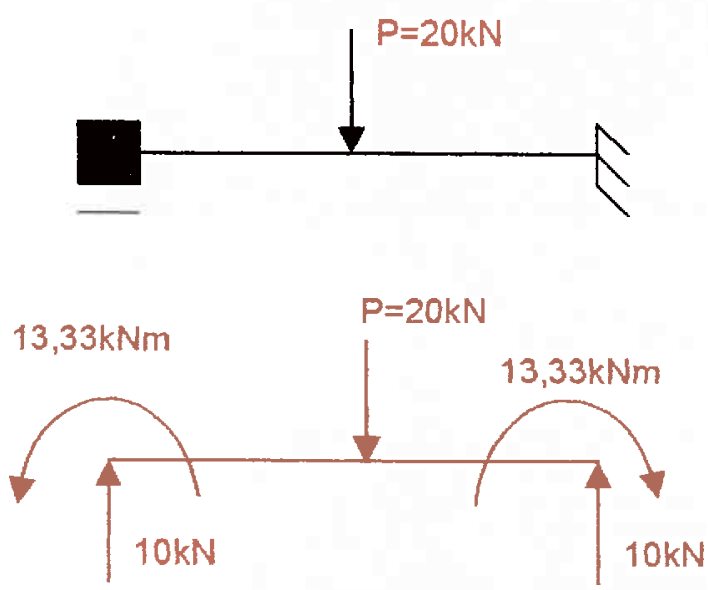

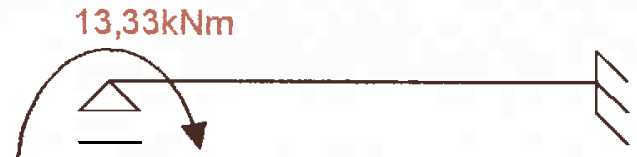

Figura 4.9: Superposição de efeitos para a resolução da viga apoiada - engastada

O caso 2 será resolvido pela teoria desenvolvida no presente capítulo.

Para a obtenção da equação de equilíbrio, deve-se aplicar o Teorema dos Deslocamentos Virtuais. Para tanto, impõe-se um deslocamento virtual segundo o grau de liberdade $a_{1}$, conforme ilustra a Figura 4.10.

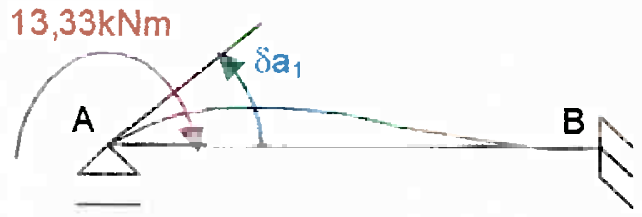

Figura 4.10: Deslocamento virtual imposto segundo o grau de liberdade $\mathrm{a}_{1}$ 
O trabalho virtual dos esforços internos é dado por:

$$
\begin{aligned}
& \delta W_{i}=M_{1} \delta a_{1} \\
& \delta W_{e}=-13,33 \delta a_{1}
\end{aligned}
$$

Fazendo:

$$
\delta W_{i}=\delta W_{e}
$$

Obtém-se:

$M_{1}=-13,33 k N m$

O próximo passo é a obtenção de uma equação de compatibilidade utilizando o Teorema dos Esforços Virtuais. Para tanto, escolhe-se uma estrutura isostática fundamental, conforme mostra a Figura 4.11.

A seguir, aplica-se o esforço relativo ao vínculo subtraído na obtenção da estrutura isostática fundamental.

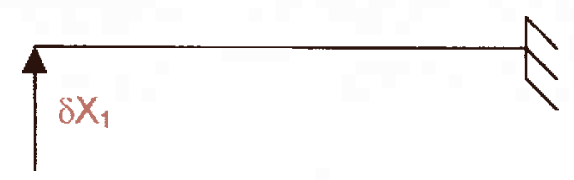

Figura 4.12: Esforço virtual aplicado sobre a estrutura isostática fundamental

Com isso, obtém-se o diagrama do momento fletor da estrutura da Figura 4.13.

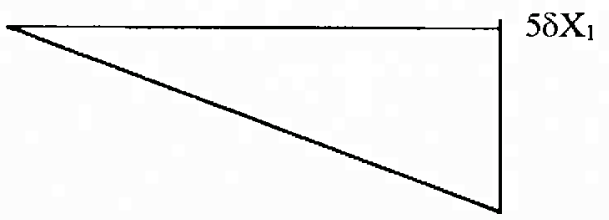

Figura 4.13: Diagrama de momento fletor decorrente da ação de $\delta X_{I}$

O diagrama de curvaturas reais da barra é obtido de acordo com os esforços mostrados na Figura 4.14.

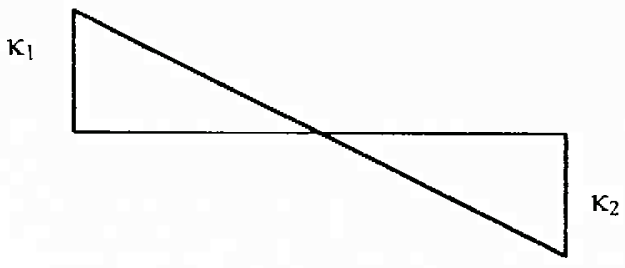

Figura 4.14: Diagrama de curvaturas reais da viga apoiada - engastada 
O trabalho virtual complementar dos esforços internos é dado por:

$\delta W_{i}^{*}=\int_{0}^{L} \delta M \kappa d x$

Integrando os diagramas das Figuras 4.13 e 4.14, obtém-se:

$\delta \mathrm{W}_{\mathrm{i}}^{*}=\frac{5}{6}\left(-\kappa_{1}+2 \kappa_{2}\right) 5 \delta \mathrm{X}_{1}$

Como não há deslocamentos impostos na estrutura, então:

$\delta W_{e}^{*}=0$

Fazendo:

$\delta \mathrm{W}_{\mathrm{i}}^{*}=\delta \mathrm{W}_{\mathrm{e}}^{*}$

Obtém-se:

$-\kappa_{1}+2 \kappa_{2}=0$

Substituindo a equação constitutiva $\mathrm{M}_{\mathrm{i}}=\mathrm{EI}_{\mathrm{i}}$ na equação de compatibilidade, (4.48), tem-se:

$-\mathrm{M}_{1}+2 \mathrm{M}_{2}=0$

Substituindo (4.43) em (4.49), obtém-se:

$\mathrm{M}_{2}=6,67 \mathrm{kNm}$

Sendo assim, tem-se os resultados dos casos 1 e 2 :

CASO 1

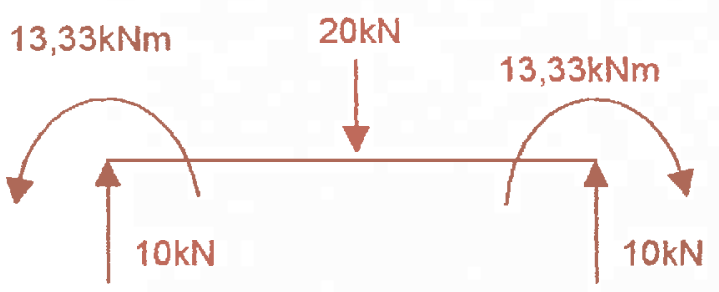

CASO 2

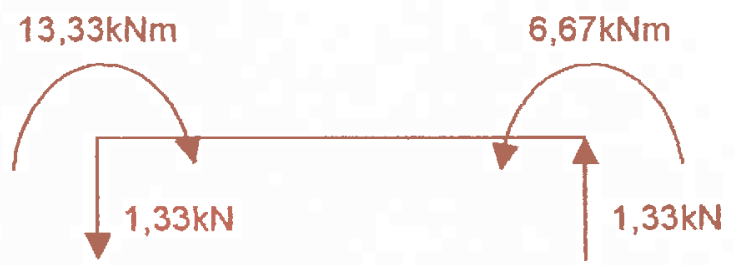

Figura 4.15: Resultados dos casos 1 e 2 da viga apoiada - engastada 


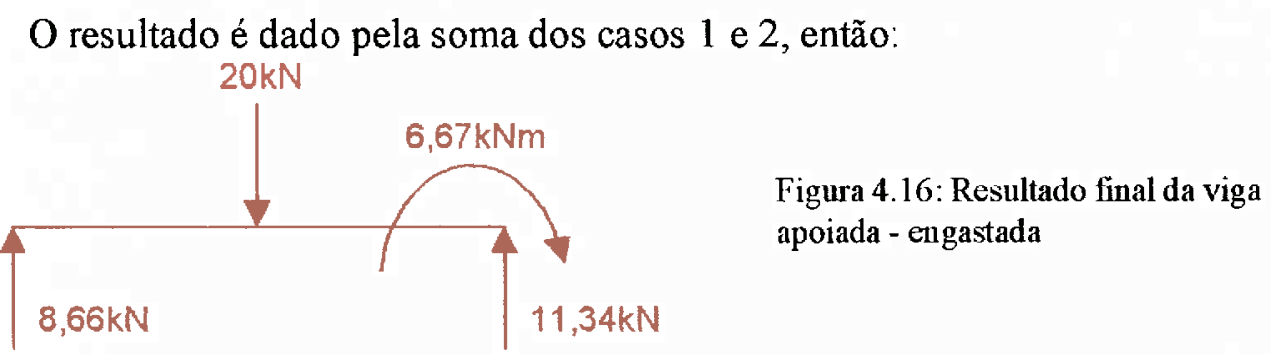

\subsection{Aplicação do Processo Direto a um Pórtico Plano Hiperestático}

Considere o pórtico abaixo, onde: $\mathrm{L}_{1}=4 \mathrm{~m}$ e $\mathrm{L}_{2}=5 \mathrm{~m}$ e $E I=10^{3} \mathrm{kNm}^{2}$

$8 \mathrm{KNm}$
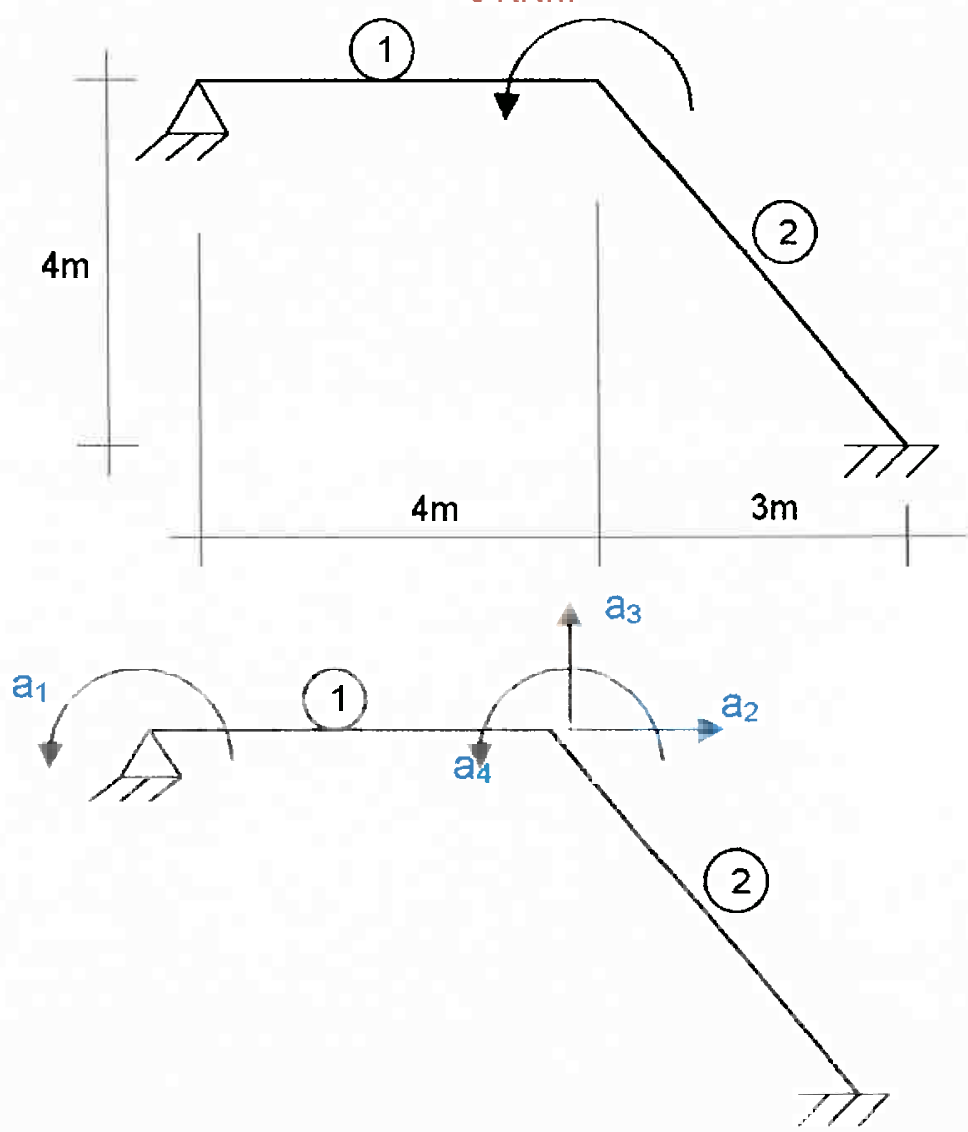

Figura 4.17: Pórtico plano hiperestático

Figura 4.18: Graus de liberdade do pórtico plano hiperestático

Deve-se aplicar o Teorema dos Deslocamentos Virtuais tantas vezes quantos forem os graus de liberdade. Vale lembrar que as equações de equilibrio podem ser obtidas através do equilíbrio dos nós do pórtico.

Inicialmente, os esforços solicitantes nas barras do pórtico são representados na Figura 4.19. 


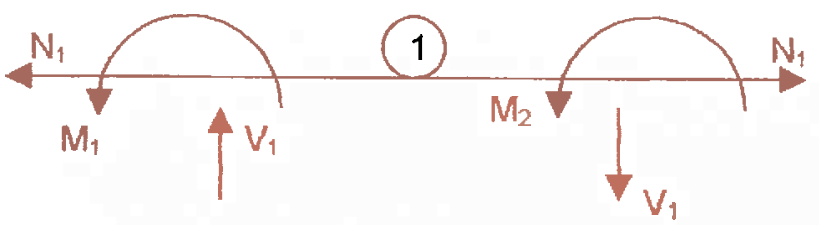

Figura 4.19: Convenção de sinais dos esforços solicitantes nas barras do pórtico

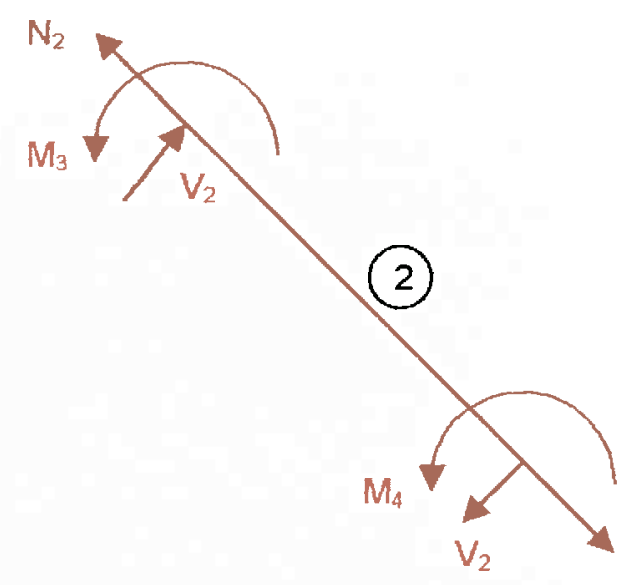

$\mathrm{N}_{2}$

PASSO 1: Obtenção das equações de equilibrio a partir da aplicação do Teorema dos Deslocamentos Virtuais. Admite-se que os esforços reais possuem o sentido indicado na Figura 4.19.

Impondo a rotação virtual correspondente ao grau de liberdade $\mathrm{a}_{1}$ :

Figura 4.20: Rotação virtual imposta segundo o grau de liberdade $\mathbf{a}_{1}$

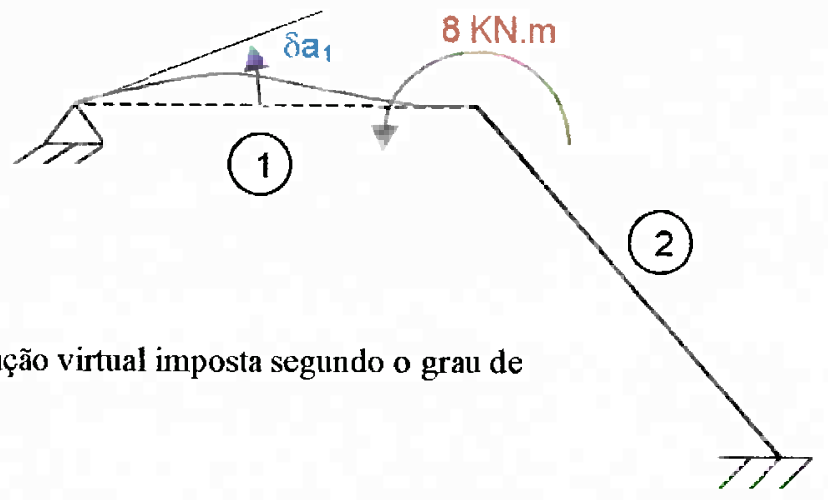

A expressão do trabalho virtual dos esforços internos é dada por:

$\delta W_{i}=\delta W_{i 1}+\delta W_{i 2}$

onde, $\delta W_{i 1}$ é o trabalho virtual dos esforços internos da barra 1 e $\delta W_{i 2}$ é o trabalho virtual dos mesmos na barra 2 .

Reescrevendo os termos de (4.51), tem-se:

$\delta W_{i 1}=N_{1} \delta\left(\Delta L_{1}\right)-V_{1} \delta\left(\Delta \rho_{1}\right)+M_{1} \delta \theta_{1}+M_{2} \delta \theta_{2}$

$\delta W_{i 2}=0$

Como $\delta\left(\Delta L_{1}\right)=\delta\left(\Delta \rho_{1}\right)=\delta \theta_{2}=0$, então a equação (4.52) adquire a seguinte forma:

$\delta W_{i}=M_{1} \delta \theta_{1}$ 
A igualdade expressa em (4.54) é decorrente de não haver deslocamento virtual na barra 2 em virtude da imposição da rotação virtual em $a_{1}$.

Como não há nenhum esforço externo real correspondente à rotação virtual imposta, o trabalho virtual dos esforços externos é dado por:

$\delta W_{e}=0$

Aplicando o Teorema dos Deslocamentos Virtuais (TDV):

$\delta W_{e}=\delta W_{i}$

Obtém-se:

$M_{1}=0$

Impondo o deslocamento virtual correspondente ao grau de liberdade $\mathrm{a}_{2}$ :

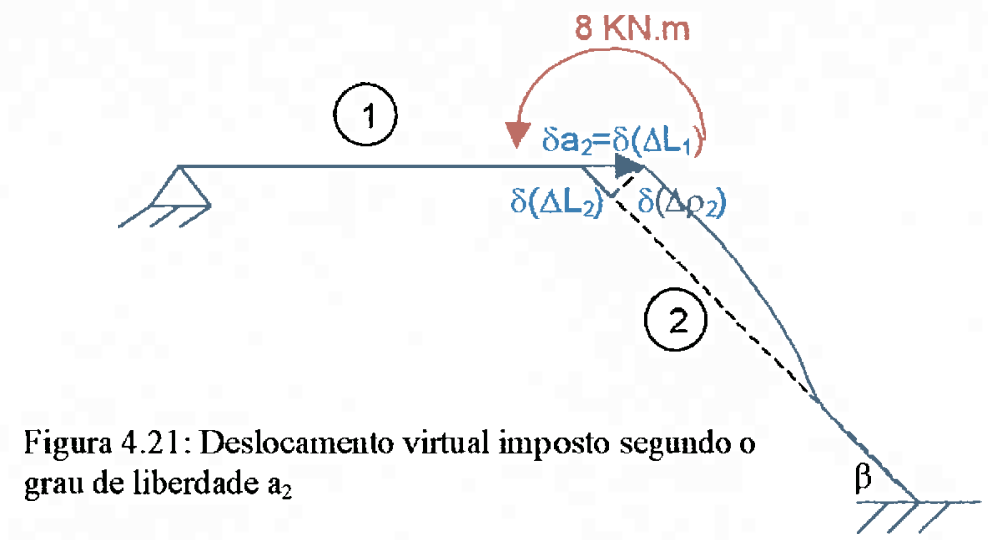

Sendo $\beta$ o ângulo mostrado na Figura 4.21, sabe-se que:

$\operatorname{sen} \beta=\frac{4}{5} \quad$ e $\quad \cos \beta=\frac{3}{5}$

São obtidas as seguintes relações:

$$
\begin{aligned}
& \delta\left(\Delta \rho_{2}\right)=-\frac{4}{5} \delta a_{2} \\
& \delta\left(\Delta L_{2}\right)=-\frac{3}{5} \delta a_{2}
\end{aligned}
$$


$\delta\left(\Delta_{1}\right)=\delta a_{2}$

Novamente, a expressão do trabalho virtual dos esforços internos é dada por:

$\delta W_{i}=\delta W_{i 1}+\delta W_{i 2}$

Para as barras, tem-se:

$\delta W_{i 1}=N_{1} \delta\left(\Delta_{1}\right)-V_{1} \delta\left(\Delta \rho_{1}\right)+M_{1} \delta \theta_{1}+M_{2} \delta \theta_{2}$

$\delta W_{i 2}=N_{2} \delta\left(\Delta L_{2}\right)-V_{2} \delta\left(\Delta \rho_{2}\right)+M_{3} \delta \theta_{3}+M_{4} \delta \theta_{4}$

Como $\delta\left(\Delta \rho_{1}\right)=\delta \theta_{1}=\delta \theta_{2}=\delta \theta_{3}=\delta \theta_{4}=0$ e substituindo (4.62) e (4.63) em (4.61), tem-se:

$\delta W_{i}=N_{1} \delta\left(\Delta_{1}\right)+N_{2} \delta\left(\Delta L_{2}\right)-V_{2} \delta\left(\Delta \rho_{2}\right)$

Novamente, não há esforços externos reais correspondentes aos deslocamentos virtuais, então:

$\delta W_{e}=0$

Aplicando o Teorema:

$\delta W_{e}=\delta W_{i}$

Substituindo (4.64) e (4.65) em (4.66), chega-se a:

$5 N_{1}-3 N_{2}+4 V_{2}=0$

como $V_{2}=\frac{M_{3}+M_{4}}{5}$, então a equação (4.67) se transforma em:

$25 N_{1}-15 N_{2}+4 M_{3}+4 M_{4}=0$ 
Impondo o deslocamento virtual correspondente ao grau de liberdade $\mathrm{a}_{3}$ :

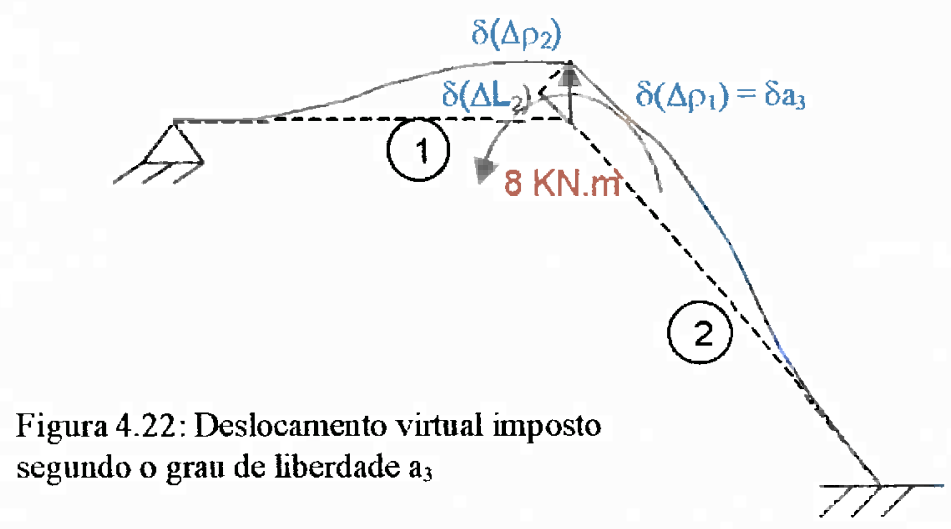

Sendo assim, obtém-se as seguintes relações:

$$
\begin{aligned}
& \delta\left(\Delta \rho_{2}\right)=-\frac{3}{5} \delta a_{3} \\
& \delta\left(\Delta \rho_{1}\right)=\delta a_{3} \\
& \delta\left(\Delta L_{2}\right)=\frac{4}{5} \delta a_{3}
\end{aligned}
$$

A expressão do trabalho virtual dos esforços internos é dada por:

$$
\delta W_{i}=\delta W_{i 1}+\delta W_{12}
$$

Onde:

$$
\begin{aligned}
& \delta W_{i 1}=N_{1} \delta\left(\Delta L_{1}\right)-V_{1} \delta\left(\Delta \rho_{1}\right)+M_{1} \delta \theta_{1}+M_{2} \delta \theta_{2} \\
& \delta W_{i 2}=N_{2} \delta\left(\Delta L_{2}\right)-V_{2} \delta\left(\Delta \rho_{2}\right)+M_{3} \delta \theta_{3}+M_{4} \delta \theta_{4}
\end{aligned}
$$

Como $\delta\left(\Delta L_{1}\right)=\delta \theta_{1}=\delta \theta_{2}=\delta \theta_{3}=\delta \theta_{4}=0$, então a expressão (4.72), transformase em:

$$
\delta W_{i}=N_{2} \delta\left(\Delta L_{2}\right)-V_{1} \delta\left(\Delta \rho_{1}\right)-V_{2} \delta\left(\Delta \rho_{2}\right)
$$

Como não há esforço externo real correspondente ao deslocamento virtual imposto, então:

$$
\delta W_{e}=0
$$


Fazendo;

$\delta W_{e}=\delta W_{i}$

Substituindo (4.64) e (4.65) em (4.66), obtém-se:

$4 N_{2}-5 V_{1}+3 V_{2}=0$

Sabendo que:

$V_{1}=\frac{M_{1}+M_{2}}{4}$ e $V_{2}=\frac{M_{3}+M_{4}}{5}$, então a expressão (4.78) transforma-se em:

$80 N_{2}-25 M_{1}-25 M_{2}+12 M_{3}+12 M_{4}=0$

Impondo a rotação virtual correspondente ao grau de liberdade $a_{4}$ :

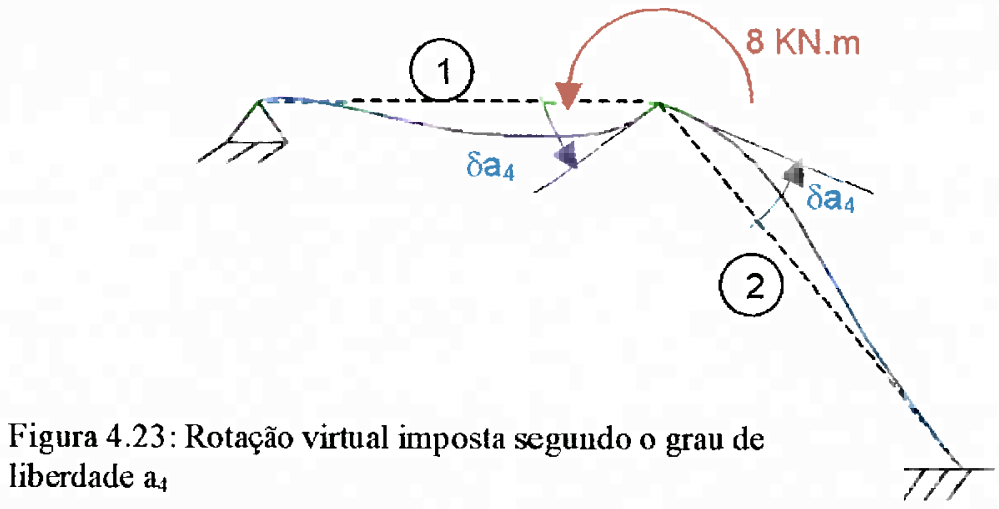

A expressão do trabalho virtual dos esforços internos é dada por:

$\delta W_{i}=\delta W_{i 1}+\delta W_{i 2}$

Onde:

$\delta W_{i 1}=N_{1} \delta\left(\Delta L_{1}\right)-V_{1} \delta\left(\Delta \rho_{1}\right)+M_{1} \delta \theta_{1}+M_{2} \delta \theta_{2}$

$\delta W_{i 2}=N_{2} \delta\left(\Delta L_{2}\right)-V_{2} \delta\left(\Delta \rho_{2}\right)+M_{3} \delta \theta_{3}+M_{4} \delta \theta_{4}$ 
Como $\delta\left(\Delta L_{1}\right)=\delta\left(\Delta l_{2}\right)=\delta\left(\Delta \rho_{1}\right)=\delta\left(\Delta \rho_{2}\right)=\delta \theta_{1}=\delta \theta_{4}=0$, a expressão (4.80), transforma-se em:

$$
\delta W_{i}=M_{2} \delta \theta_{2}+M_{3} \delta \theta_{3}
$$

Neste caso, há esforço externo real correspondente à rotação virtual imposta, então o trabalho virtual dos esforços internos é dado por:

$\delta W_{e}=8 \delta a_{4}$

O sinal positivo deve-se ao fato de possuírem o mesmo sentido, o esforço externo existente e a rotação virtual imposta. Aplicando o TDV:

$\delta W_{e}=\delta W_{i}$

Como $\delta\left(\Delta L_{1}\right)=\delta\left(\Delta L_{2}\right)=\delta\left(\Delta \rho_{1}\right)=\delta\left(\Delta \rho_{2}\right)=\delta \theta_{1}=\delta \theta_{4}=0, M_{1}=0$ e ainda $\delta \theta_{2}=\delta \theta_{3}=\delta a_{4}$, a equação (4.85) toma a seguinte forma após a substituição pelas equações (4.83) e (4.84).

$$
M_{2}+M_{3}=8
$$

PASSO 2: É necessário obter as equações de compatibilidade, o que será feito a partir da aplicação do Teorema dos Esforços Virtuais (TEV) tantas vezes quantas forem as incógnitas da estrutura. Nessas equações de compatibilidade são inseridas as equações constitutivas.

A seguir, encontra-se a estrutura isostática fundamental do pórtico em questão. São subtraídos os vínculos que caracterizam a hiperestaticidade da estrutura e são inseridas as reações vinculares correspondentes. Como o apoio engastado se transformou em apoio articulado móvel, serão aplicados os esforços virtuais, $\delta X_{1}$ e $\delta X_{2}$, decorrentes dessa transformação.

Figura 4.24: Aplicação do esforço virtual $\delta X_{1}$ na estrutura isostática fundamental

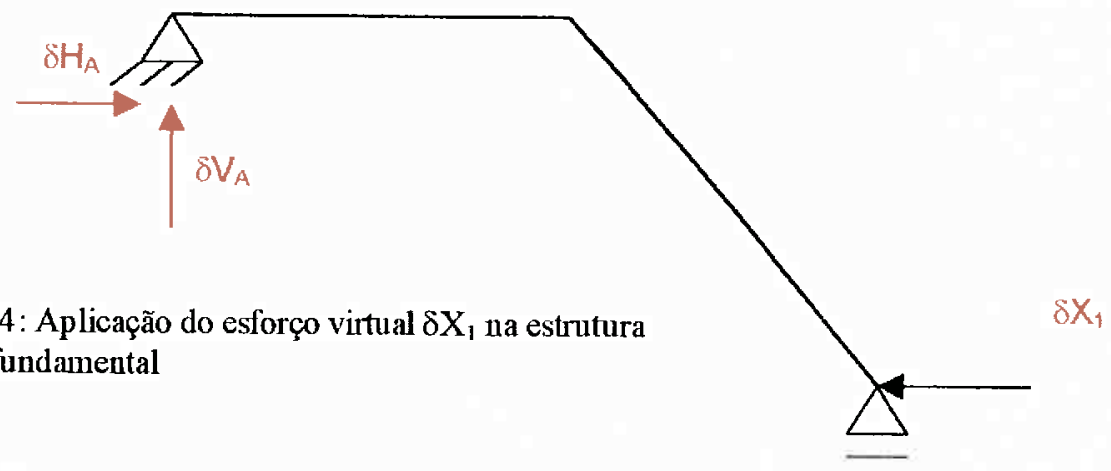


Através das equações da estática, obtém-se:

$\delta H_{A}=\delta X_{1}$

$\delta V_{A}=-\frac{4}{7} \delta X_{1}$

$\delta V_{B}=\frac{4}{7} \delta X_{1}$

Com isso, são traçados os diagramas de esforços solicitantes.

\section{Diagrama de Esforço Normal}

Figura 4.25: Diagrama de esforço normal da estrutura isostática fundamental devido à ação de $\delta \mathrm{X}_{1}$

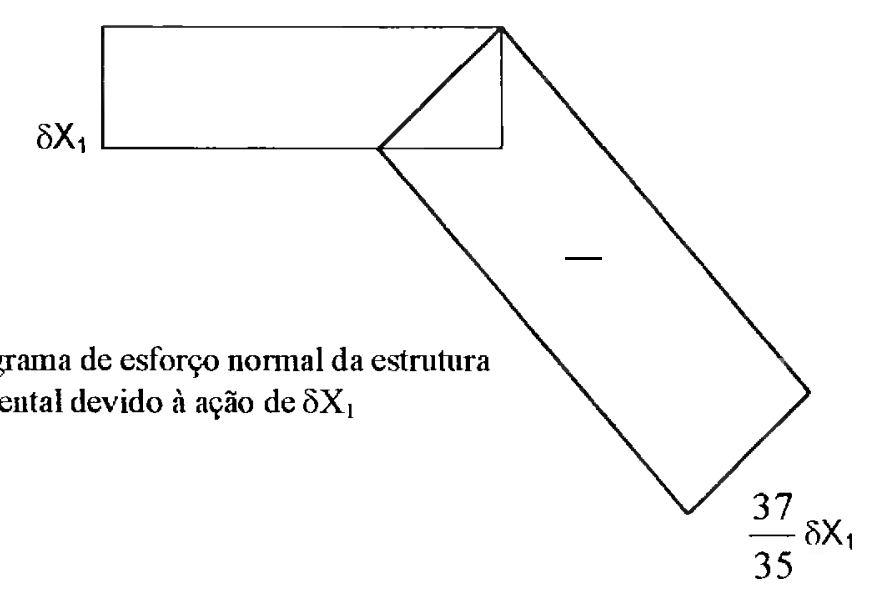

\section{Diagrama de Momento Fletor}

Figura 4.26: Diagrama de momento fletor da estrutura isostática fundamental devido à ação de $\delta \mathrm{X}_{1}$

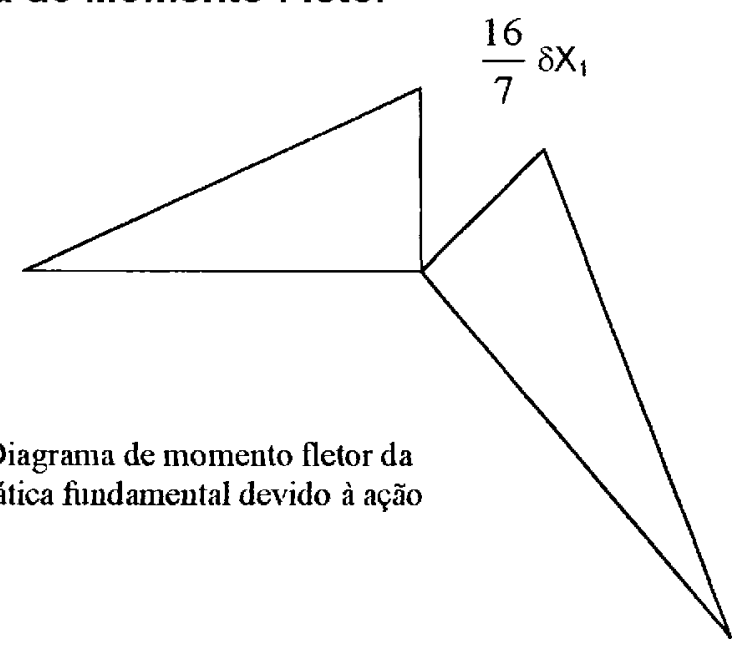


Abaixo encontra-se o diagrama de curvaturas reais do pórtico. Deve-se atentar ao fato de o diagrama estar desenhado do lado em que as fibras estão tracionadas, seguindo os sentidos dos esforços reais, conforme a Figura 4.19.

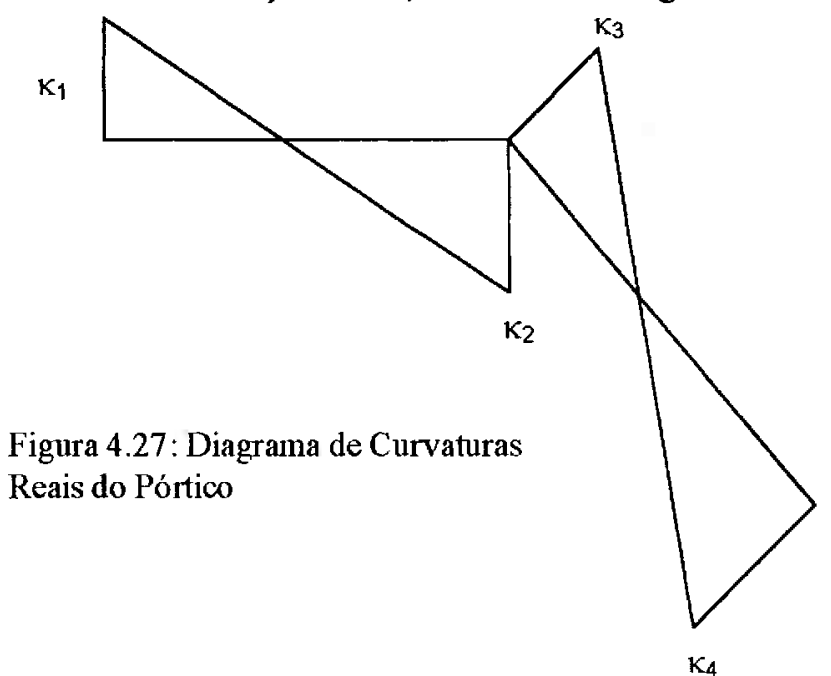

O trabalho virtual complementar dos esforços internos é dado pela expressão (4.90):

$$
\delta W_{i}^{*}=\sum \int \delta M \kappa d x+\sum \delta N \varepsilon L
$$

Integrando os diagramas dos esforços virtuais com o das curvaturas reais, chegase $\mathrm{a}$ :

$\delta W_{i}^{*}=\frac{4}{6}\left[\frac{16}{7}\left(-2 \kappa_{2}+\kappa_{1}\right)\right]-4 \varepsilon_{1}-\frac{37}{7} \varepsilon_{2}+\frac{5}{6}\left[\frac{16}{7}\left(2 \kappa_{3}-\kappa_{4}\right)\right]$

Como não há deslocamento real correspondente ao esforço virtual extemo aplicado, $\delta \mathrm{X}_{1}$, o trabalho virtual complementar dos esforços externos é nulo, então:

$\delta W_{e}^{*}=0$

Aplicando o Teorema dos Esforços Virtuais:

$\delta W_{i}^{*}=\delta W_{e}^{*}$

Obtém-se:

$-\frac{64}{21} \kappa_{2}+\frac{80}{21} \kappa_{3}-\frac{40}{21} \kappa_{4}-4 \varepsilon_{1}-\frac{37}{7} \varepsilon_{2}=0$ 
Abaixo, encontram-se as equações de compatibilidade:

$$
\begin{aligned}
& N_{i}=(E A)_{i} \varepsilon_{i} \\
& M_{i}=(E I)_{i} \kappa_{i}
\end{aligned}
$$

Substituindo as equações constitutivas (4.95) e (4.96) em (4.94), obtém-se a primeira equação de compatibilidade escrita em função dos esforços solicitantes:

$-64 M_{2}+80 M_{3}-40 M_{4}-84 N_{1}-111 N_{2}=0$

Segue-se a aplicação do segundo esforço virtual.

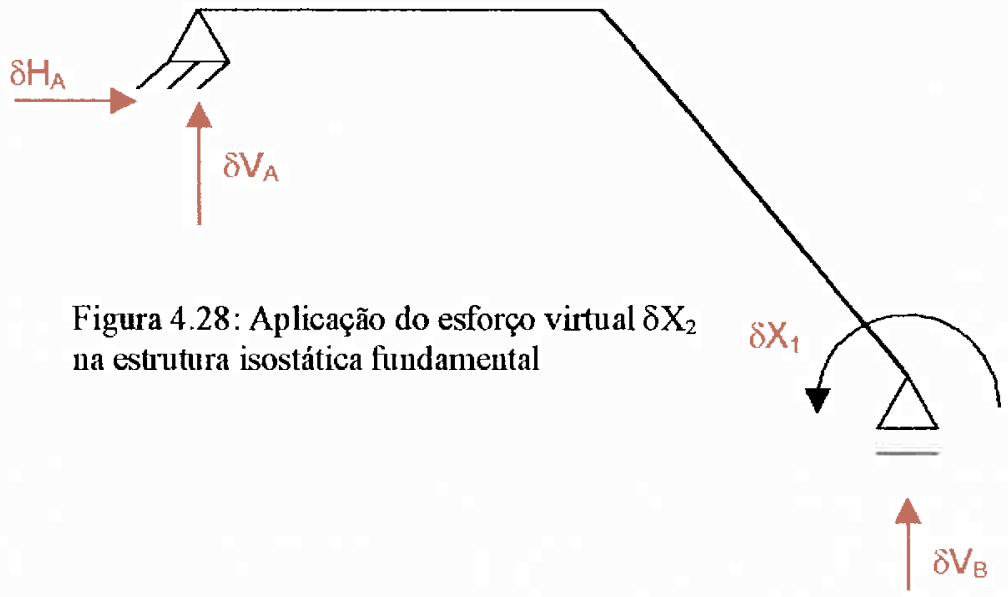

Através das equações da estática, obtém-se:

$\delta H_{A}=0$

$\delta V_{A}=\frac{\delta X_{2}}{7}$

$\delta V_{B}=-\frac{\delta X_{2}}{7}$

Com isso, são traçados os diagramas de esforços solicitantes. 


\section{Diagrama de Esforço Normal}

Figura 4.29: Diagrama de esforço normal da estrutura isostática fundamental devido à ação de $\delta X_{2}$

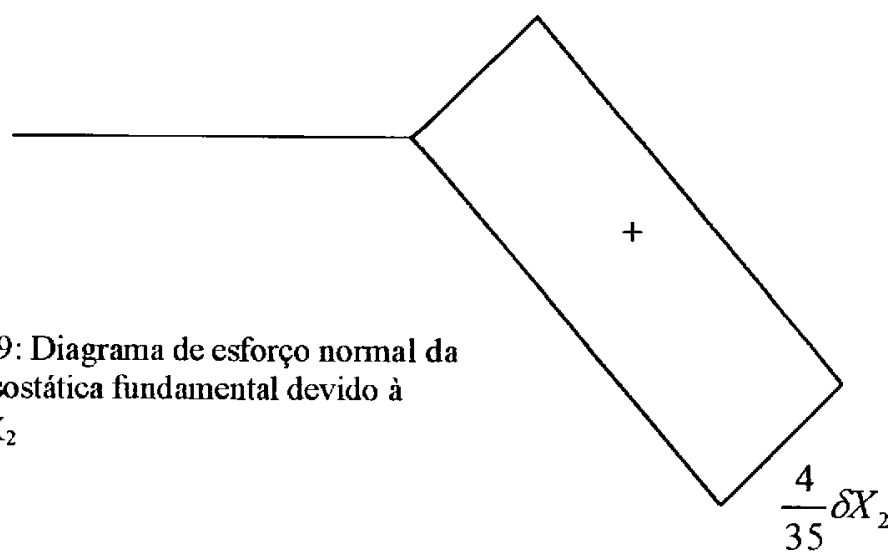

\section{Diagrama de Momento Fletor}

Figura 4.30: Diagrama de momento fletor da estrutura isostática fundamental devido à ação de $\delta \mathrm{X}_{2}$

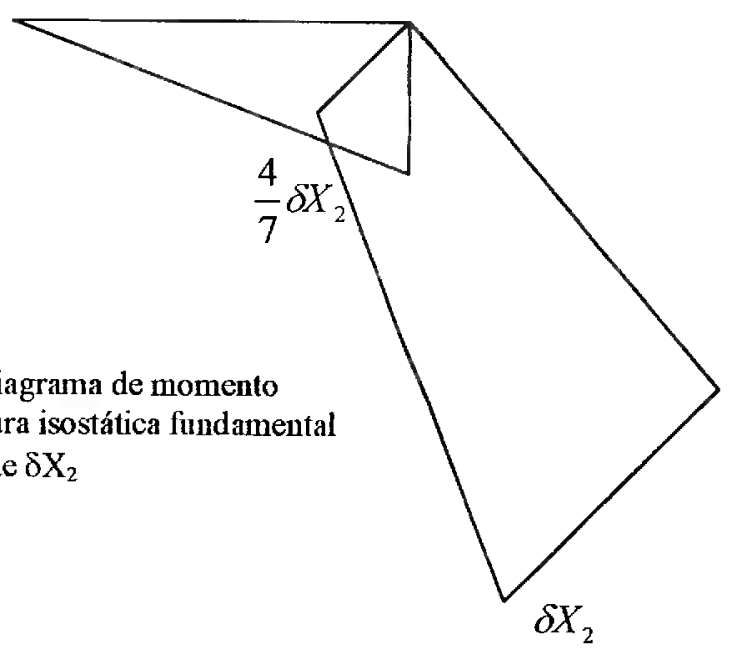

Novamente, integrando os diagramas dos esforços solicitantes (virtuais) e o diagrama de curvaturas reais do pórtico, obtém-se o trabalho virtual complementar dos esforços internos.

$$
\delta W_{i}^{*}=\frac{4}{6}\left[\frac{4}{7}\left(2 \kappa_{2}-\kappa_{1}\right)\right]+\frac{5}{6}\left[\frac{4}{7}\left(-2 \kappa_{3}+\kappa_{4}\right)+\left(2 \kappa_{4}-\kappa_{3}\right)\right]+\frac{4}{7} \varepsilon_{2}
$$

Como não há deslocamento real correspondente ao esforço virtual externo aplicado, $\delta \mathrm{X}_{2}$, então:

$$
\delta W_{e}^{*}=0
$$


Pelo Teorema dos Esforços Virtuais:

$\delta W_{e}^{*}=\delta W_{i}^{*}=0$

O que resulta na equação de compatibilidade abaixo:

$\frac{16}{21} \kappa_{2}-\frac{41}{21} \kappa_{3}+\frac{52}{21} \kappa_{4}+\frac{4}{7} \varepsilon_{2}=0$

Substituindo as equações constitutivas na expressão (4.104), obtém-se:

$16 M_{2}-41 M_{3}+52 M_{4}+12 N_{2}=0$

As equações (4.57), (4.68), (4.79), (4.86), (4.97) e (4.105) formam o sistema linear indicado a seguir:

$\left[\begin{array}{cccccc}0 & 0 & 1 & 0 & 0 & 0 \\ 25 & -15 & 0 & 0 & 4 & 4 \\ 0 & 80 & 0 & -25 & 12 & 12 \\ 0 & 0 & 0 & 1 & 1 & 0 \\ -84 & -111 & 0 & -64 & 80 & -40 \\ 0 & 12 & 0 & 16 & -41 & 52\end{array}\right]\left\{\begin{array}{l}N_{1} \\ N_{2} \\ M_{1} \\ M_{2} \\ M_{3} \\ M_{4}\end{array}\right\}=\left\{\begin{array}{l}0 \\ 0 \\ 0 \\ 8 \\ 0 \\ 0\end{array}\right\}$

A solução do sistema é dada por:

$N_{1}=-0,68 k N$

$N_{2}=0,398 k N$

$M_{1}=0$

$M_{2}=4,037 \mathrm{kNm}$

$M_{3}=3,963 \mathrm{kNm}$

$M_{4}=1,79 k N m$ 
DIAGRAMAS DE ESFORÇOS SOLICITANTES - PÓRTICO
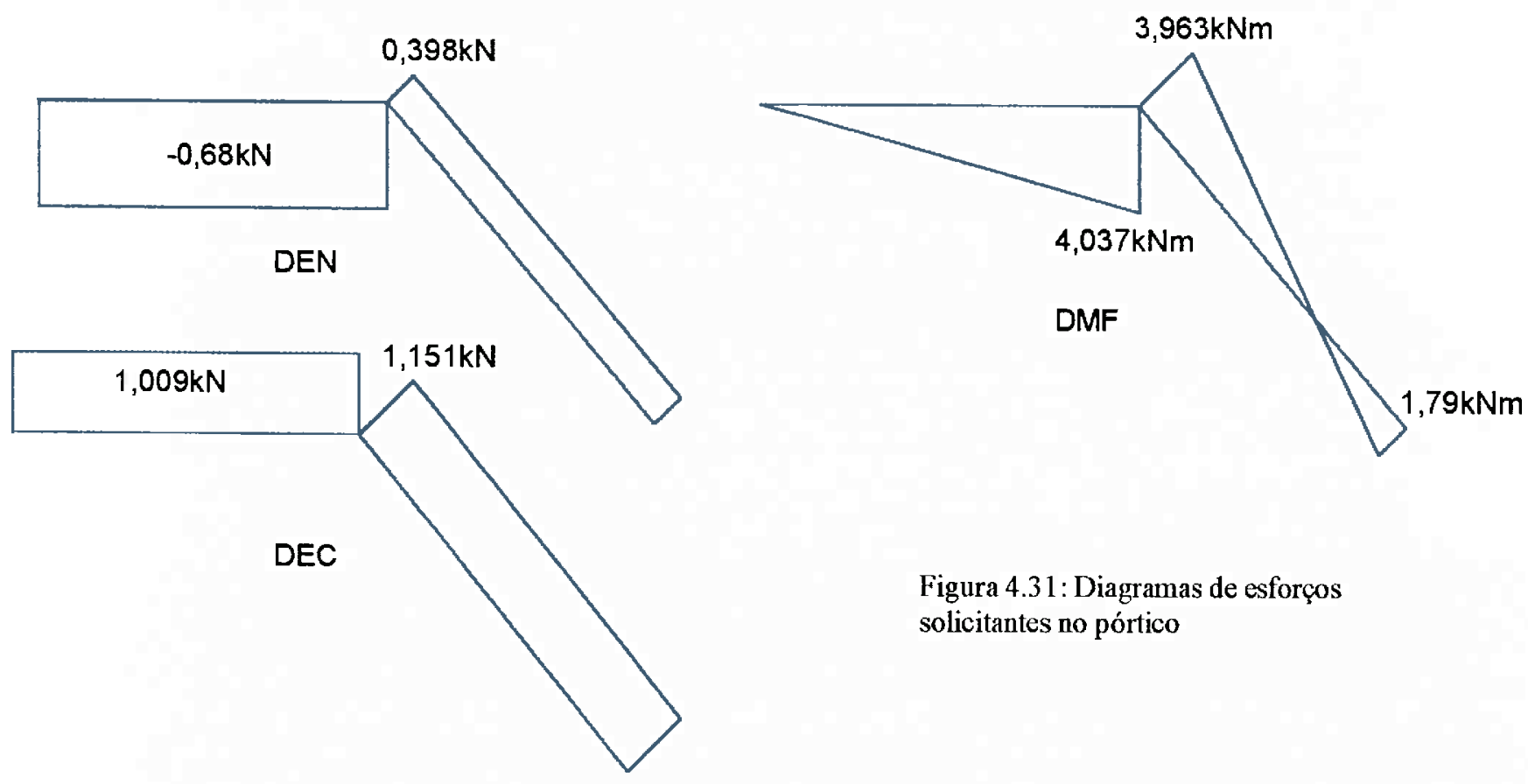

Figura 4.31: Diagramas de esforços solicitantes no pórtico 


\section{Capítulo 5}

\section{Introdução aos Processos dos Esforços e dos Deslocamentos}

\subsection{Preâmbulo}

Neste capítulo, utilizando a treliça analisada no Capítulo 3 e o pórtico analisado no Capítulo 4, serão introduzidos os processos dos Esforços e dos Deslocamentos a partir das equações obtidas pelo Processo Direto. Isto equivale a afirmar que a formulação deste último não é irredutivel, como ocorre nos dois primeiros.

As equações de equilíbrio e de compatibilidade serão tomadas diretamente dos Capítulos 3 e 4 com as devidas adaptações. Será necessário considerar um conjunto de equações ainda não mencionado neste trabalho: são as equações de compatibilidade entre deformações e deslocamentos. Como o próprio nome menciona, essas equações relacionam as deformações em cada barra com os deslocamentos dos nós da estrutura.

Os deslocamentos de principal interesse são, na maioria das vezes, as translações e as rotações nos nós. Sendo assim, torna-se mais prático considerar cada barra individualmente, ou seja, isolada do resto da estrutura e calcular os esforços de extremidade, que são representados pelas forças e momentos atuantes nas extremidades de cada barra, conforme foi desenvolvido nos capítulos anteriores.

\subsection{O Processo dos Deslocamentos}

No Processo dos Deslocamentos aplicado a estruturas reticuladas, as incógnitas são os deslocamentos dos nós da estrutura, então o número de equações a serem consideradas é igual ao número de graus de liberdade da estrutura. Este processo envolve o uso extensivo de ações e deslocamentos em barras com extremidades engastadas, isto é, deve-se obter uma estrutura cinematicamente determinada, alterando-se a estrutura real de tal modo que os deslocamentos desconhecidos sejam nulos. A estrutura obtida fixando todos os nós da estrutura real é denominada estrutura bloqueada. 


\subsection{Introdução ao Processo dos Deslocamentos}

Neste item, torna-se necessária a consideração do novo conjunto de equações mencionado no item 5.1.

A introdução ao Processo dos Deslocamentos se dá através da inserção das equações de compatibilidade entre deformações e deslocamentos nas equações constitutivas e estas, por sua vez, nas equações de equilíbrio, obtendo-se um sistema linear de ordem hxh, onde h é o número de graus de liberdade da estrutura, assim definido no item 2.2.1. Este sistema linear tem como incógnitas os deslocamentos nodais da estrutura segundo os respectivos graus de liberdade, ou seja, no Processo dos Deslocamentos são obtidos os deslocamentos nodais da estrutura. Para obtermos os esforços, é necessário substituir os deslocamentos nas equações constitutivas nas quais foram já introduzidas as equações de compatibilidade entre deformações e deslocamentos. O que foi exposto neste ponto, pode ser visualizado melhor no item que segue.

\subsubsection{O Processo dos Deslocamentos - Treliça}

Considere a treliça do Capítulo 3 , onde $\mathrm{L}_{1}=\mathrm{L}_{2}=\mathrm{L}_{4}=\mathrm{L}_{5}=5 \mathrm{~m}, \mathrm{~L}_{3}=6 \mathrm{~m}$ e $E A=10^{3} \mathrm{kN}$

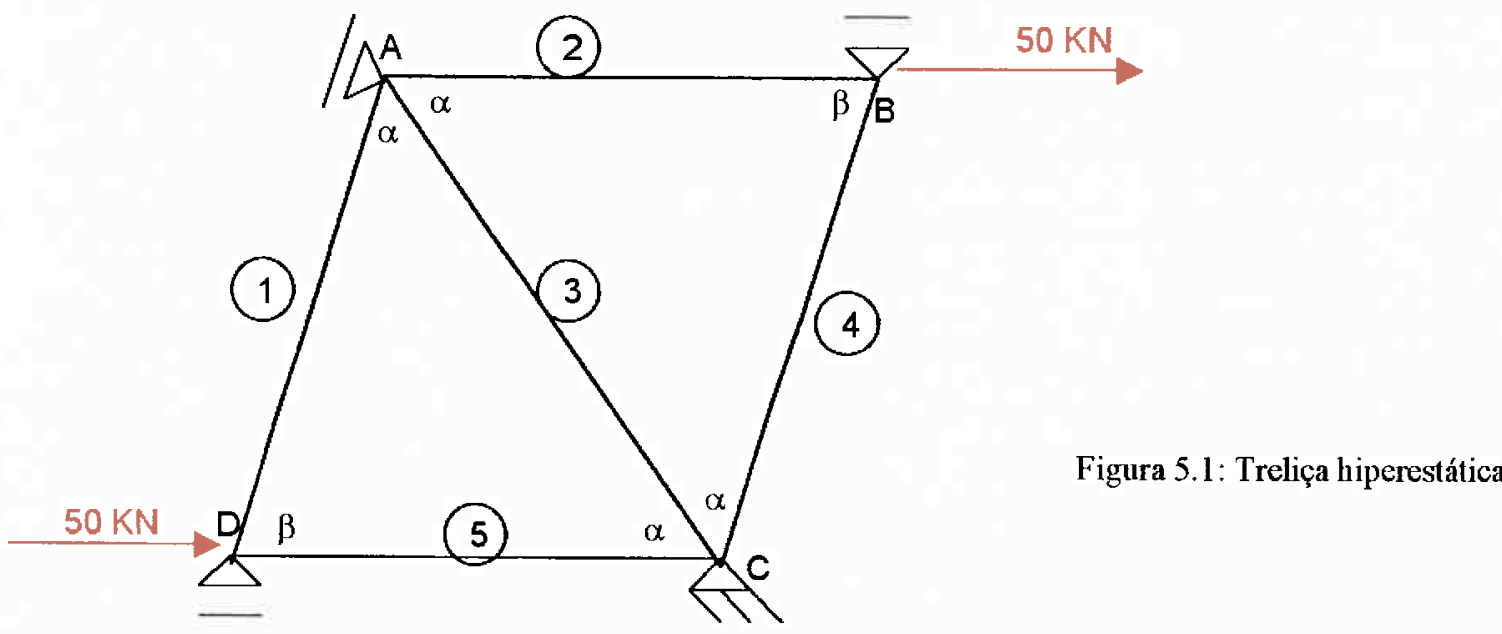


As equações de compatibilidade entre deformações e deslocamentos são obtidas através da aplicação de deslocamentos segundo os graus de liberdade da estrutura, conforme mostra a Figura 5.2.

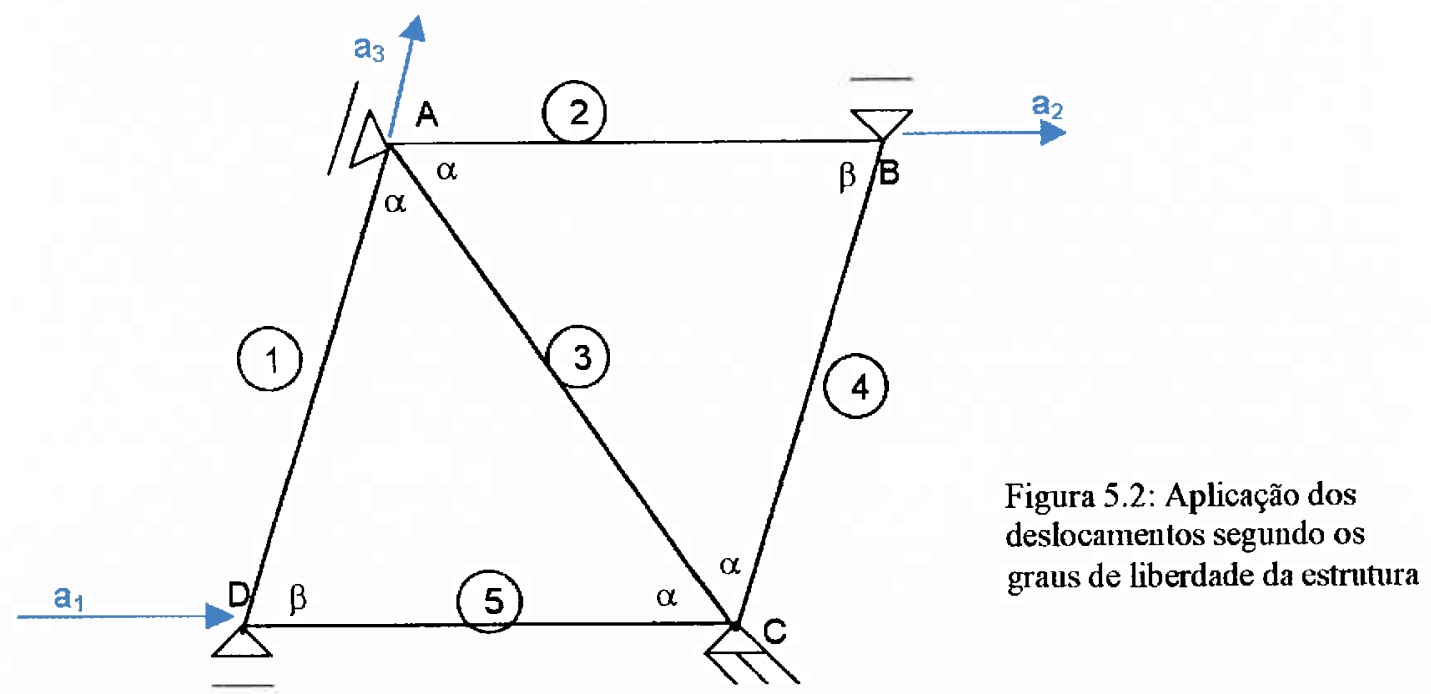

As relações de compatibilidade entre as deformações das barras e os deslocamentos dos nós obtidas no Capítulo 3 são utilizadas para a dedução do novo conjunto de equações. Portanto, devem ser consideradas as equações (3.34), (3.35), (3.40), (3.41), (3.46), (3.47) e (3.48), porém é utilizada a relação entre deslocamentos e deformações reais, sendo necessário retirar a letra $\delta$, que caracteriza grandezas virtuais.

$$
\begin{aligned}
& \Delta L_{1}=-\frac{7}{25} a_{1} \\
& \Delta L_{5}=-a_{1} \\
& \Delta L_{4}=\frac{7}{25} a_{2} \\
& \Delta L_{2}=a_{2} \\
& \Delta L_{2}=-\frac{7}{25} a_{3} \\
& \Delta L_{3}=\frac{3}{5} a_{3} \\
& \Delta L_{1}=a_{3}
\end{aligned}
$$


As equações (5.1) até (5.7) permitem obter as equações de compatibilidade entre deformações e deslocamentos, mostradas a seguir:

$$
\begin{aligned}
& \Delta_{1}=-\frac{7}{25} a_{1}+a_{3} \\
& \Delta_{2}=a_{2}-\frac{7}{25} a_{3} \\
& \Delta L_{3}=\frac{3}{5} a_{3} \\
& \Delta_{4}=\frac{7}{25} a_{2} \\
& \Delta L_{5}=-a_{1}
\end{aligned}
$$

Adota-se a mesma convenção de sinais utilizada no Capítulo 3, ou seja, que os esforços na treliça sejam todos de tração. Os deslocamentos são impostos segundo as direções e os sentidos dos graus de liberdade. $O$ sinal negativo indica que houve encurtamento na barra e o positivo, que houve alongamento.

A seguir, as equações de compatibilidade entre deformações e deslocamentos são inseridas nas equações constitutivas, $N_{i}=\frac{E A}{L_{i}} \Delta L_{i}$, obtendo-se as relações a seguir:

$$
\begin{aligned}
& N_{1}=\frac{E A}{L_{1}}\left[-\frac{7}{25} a_{1}+a_{3}\right] \\
& N_{2}=\frac{E A}{L_{2}}\left[a_{2}-\frac{7}{25} a_{3}\right] \\
& N_{3}=\frac{E A}{L_{3}}\left[\frac{3}{5} a_{3}\right] \\
& N_{4}=\frac{E A}{L_{4}}\left[\frac{7}{25} a_{2}\right]
\end{aligned}
$$




$$
N_{5}=\frac{E A}{L_{5}}\left[-a_{1}\right]
$$

A próxima etapa consiste em introduzir as equações (5.13) a (5.17) nas equaçôes de equilíbrio, dadas por (3.39), (3.45) e (3.52), mostradas logo abaixo:

$$
\begin{aligned}
& -7 N_{1}-25 N_{5}=1250 \\
& 25 N_{2}+7 N_{4}=1250 \\
& 25 N_{1}-7 N_{2}+15 N_{3}=0
\end{aligned}
$$

A última introdução de equações fornece o seguinte sistema linear:

$$
\left[\begin{array}{ccc}
5392 & 0 & -1400 \\
0 & 5392 & -1400 \\
-1400 & -1400 & 6892
\end{array}\right]\left\{\begin{array}{l}
a_{1} \\
a_{2} \\
a_{3}
\end{array}\right\}=\left\{\begin{array}{c}
1250 \\
1250 \\
0
\end{array}\right\}
$$

A solução deste sistema é dada por:

$$
\begin{aligned}
& a_{1}=0,25916 \mathrm{~m} \\
& a_{2}=0,25916 \mathrm{~m} \\
& a_{3}=0,10529 \mathrm{~m}
\end{aligned}
$$

Introduzindo os deslocamentos obtidos em (5.13) até (5.17), obtém-se os esforços normais nas barras da treliça, dados por:

$$
\begin{aligned}
& N_{1}=6,545 k N \\
& N_{2}=45,936 k N \\
& N_{3}=10,529 k N \\
& N_{4}=14,513 k N \\
& N_{5}=-51,832 k N
\end{aligned}
$$

Pode-se observar que a matriz do Processo dos Deslocamentos é simétrica. 


\subsubsection{O Processo dos Deslocamentos - Pórtico}

Considere o pórtico do Capítulo $4, \mathrm{~L}_{1}=4 \mathrm{~m}, \mathrm{~L}_{2}=5 \mathrm{~m}$ e $E I=10^{3} \mathrm{kNm} \mathrm{m}^{2}$.

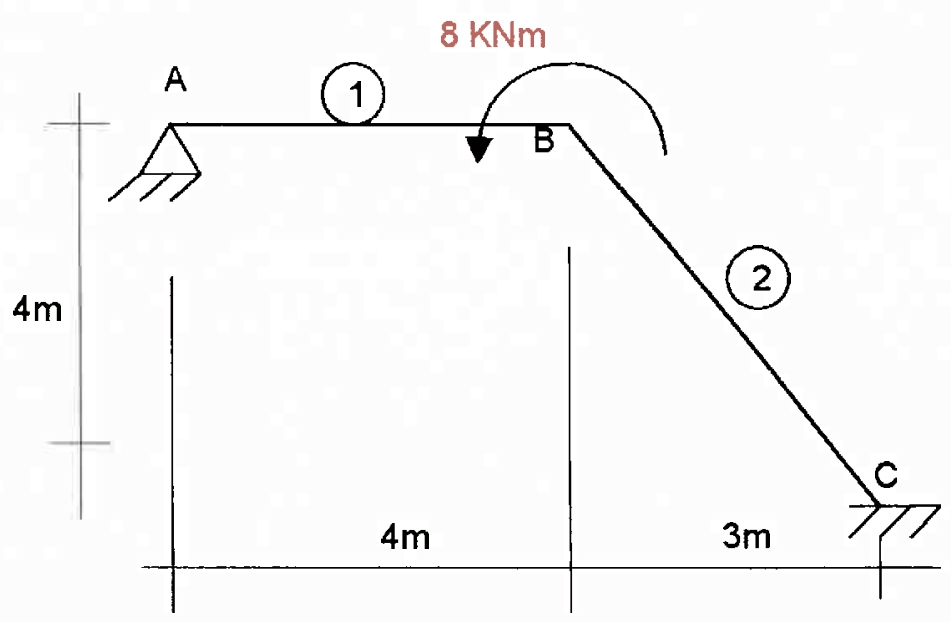

Figura 5.3: Pórtico plano hiperestático

As equações de compatibilidades entre deformações e deslocamentos são obtidas de maneira análoga ao item 5.3.1, devendo ser considerados os efeitos devidos à flexão, o que não ocorreu com a treliça em virtude da própria natureza da estrutura. A seguir podem ser visualizados na Figura 5.4 os deslocamentos a serem impostos na estrutura para a obtenção das equações de compatibilidade entre deformações e deslocamentos.

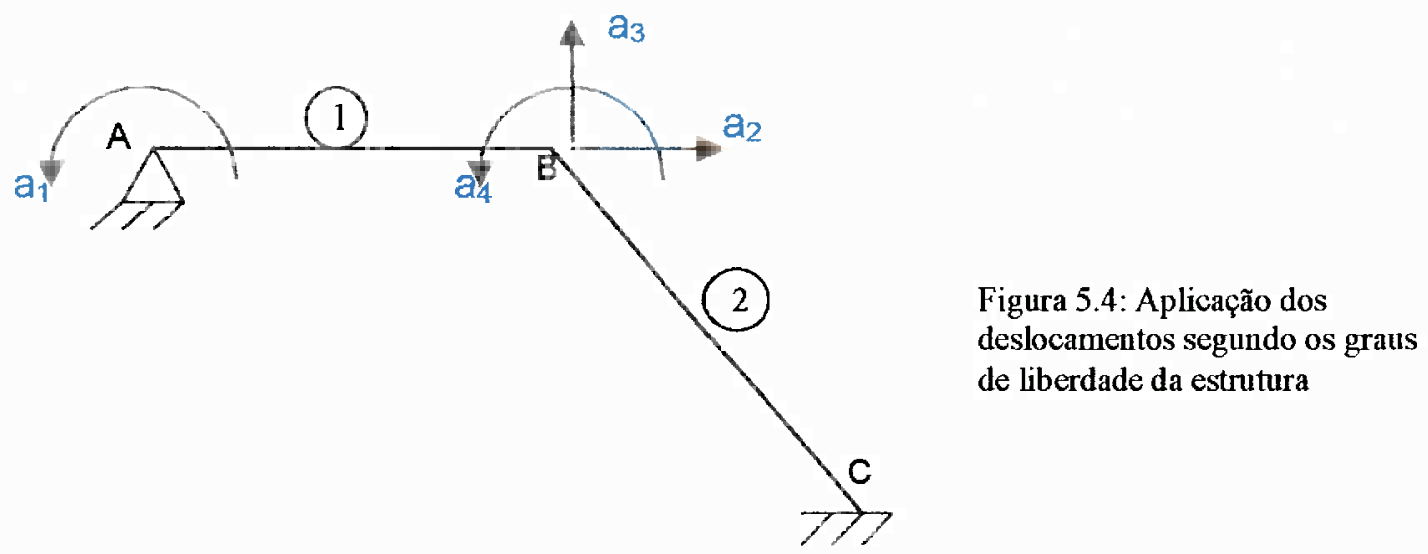


Analogamente, são utilizadas as relações entre as deformações das barras e os deslocamentos dos nós obtidas no Capítulo 4. Devem ser consideradas as seguintes equações: (4.58) a (4.60) e (4.69) a (4.71), que auxiliam a montagem dos diagramas de deformação axial, $\varepsilon$, e da curvatura, $\kappa$.
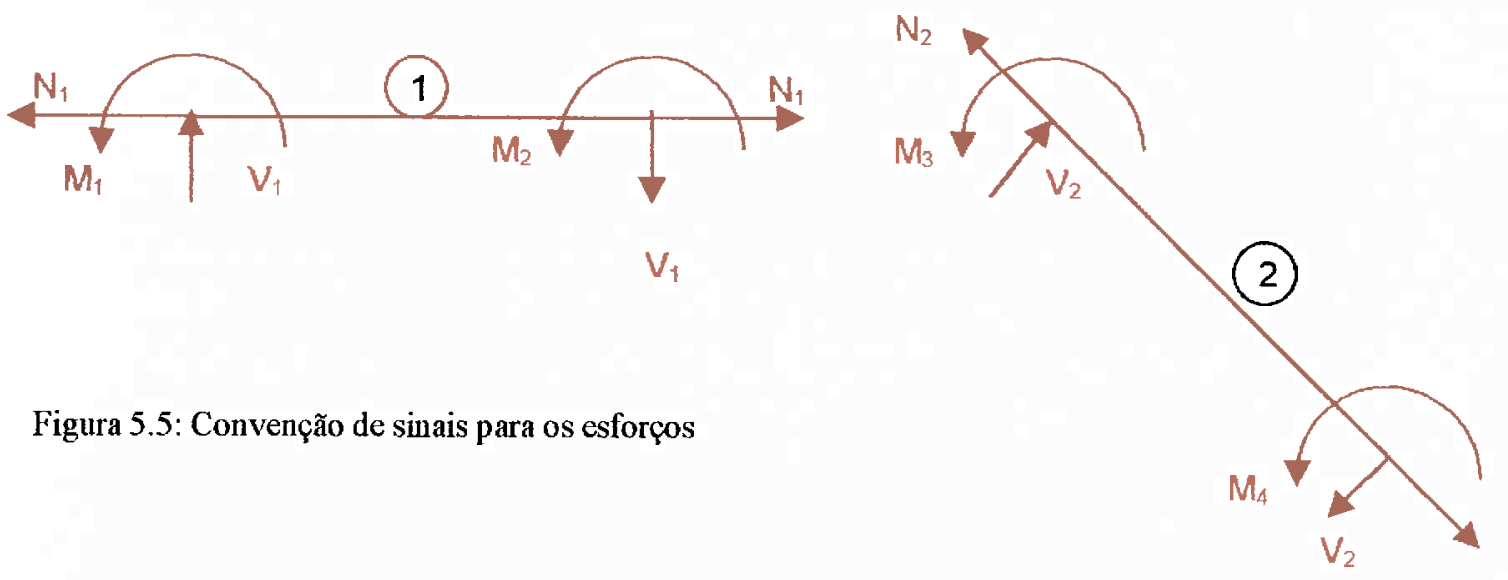

Figura 5.5: Convenção de sinais para os esforços

Os diagramas são obtidos da seguinte maneira: ao se impor o deslocamento segundo um grau de liberdade, obtêm-se os deslocamentos em cada barra que concorre ao nó deslocado, por meio da geometria da estrutura. A seguir, são obtidos as expressões dos esforços de engastamento perfeito, nas quais são inseridas as equações constitutivas. Substituindo os deslocamentos da barra nas expressões dos esforços (já tendo substituído as equações constitutivas), obtêm-se os diagramas.

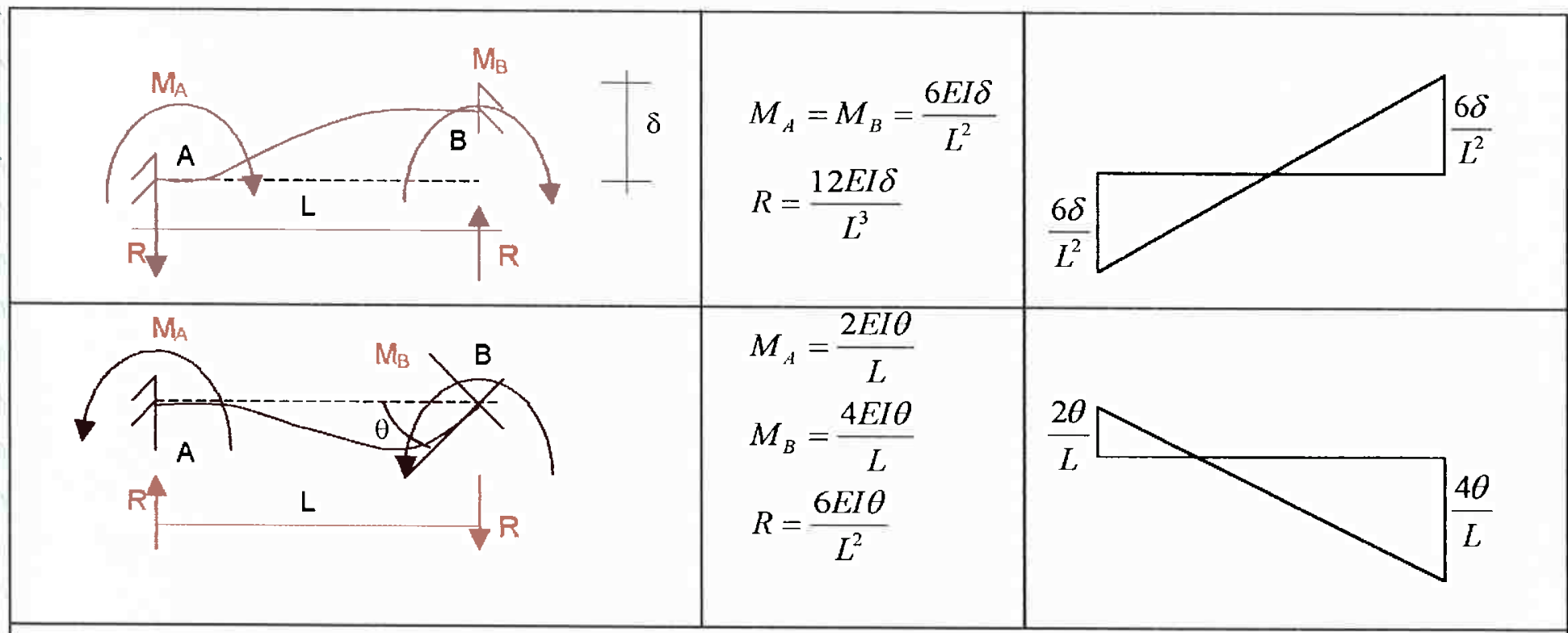

Figura 5.6: Ações de engastamento perfeito produzidas por deslocamentos de extremidade e o diagrama de curvaturas correspondentes 
Impondo o deslocamento $a_{1}$, ou seja, uma rotação no nó $A$, segundo o sentido de $a_{1}$ da Figura 5.4, análogo ao deslocamento $\delta \mathrm{a}_{1}$ da Figura 4.20, tem-se:
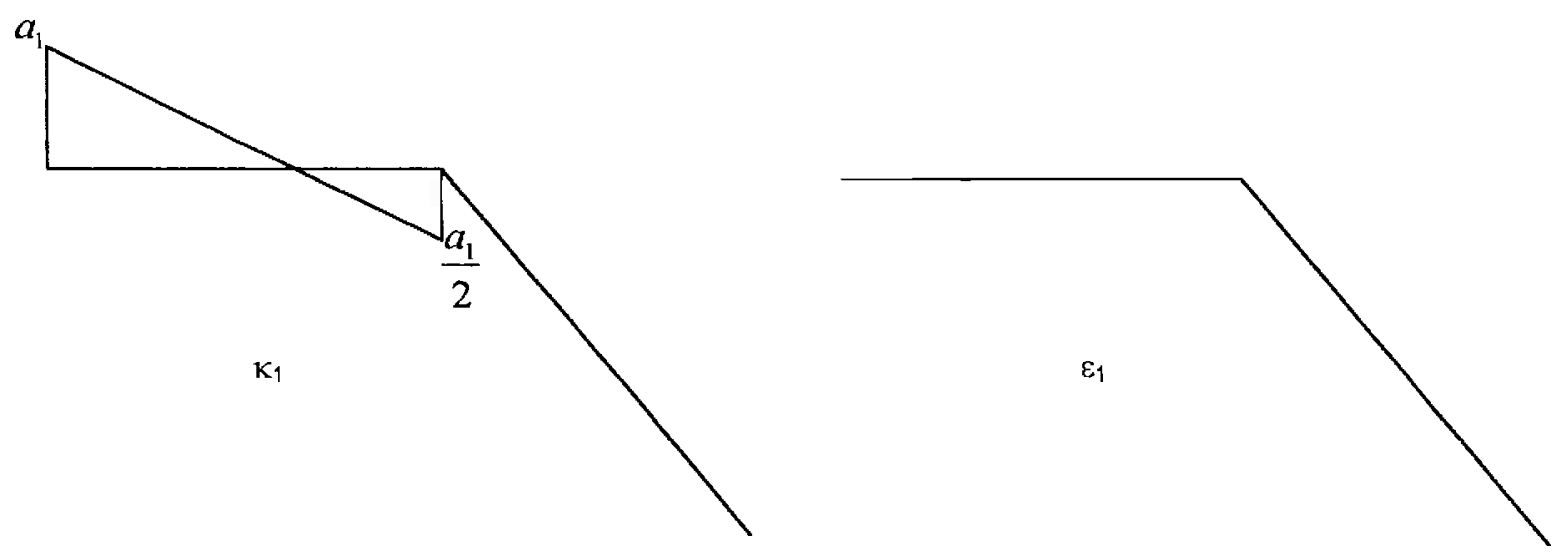

Figura 5.7-a: Diagramas de curvatura e deformação axial do pórtico quando imposto o deslocamento $\mathbf{a}_{1}$.

Impondo o deslocamento $\mathrm{a}_{2}$, que é análogo ao deslocamento $\delta \mathrm{a}_{2}$, da Figura 4.21 , tem-se:

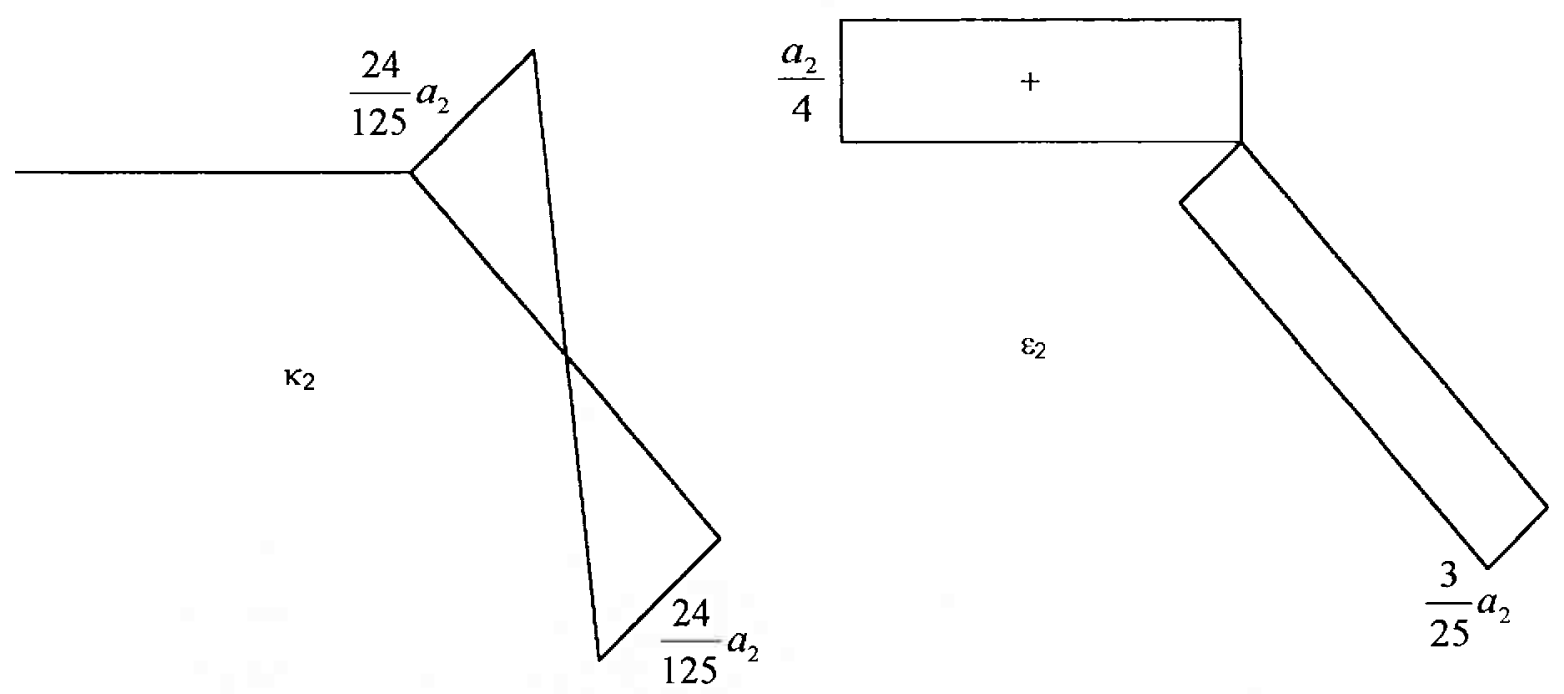

Figura 5.7-b: Diagramas de curvatura e deformação axial do pórtico quando imposto o deslocamento $\mathbf{a}_{2}$. 
Impondo o deslocamento $\mathrm{a}_{3}$, análogo ao deslocamento $\delta \mathrm{a}_{3}$, da Figura 4.22, tem-se:
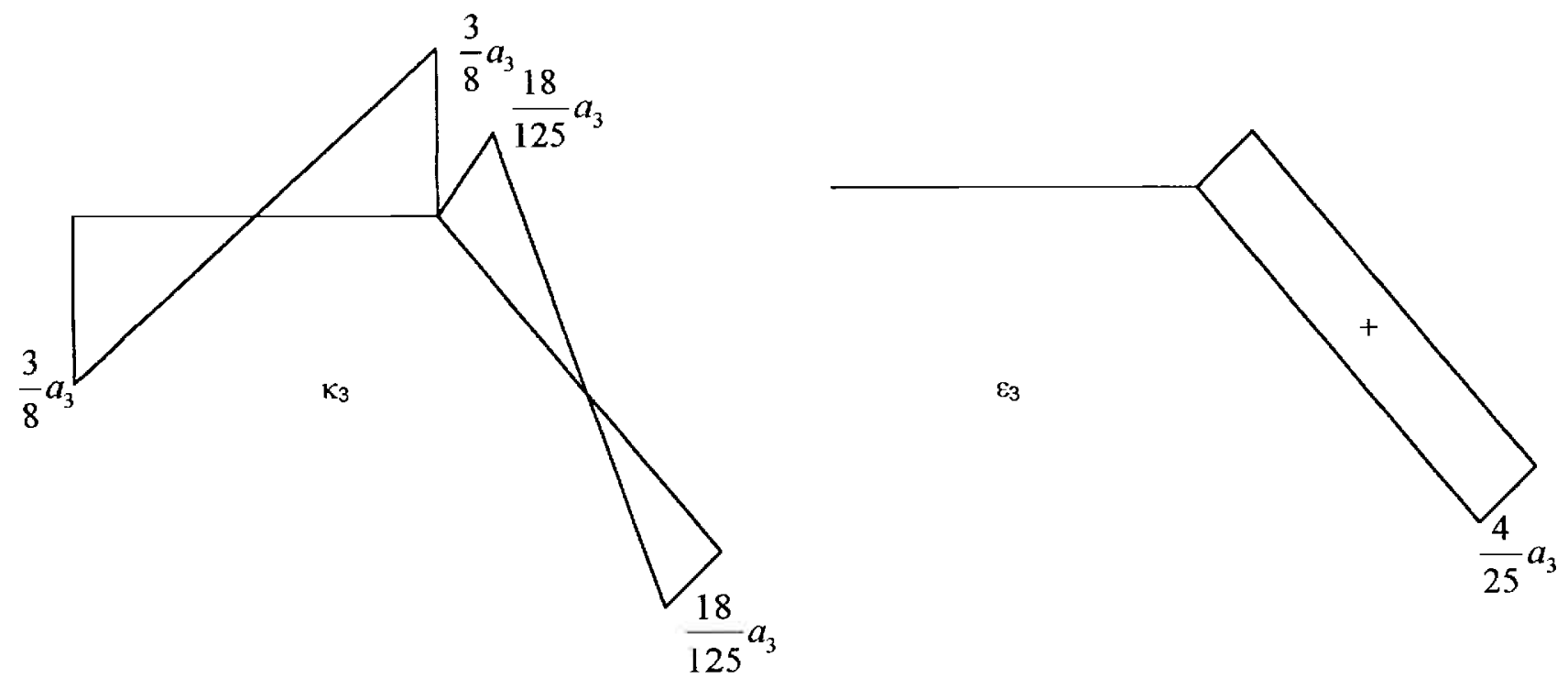

Figura 5.7-c: Diagramas de curvatura e deformação axial do pórtico quando imposto o deslocamento $a_{3}$.

Impondo o deslocamento $\mathrm{a}_{4}$, análogo ao deslocamento $\delta \mathrm{a}_{4}$ (rotação), da Figura 4.23, temse:

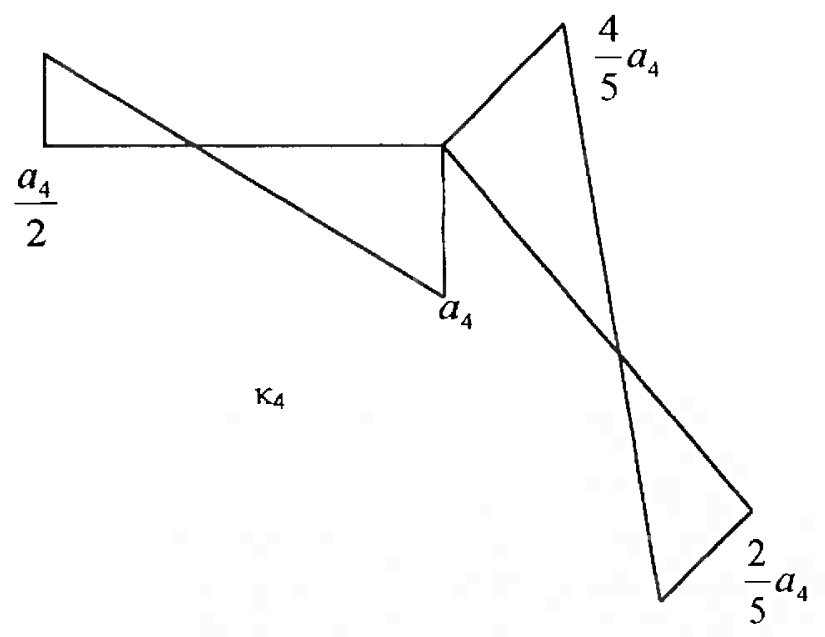

$\varepsilon_{4}$

Figura 5.7-d: Diagramas de curvatura e deformação axial do pórtico quando imposto o deslocamento $\mathbf{a}_{4}$. 
Por meio dos diagramas das figuras 5.7-a,b,c e d, são obtidas as equações de compatibilidade entre deformações e deslocamentos, mostradas abaixo:

$\kappa_{1}=a_{1}-\frac{3}{8} a_{3}+\frac{a_{4}}{2}$

$\kappa_{2}=\frac{a_{1}}{2}-\frac{3}{8} a_{3}+a_{4}$

$\kappa_{3}=\frac{24}{125} a_{2}+\frac{18}{125} a_{3}+\frac{4}{5} a_{4}$

$\kappa_{4}=\frac{24}{125} a_{2}+\frac{18}{125} a_{3}+\frac{2}{5} a_{4}$

$\varepsilon_{1}=\frac{a_{2}}{4}$

$\varepsilon_{2}=-\frac{3}{25} a_{2}+\frac{4}{25} a_{3}$

As equações de compatibilidade entre deformações e deslocamentos são inseridas nas equações constitutivas, $N_{i}=E A \varepsilon_{i}$ e $M_{i}=E I \kappa_{i}$, obtendo-se:

$$
\begin{aligned}
& N_{1}=E A\left[\frac{a_{2}}{4}\right] \\
& N_{2}=E A\left[-\frac{3}{25} a_{2}+\frac{4}{25} a_{3}\right] \\
& M_{1}=E I\left[a_{1}-\frac{3}{8} a_{3}+\frac{a_{4}}{2}\right] \\
& M_{2}=E I\left[\frac{a_{1}}{2}-\frac{3}{8} a_{3}+a_{4}\right] \\
& M_{3}=E I\left[\frac{24}{125} a_{2}+\frac{18}{125} a_{3}+\frac{4}{5} a_{4}\right]
\end{aligned}
$$


$M_{4}=E I\left[\frac{24}{125} a_{2}+\frac{18}{125} a_{3}+\frac{2}{5} a_{4}\right]$

Introduzindo as expressões (5.25) a (5.30) nas equações de equilíbrio, dadas por (4.57), (4.68), (4.79) e (4.86), mostradas abaixo:

$M_{1}=0$

$25 N_{1}-15 N_{2}+4 M_{3}+4 M_{4}=0$

$80 N_{2}-25 M_{1}-25 M_{2}+12 M_{3}+12 M_{4}=0$

$M_{2}+M_{3}=8$

Obtém-se o sistema linear a seguir:

$\left[\begin{array}{cccc}50000 & 0 & -18750 & 25000 \\ 0 & 19172 & -2496 & 9600 \\ -18750 & -2496 & 17503 & -11550 \\ 25000 & 9600 & -11550 & 90000\end{array}\right]\left\{\begin{array}{l}a_{1} \\ a_{2} \\ a_{3} \\ a_{4}\end{array}\right\}=\left\{\begin{array}{c}0 \\ 0 \\ 0 \\ 400\end{array}\right\}$

A solução do sistema linear é dada por:

$a_{1}=-2,56.10^{-3} m$

$a_{2}=-2,69 \cdot 10^{-3} m$

$a_{3}=5,02 \cdot 10^{-4} \mathrm{~m}$

$a_{4}=5,50 \cdot 10^{-3} m$ 
Substituindo os valores acima nas equações (5.25) a (5.30), obtém-se:

$$
\begin{aligned}
& N_{1}=-0,6732 \mathrm{kN} \\
& N_{2}=0,4035 \mathrm{kN} \\
& M_{1}=0 \\
& M_{2}=4,0375 \mathrm{kNm} \\
& M_{3}=3,9625 \mathrm{kNm} \\
& M_{4}=1,7588 \mathrm{kNm}
\end{aligned}
$$

\subsection{O Processo dos Esforços}

O Processo dos Esforços pode ser utilizado para analisar qualquer estrutura estaticamente indeterminada. Neste processo, as quantidades desconhecidas são as incógnitas hiperestáticas. $O$ número de equações a serem consideradas corresponde ao grau de hiperestaticidade da estrutura. No seu procedimento, deve-se obter uma estrutura estaticamente determinada, denominada estrutura isostática fundamental.

\subsection{Introdução ao Processo dos Esforços}

O Processo dos Esforços inicia-se com a escolha de uma estrutura isostática fundamental da estrutura original. A seguir, são obtidos os valores de $Y_{i}$, onde $Y_{i 0}$ é o esforço solicitante da barra i relativo ao carregamento de número zero, dado pelas cargas que atuam na estrutura original. Segue a obtenção dos valores de $Y_{i 1}, Y_{i 2}, \ldots, Y_{i g}$ onde g é o grau de hiperestaticidade, por meio da aplicação de uma carga unitária relativa à incógnita hiperestática, por exemplo: se a incógnita for a de índice 2, estarão sendo determinados os termos $Y_{i}$. Os valores de $Y_{i 0}, Y_{i 1}, \ldots, Y_{i g}$ são obtidos na estrutura isostática fundamental. $\mathrm{O}$ esforço em cada barra $i$, na estrutura original, é dado pela expressão:

$$
Y_{i}=Y_{i 0}+Y_{i 1} X_{1}+Y_{i 2} X_{2}+\ldots+Y_{i g} X_{g}
$$

onde $X_{1}, X_{2}, \ldots, X_{g}$ são as incógnitas hiperestáticas. 
Posteriormente, essas expressões são inseridas nas equações constitutivas, que, por sua vez, são introduzidas nas equações de compatibilidade, obtendo-se um sistema linear de ordem gxg.

\subsubsection{O Processo dos Esforços - Treliça}

Considerando novamente a treliça do Capítulo 3 . Serão obtidos os coeficientes $\mathbf{N}_{i 0}$, onde $i=1,2, \ldots, 5$. Esses coeficientes são as forças normais nas barras i na isostática fundamental, decorrentes da aplicação dos esforços atuantes na estrutura original, conforme ilustra a figura seguinte.

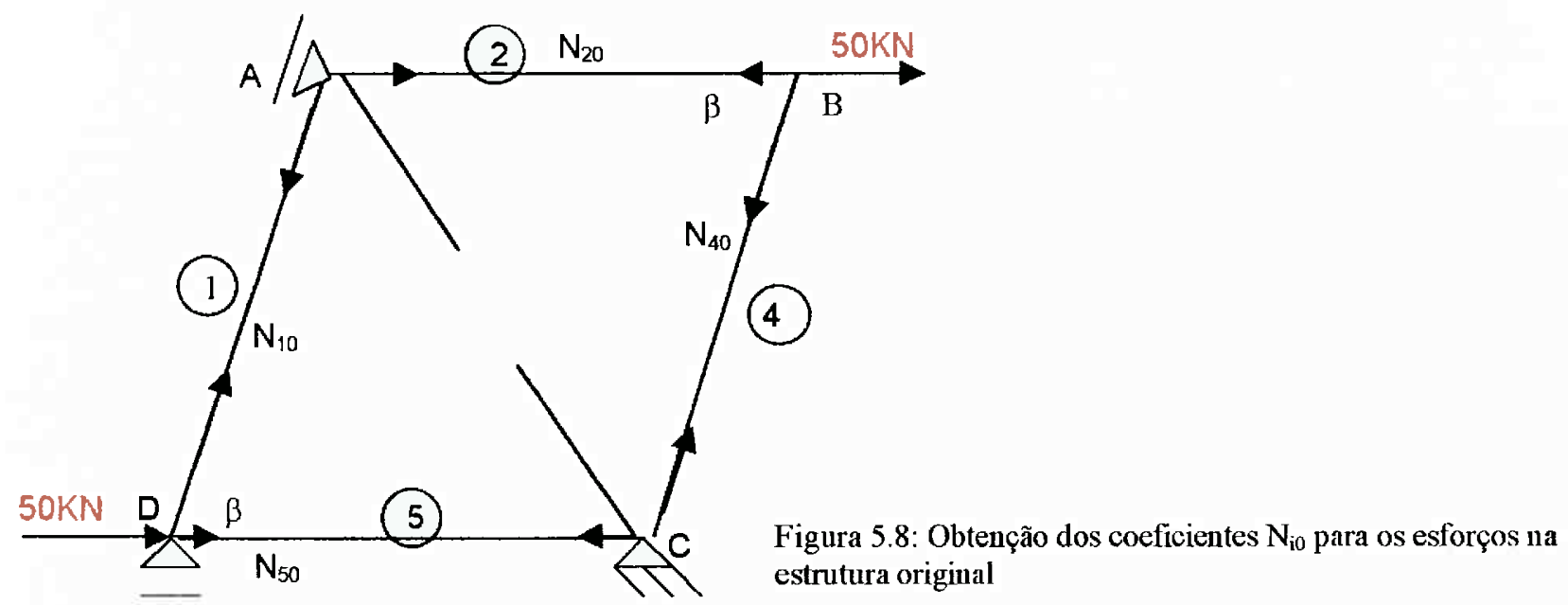

Os coeficientes $\mathrm{N}_{\mathrm{i} 0}$ são dados por:

$$
\begin{aligned}
& N_{10}=14 k N \\
& N_{20}=50 k N \\
& N_{30}=0 \\
& N_{40}=0 \\
& N_{50}=-\frac{1348}{25} k N
\end{aligned}
$$


A seguir são obtidos os coeficientes que multiplicarão a incógnita hiperestática, $X_{1}$. A obtenção desses coeficientes se dá através da aplicação do esforço unitário atribuído à incógnita $\mathrm{X}_{1}$.

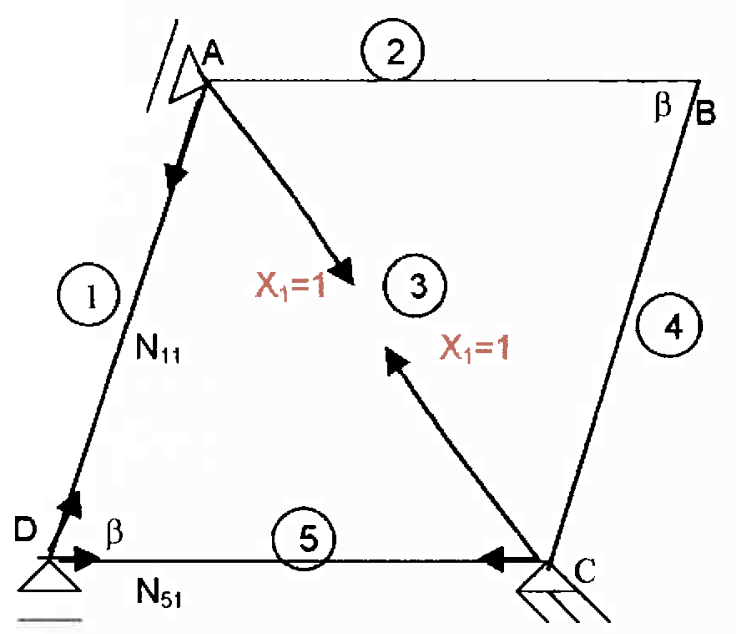

Os coeficientes $\mathrm{N}_{\mathrm{il}}$ são dados por:

$$
N_{11}=-\frac{3}{5}
$$$$
N_{21}=0
$$$$
N_{31}=1
$$$$
N_{41}=0
$$$$
N_{51}=\frac{21}{125}
$$

Figura 5.9: Aplicação do esforço unitário relativo à incógnita $\mathrm{X}_{1}$ para obtenção dos coeficientes $\mathrm{N}_{\mathrm{il}}$ 
Analogamente, são obtidos os coeficientes que multiplicarão a incógnita hiperestática,

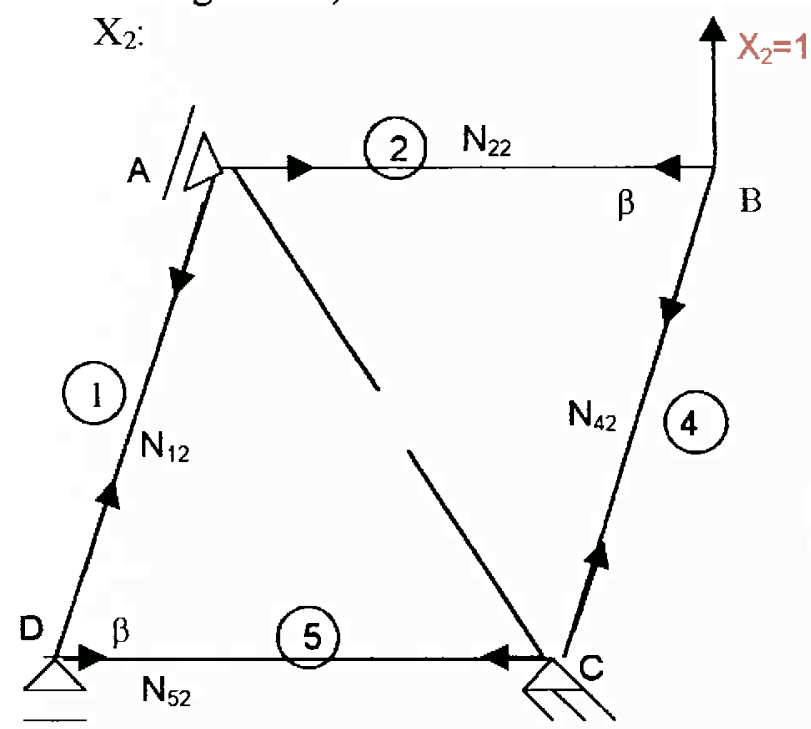

Figura 5.10: Aplicação do esforço unitário relativo à incógnita $\mathrm{X}_{2}$, para a obtenção dos coeficientes $\mathrm{N}_{\mathrm{i} 2}$

Os coeficientes são dados por:

$$
\begin{aligned}
& N_{12}=-\frac{49}{600} \\
& N_{22}=-\frac{7}{24}
\end{aligned}
$$

$N_{32}=0$

$N_{42}=\frac{24}{25}$

$N_{52}=\frac{343}{15000}$ 
Os esforços na estrutura original são dados por:

$$
\begin{aligned}
& N_{1}=N_{10}+N_{11} X_{1}+N_{12} X_{2} \\
& N_{2}=N_{20}+N_{21} X_{1}+N_{22} X_{2} \\
& N_{3}=N_{30}+N_{31} X_{1}+N_{32} X_{2} \\
& N_{4}=N_{40}+N_{41} X_{1}+N_{42} X_{2} \\
& N_{5}=N_{50}+N_{51} X_{1}+N_{52} X_{2}
\end{aligned}
$$

Substituindo (5.32) a (5.46) em (5.47) a (5.51), tem-se:

$$
\begin{aligned}
& N_{1}=14-\frac{3}{5} X_{1}-\frac{49}{600} X_{2} \\
& N_{2}=50-\frac{7}{24} X_{2} \\
& N_{3}=X_{1} \\
& N_{4}=\frac{24}{25} X_{2} \\
& N_{5}=-\frac{1348}{25}+\frac{21}{125} X_{1}+\frac{343}{15000} X_{2}
\end{aligned}
$$


As equações (5.52) a (5.56) são inseridas nas equações constitutivas $\Delta L_{i}=\frac{N_{i} L_{i}}{E S}$, obtendo-se:

$$
\begin{aligned}
& \Delta L_{1}=\frac{5}{E S}\left[14-\frac{3}{5} X_{1}-\frac{49}{600} X_{2}\right] \\
& \Delta L_{2}=\frac{5}{E S}\left[50-\frac{7}{24} X_{2}\right] \\
& \Delta L_{3}=\frac{6}{E S}\left[X_{1}\right] \\
& \Delta L_{4}=\frac{5}{E S}\left[\frac{24}{25} X_{2}\right] \\
& \Delta L_{5}=\frac{5}{E S}\left[-\frac{1348}{25}+\frac{21}{125} X_{1}+\frac{343}{15000} X_{2}\right]
\end{aligned}
$$

Inserindo as equações (5.57) a (5.61) nas equações de compatibilidade mostradas abaixo, obtém-se o sistema linear de ordem $2 \times 2$.

$-75 \Delta L_{1}+125 \Delta L_{3}+21 \Delta L_{5}=0$

$-\frac{49}{600} \Delta L_{1}-\frac{7}{24} \Delta L_{2}+\frac{25}{24} \Delta L_{4}+\frac{343}{15000} \Delta L_{5}=0$

Um procedimento mais prático poderia ser feito através da inserção da equações (5.52) a (5.56) nas equações de compatibilidade escritas em função dos esforços $(3.59)$ e $(3.68)$, na qual já houve a utilização da lei de Hooke.

$$
\left[\begin{array}{cc}
89337600 & 2972340 \\
2972340 & 61248323
\end{array}\right]\left\{\begin{array}{l}
X_{1} \\
X_{2}
\end{array}\right\}=\left\{\begin{array}{l}
982044000 \\
953979600
\end{array}\right\}
$$

A solução é dada por:

$$
\begin{aligned}
& X_{1}=10,49123 k N \\
& X_{2}=15,06647 k N
\end{aligned}
$$


Substituindo os valores de $\mathrm{X}_{1}$ e $\mathrm{X}_{2}$ nas equações (5.52) a (5.56), tem-se:

$$
\begin{aligned}
& N_{1}=6,47483 k N \\
& N_{2}=45,60561 k N \\
& N_{3}=10,49123 k N \\
& N_{4}=14,46381 k N \\
& N_{5}=-51,81295 k N
\end{aligned}
$$

\subsubsection{O Processo dos Esforços - Pórtico}

Considere o pórtico do Capitulo 4. Serão obtidos os coeficientes relativos às expressões dos esforços solicitantes em cada barra da estrutura. São utilizados os mesmos passos descritos no item 5.5 .

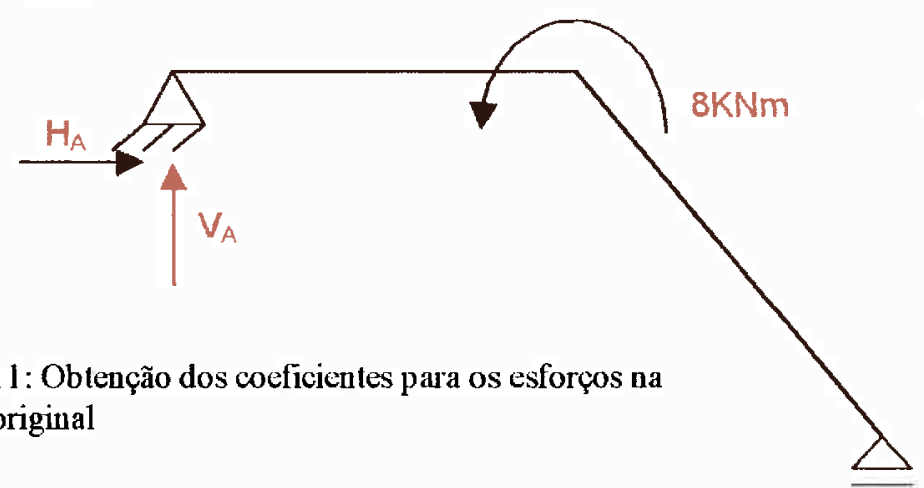

Figura 5.11: Obtenção dos coeficientes para os esforços na estrutura original
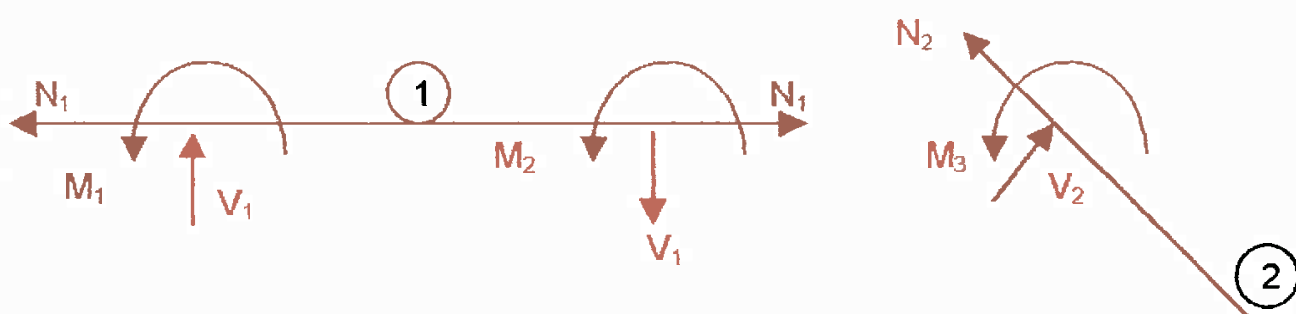

Figura 5.5: Convenção de sinais para os esforços

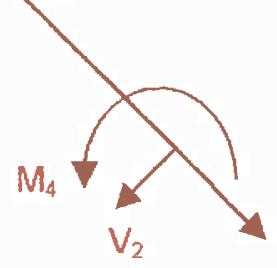


Os sinais para obtenção dos coeficientes obedecem a convenção estabelecida pela Figura 5.5 .

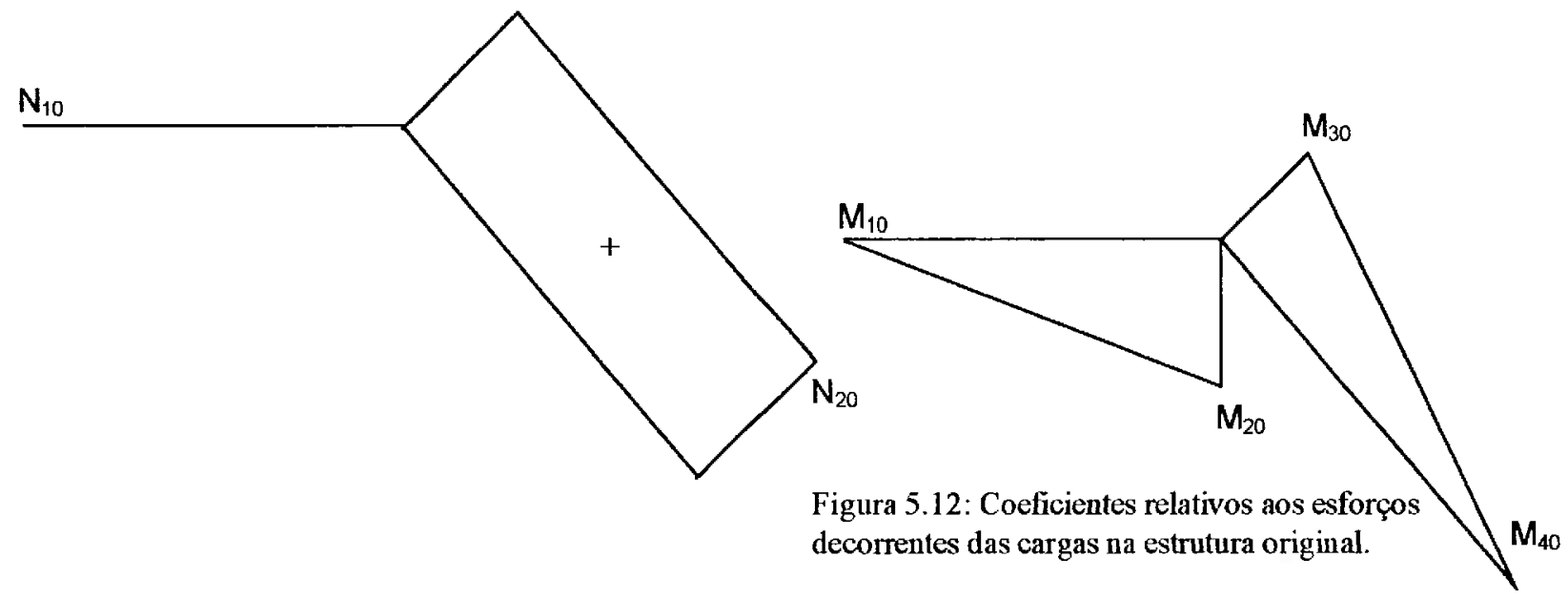

Pode-se concluir:

$N_{10}=0$

$N_{20}=\frac{32}{35} k N$

$M_{10}=0$

$M_{20}=\frac{32}{7} k N m$

$M_{30}=\frac{24}{7} k N m$

$M_{40}=0$ 
Para obtermos os demais coeficientes, será necessário aplicar os esforços unitários nos vínculos retirados da estrutura original:
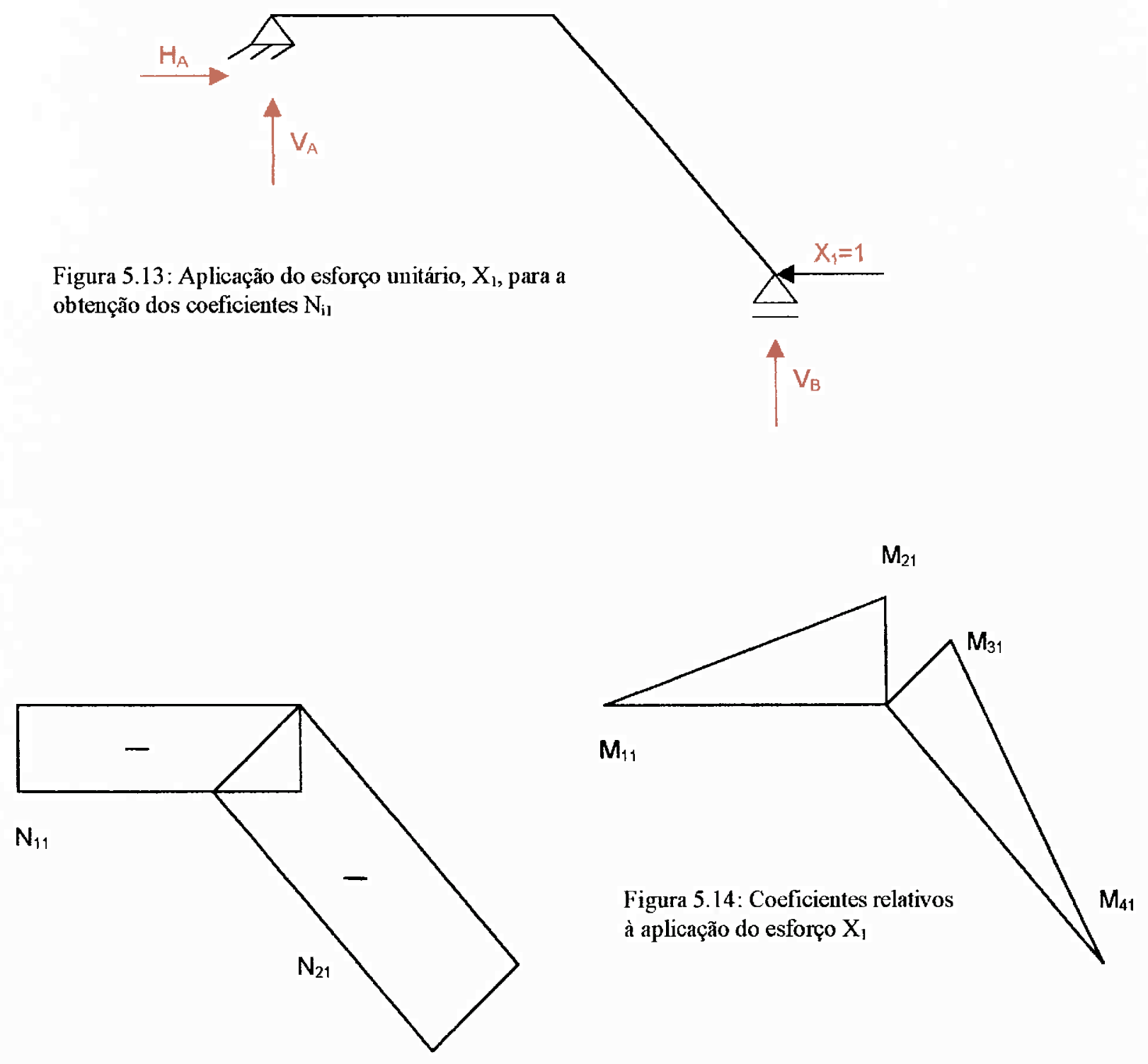
Sendo assim, obtém-se:

$N_{11}=-1$

$N_{21}=-\frac{37}{35}$

$M_{11}=0$

$M_{21}=-\frac{16}{7}$

$M_{31}=\frac{16}{7}$

$M_{41}=0$

Para obtermos os últimos coeficientes, é necessário aplicar o esforço unitário na direção do outro vínculo subtraído:

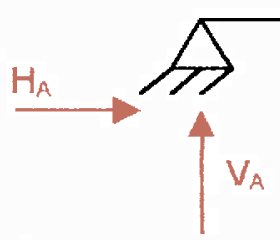

Figura 5.15:Aplicação do esforço unitário, $\mathrm{X}_{2}$, para a obtenção dos coeficientes $\mathrm{N}_{\mathrm{iz}}$

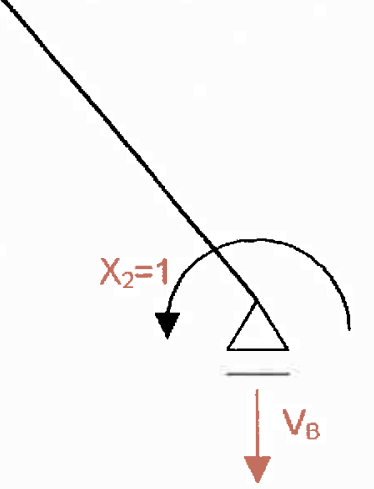




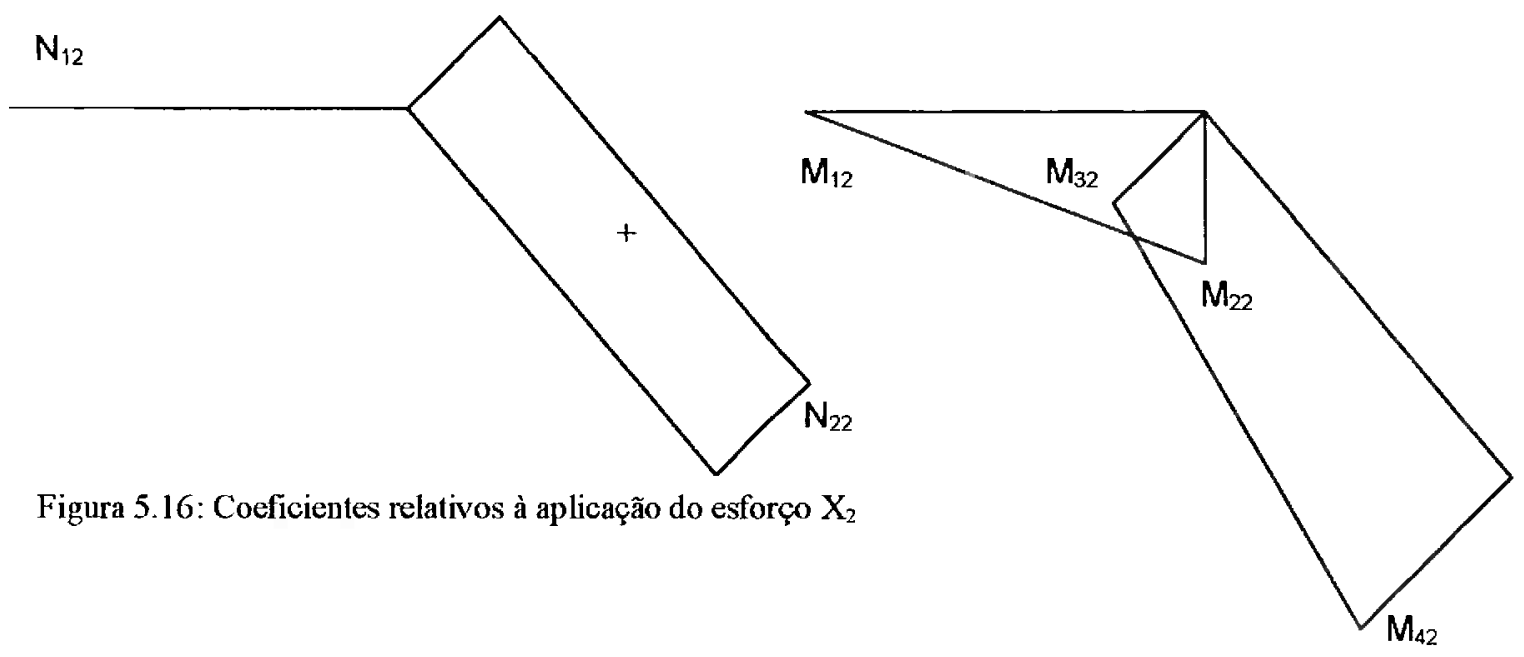

Então, pode-se concluir:

$N_{12}=0$

$N_{22}=\frac{4}{35}$

$M_{12}=0$

$M_{22}=\frac{4}{7}$

$M_{32}=-\frac{4}{7}$

$M_{42}=1$ 
Os esforços nas barras do pórtico são dados por:

$$
\begin{aligned}
& N_{1}=N_{10}+N_{11} X_{1}+N_{12} X_{2} \\
& N_{2}=N_{20}+N_{21} X_{1}+N_{22} X_{2} \\
& M_{1}=M_{10}+M_{11} X_{1}+M_{12} X_{2} \\
& M_{2}=M_{20}+M_{21} X_{1}+M_{22} X_{2} \\
& M_{3}=M_{30}+M_{31} X_{1}+M_{32} X_{2} \\
& M_{4}=M_{40}+M_{41} X_{1}+M_{42} X_{2}
\end{aligned}
$$

Substituindo (5.63) a (5.80) em (5.81) a (5.86), obtém-se:

$$
\begin{aligned}
& N_{1}=-X_{1} \\
& N_{2}=\frac{32}{35}-\frac{37}{35} X_{1}+\frac{4}{35} X_{2} \\
& M_{1}=0 \\
& M_{2}=\frac{32}{7}-\frac{16}{7} X_{1}+\frac{4}{7} X_{2} \\
& M_{3}=\frac{24}{7}+\frac{16}{7} X_{1}-\frac{4}{7} X_{2} \\
& M_{4}=X_{2}
\end{aligned}
$$


Substituindo as equações (5.87) a (5.92) nas equações constitutivas, $\varepsilon_{i}=\frac{N_{i}}{E A} \quad \mathrm{e}$ $\kappa_{i}=\frac{M_{i}}{E I}$, e estas nas equações de compatibilidade (4.94) e (4.104):

$-\frac{64}{21} \kappa_{2}+\frac{80}{21} \kappa_{3}-\frac{40}{21} \kappa_{4}-4 \varepsilon_{1}-\frac{37}{7} \varepsilon_{2}=0$

$\frac{16}{21} \kappa_{2}-\frac{41}{21} \kappa_{3}+\frac{52}{21} \kappa_{4}+\frac{4}{7} \varepsilon_{2}=0$

Da mesma forma como foi observado na introdução do Processo dos Esforços para a treliça, as equações (5.87) a (5.92) poderiam ter sido introduzidas nas equações de compatibilidade escritas em função dos esforços, que são dadas por (4.97) e (4.105).

As equações (4.94) e (4.104) formam o seguinte sistema linear:

$\left[\begin{array}{cc}23227317 & -5909724 \\ -5909724 & 3552448\end{array}\right]\left\{\begin{array}{l}X_{1} \\ X_{2}\end{array}\right\}=\left\{\begin{array}{l}5244192 \\ 2333656\end{array}\right\}$

Resolvendo o sistema linear, obtém-se:

$$
\begin{aligned}
& X_{1}=0,68127 k N \\
& X_{2}=1,79025 k N
\end{aligned}
$$


Substituindo $\mathrm{X}_{1}$ e $\mathrm{X}_{2}$ nas equações (5.87) a (5.92), tem-se:

$$
\begin{aligned}
& N_{1}=-0.68127 \mathrm{kN} \\
& N_{2}=0,39869 \mathrm{kN} \\
& M_{1}=0 \\
& M_{2}=4,037 \mathrm{kNm} \\
& M_{3}=3.963 \mathrm{kNm} \\
& M_{4}=1,79025 \mathrm{kNm}
\end{aligned}
$$




\section{Capítulo 6}

\section{Comparação entre os Processos dos Esforços e dos Deslocamentos}

\subsection{Introdução}

Conforme foi mencionado no Capítulol, um método se traduz pelas hipóteses que o mesmo comporta. O processo nada mais é do que as rotinas de cálculos dentro das hipóteses encerradas pelo método. Dentro deste, podem existir vários processos e que devem conduzir a análise aos mesmos resultados. Os Processos dos Esforços e dos Deslocamentos foram introduzidos no capítulo anterior através do Processo Direto e ainda foram expostos conceitos relativos aos mesmos. No presente capitulo, é realizada uma comparação entre os processos clássicos, através de quadros comparativos, ressaltando a dualidade existente entre ambos.

\subsection{Quadro Comparativo Entre os Processos dos Esforços e dos Deslocamentos}

Costa $^{1}$ fornece um quadro comparativo entre os Processos dos Esforços e dos Deslocamentos. Sua utilização possibilita uma visualização imediata da dualidade existente entre esses dois processos.

\begin{tabular}{|c|c|}
\hline Processo dos Esforços & Processo dos Deslocamentos \\
\hline \multicolumn{2}{|c|}{ Campo de Aplicação } \\
\hline $\begin{array}{c}\text { Estruturas Estaticamente Indeterminadas } \\
\text { (Hiperestáticas) }\end{array}$ & $\begin{array}{l}\text { Estruturas Cinematicamente } \\
\text { Indeterminadas }\end{array}$ \\
\hline
\end{tabular}

${ }^{1}$ Costa, H. B. Notas de Aula de PEF-212 - Resistência dos Materiais II, 1996 


\begin{tabular}{|c|c|}
\hline Processo dos Esforços & Processo dos Deslocamentos \\
\hline \multicolumn{2}{|c|}{ Incógnitas } \\
\hline $\begin{array}{l}\text { Esforços hiperestáticos externos (reativos) } \\
\text { ou internos (solicitantes) }\end{array}$ & $\begin{array}{l}\text { Deslocamentos nodais (lineares ou } \\
\text { angulares) }\end{array}$ \\
\hline \multicolumn{2}{|c|}{ Número de Incógnitas } \\
\hline $\begin{array}{l}\text { Igual ao Grau de Indeterminação Estática } \\
\text { (Grau de Hiperestaticidade }- \text { g) }\end{array}$ & $\begin{array}{l}\text { Igual ao Grau de Indeterminação } \\
\text { Cinemática (Número de Graus de } \\
\text { Liberdade }-h \text { ) }\end{array}$ \\
\hline \multicolumn{2}{|c|}{ Estrutura Fundamental Associada à Original } \\
\hline $\begin{array}{l}\text { Estrutura Isostática Fundamental } \\
\text { (Estaticamente Determinada - } \\
\text { várias opções possíveis) }\end{array}$ & $\begin{array}{l}\text { Estrutura Bloqueada } \\
\text { (Cinematicamente Determinada - uma } \\
\text { única alternativa) }\end{array}$ \\
\hline \multicolumn{2}{|c|}{ Equações Básicas } \\
\hline COMPATIBILIDADE & EQUILÍBRIO \\
\hline Em notação matricial: & Em notação matricial: \\
\hline $\begin{array}{l}\{\delta\}=\left\{\delta^{0}\right\}+[F]\{X\} \\
\text { onde: } \\
{[F] \text { é a Matriz de Flexibilidade }}\end{array}$ & $\begin{array}{l}\{f\}=\left\{f^{0}\right\}+[K]\{a\} \\
\text { onde: } \\
{[K] \text { é a Matriz de Rigidez }}\end{array}$ \\
\hline $\begin{array}{l}\{\delta\} \text { e }\left\{\delta^{0}\right\} \text { são os vetores deslocamentos } \\
\text { comespondentes aos esforços } \\
\text { hiperestáticos }\end{array}$ & $\begin{array}{l}\{f\} \text { e }\left\{f^{0}\right\} \text { são os vetores de esforços } \\
\text { correspondentes aos deslocamentos } \\
\text { nodais }\end{array}$ \\
\hline$\{X\}$ vetor dos esforços hiperestáticos & $\{a\}$ vetor deslocamentos nodais \\
\hline
\end{tabular}




\section{Equações Básicas (continuação)}

Em notação indicial:

$\delta_{i}=\delta_{i}^{0}+\sum_{j=1}^{g}\left(\delta_{i, j} X_{j}\right)$

$(i=1,2,3, \ldots, g)$

g: Grau de Hiperestaticidade da Estrutura

$F_{i j}$ é o deslocamento correspondente a $X_{i}$ e devido a $X_{j}=1$, na estrutura isostática fundamental
Em notação indicial:

$f_{i}=f_{i}^{0}+\sum_{j=1}^{h}\left(K_{i j} a_{j}\right)$
$(\mathrm{i}=1,2,3, \ldots, \mathrm{h})$

h:Grau de Indeterminação Cinemática

$K_{i j}$ é o esforço externo ativo

correspondente a $a_{j}$ que causa $a_{j}=1$, na estrutura semi-fixa, ou seja, apenas $a_{j}$ liberado.

$K_{i j}(i \neq j)$ é o esforço externo reativo, correspondente a $a_{i}$, que surge na estrutura semi-fixa, com apenas $a_{j}$ liberado, em virtude da aplicação de $\mathrm{K}_{\mathrm{ij}}$.

\section{Interpretação Fisica das Equações Básicas}

$[F]\{X\}=\{\delta\}-\left\{\delta^{0}\right\}$

Os esforços hiperestáticos consistem na soma de duas parcelas:

$\{X\}=\left\{X^{\prime}\right\}+\left\{X^{\prime \prime}\right\}$

A primeira parcela serve para produzir os deslocamentos $\{\delta\}$ (dados):

$[F]\left\{X^{\prime}\right\}=\{\delta\}$
$[K]\{a\}=\{f\}-\left\{f^{0}\right\}$

Os deslocamentos nodais $\{a\}$ consistem na soma de duas parcelas:

$\{a\}=\left\{a^{\prime}\right\}+\left\{a^{\prime \prime}\right\}$

A primeira parcela é causada diretamente pelos esforços (dados) $\{f\}$ :

$[K]\left\{a^{\prime}\right\}=\{f\}$ 


\begin{tabular}{|c|c|}
\hline Processo dos Esforços & Processo dos Deslocamentos \\
\hline \multicolumn{2}{|c|}{ Interpretação Física das Equações Básicas (continuação) } \\
\hline $\begin{array}{l}\text { E a segunda para neutralizar os } \\
\text { deslocamentos }\left\{\delta^{0}\right\} \text { : } \\
{[F\}\left\{X^{\prime \prime}\right\}=-\left\{\delta^{0}\right\}} \\
\text { Os deslocamentos }\left\{\delta^{0}\right\} \text { são determinados } \\
\text { na condição de se ter } \\
\{X\}=\{0\} \text {, ou seja, na estrutura isostática } \\
\text { fundamental. }\end{array}$ & $\begin{array}{l}\text { E a segunda, pelos esforços opostos } \\
\text { aqueles contidos em }\left\{f^{0}\right\} \\
{[K]\left\{a^{\prime \prime}\right\}=-\left\{f^{0}\right\}} \\
\text { Os esforços }\left\{f^{0}\right\} \text { são determinados na } \\
\text { condição de se ter }\{a\}=\{0\} \text {, ou seja, na } \\
\text { estrutura bloqueada } \\
\text { Obs: } \\
\left\{f^{0}\right\} \text { : esforços de engastamento perfeito } \\
\left\{f^{0}\right\} \text { : esforços nodais equivalentes }\end{array}$ \\
\hline \multicolumn{2}{|c|}{$\begin{array}{l}\text { Comportamento da Estrutura Fundamental na Determinação das } \\
\text { Mấtítizess }\end{array}$} \\
\hline $\begin{array}{l}\text { Matriz [F] e vetor }\left\{\delta^{0}\right\} \\
\text { Comportamento governado pelo equilíbrio } \\
\text { (característica das estruturas livres) } \\
\text { No cálculo dos coeficientes } \delta_{\text {ii de }}[\mathrm{F}] \text { e } \delta_{i}^{0} \\
\text { de }\left\{\delta^{0}\right\} \text {, impõe-se o equilíbrio. Depois, com } \\
\text { auxílio da Lei de Hooke, a compatibilidade } \\
\text { decorre como conseqüência. }\end{array}$ & $\begin{array}{l}\text { Matriz }[\mathrm{K}] \text { e vetor }\left\{\mathrm{f}^{\mathrm{q}}\right\} \\
\text { Comportamento governado pela } \\
\text { compatibilidade (caracteristica das } \\
\text { estruturas bloqueadas) } \\
\\
\text { No cálculo dos coeficientes } \mathrm{K}_{\mathrm{ij}} \text { de }[\mathrm{K}] \text { e } \mathrm{f}_{\mathrm{i}}^{\mathrm{O}} \\
\text { de }\left\{\mathrm{f}^{0}\right\} \text {, impõe-se a compatibilidade. } \\
\text { Depois, com auxilio da Lei de Hooke, o } \\
\text { equilíbrio decorre como conseqüência. }\end{array}$ \\
\hline
\end{tabular}




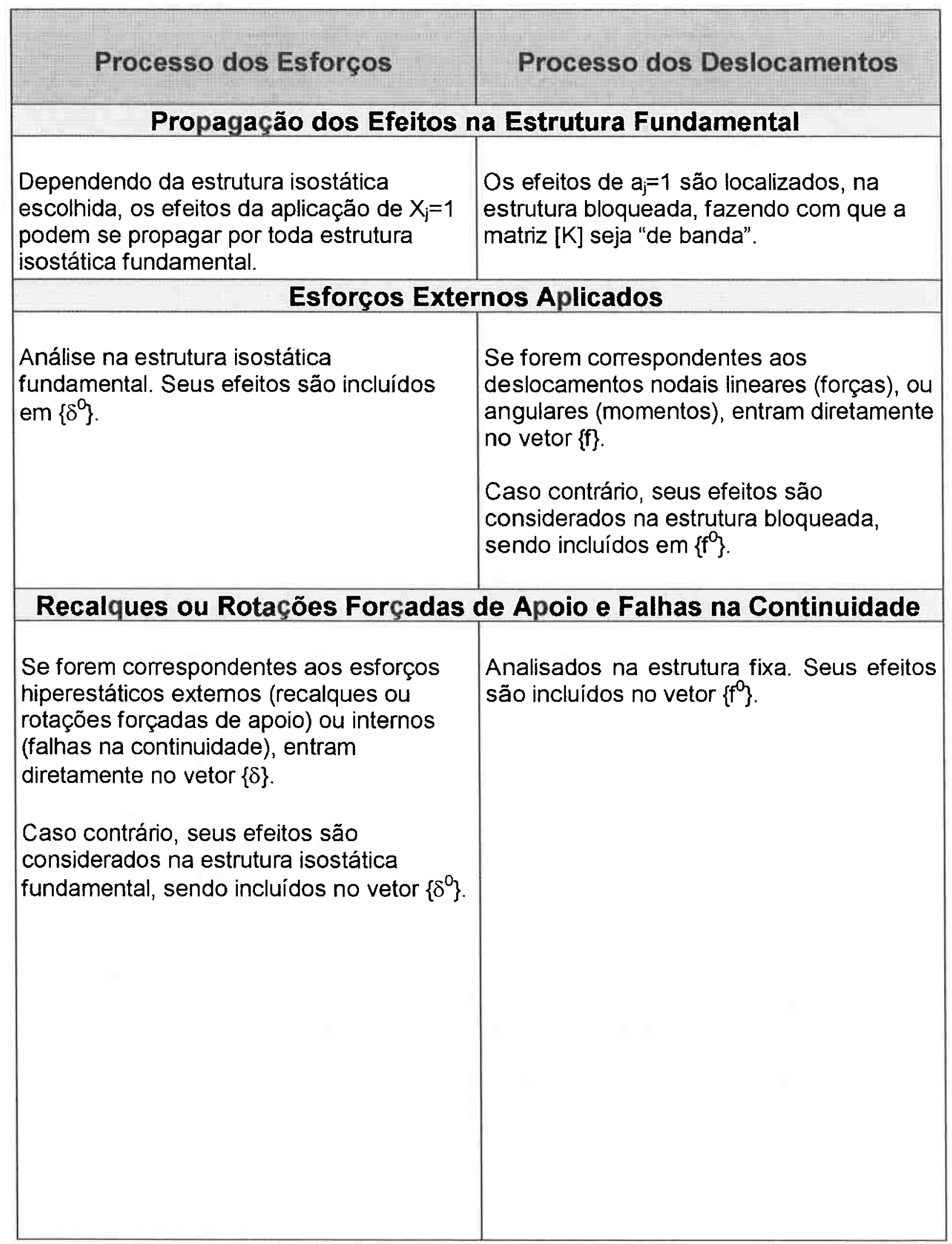




\section{Processo dos Esforços}

\section{Variação de Temperatura e Defeitos de Fabricação}

Analisados na estrutura isostática fundamental. Seus efeitos são incluídos em $\left\{\delta^{0}\right\}$.

Efeitos estudados na estrutura bloqueada e incluídos no vetor $\left\{f^{0}\right\}$.

\subsection{Observações}

1) O Processo da Carga Unitária é útil no cálculo dos coeficientes $F_{i j}$ de $[F]$ e $\delta_{i}{ }^{0}$ de $\left\{\delta^{0}\right\}$. Porém, não se deve confundir o Processo da Carga Unitária com o Processo dos Esforços;

2) Uma estrutura que tenha os dois tipos de indeterminação, estática e cinemática, (caso muito comum na prática), pode ser resolvida por qualquer dos dois processos. Entretanto, embora:

$[\mathrm{F}]^{-1}$ seja, por definição, uma matriz de rigidez $\mathrm{e},[\mathrm{K}]^{-1}$ seja, por definição, uma matriz de flexibilidade, nunca acontecerá: $[\mathrm{K}]=[\mathrm{F}]^{-1}$ (ou $[\mathrm{F}]=[\mathrm{K}]^{-1}$ )

Pelo simples fato de que, na mesma estrutura, as matrizes [K] e [F], mesmo que coincidentemente sejam da mesma ordem, jamais se referirão ao mesmo jogo de esforços e deslocamentos correspondentes;

3) A interpretação física de $[\mathrm{F}]^{-1}$ e $[\mathrm{K}]^{-1}$ pode ser facilmente introduzida:

$[\mathrm{F}]^{-1}$ é uma matriz de rigidez, definida na estrutura original e se refere ao mesmo jogo de esforços e deslocamentos correspondentes de $[\mathrm{F}]$. De $[F]\{X\}=\{\delta\}$, vem:

$$
\{X\}=[F]^{-1}\{\delta\}=\left\lceil K \mid\{\delta\} \text { ou } X_{i}=\sum_{j=1}^{g} \bar{K}_{i j} \delta_{i j} \quad(\mathrm{i}=1,2, \ldots, \mathrm{g})\right.
$$

Sendo $\overline{K_{i j}}$ esforço correspondente a $\delta_{\mathrm{i}}$ e devido a $\delta_{\mathrm{j}}=1$, na estrutura original $\left(\delta_{\mathrm{k}}=0\right.$, $\mathrm{k} \neq \mathrm{j})$. 
Por outro lado, $[\mathrm{K}]^{-1}$ é uma matriz de flexibilidade, definida na estrutura original e se refere ao mesmo jogo de esforços e deslocamentos correspondentes de $[\mathrm{K}]$. De $[K]\{a\}=\{f\}$, vem:

$\{a\}=[K]^{-1}\{f\}=[F]\{f\}$ ou $a_{i}=\sum_{j=1}^{h} \bar{\delta}_{i j} f_{j}(\mathrm{i}=1,2, \ldots, \mathrm{h})$

Sendo $\overline{\delta_{i j}}$ deslocamento correspondente a $\mathrm{f}_{\mathrm{i}}$ e devido a $\mathrm{f}_{\mathrm{j}}=\mathrm{l}$, na estrutura original ( $f_{k}=0, k \neq j$ ).

4) Uma pergunta que surge naturalmente é a seguinte: não seria mais fácil determinar $[F]^{-1}$ (no processo dos esforços) e $[K]^{-1}$ (no processo dos deslocamentos)?

A resposta é negativa, pois para determinarmos $\left[\mathrm{F}^{-1}\right.$ é necessário resolver várias vezes a estrutura original, sujeita a deslocamentos unitários impostos. Para determinarmos $[\mathrm{K}]^{-1}$ é necessário resolver várias vezes a estrutura original, sujeita a esforços unitários aplicados.

\subsection{Ilustração da Aplicação dos Processos dos Esforços e dos Deslocamentos}

Considere a treliça apresentada por Costa e $\operatorname{Diogo}^{2}$. São atribuídos os seguintes valores para a mesma:

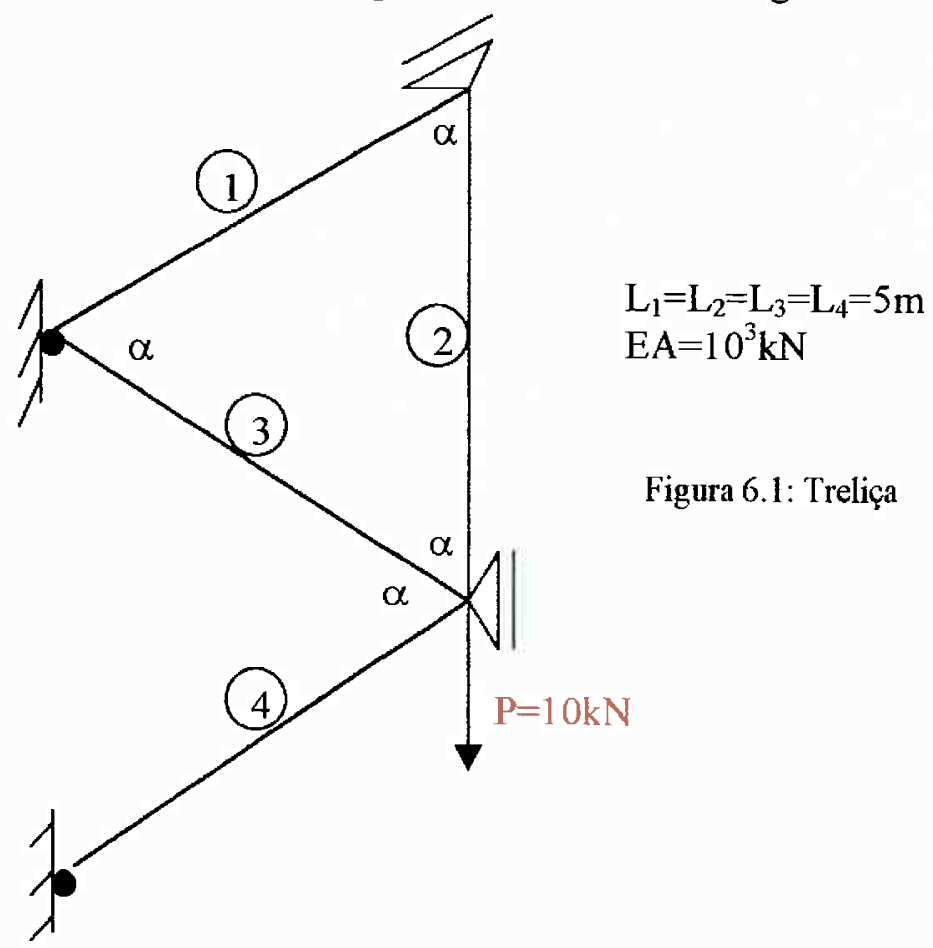

${ }^{2}$ Costa, H.B; Diogo, L.A.C. Considerações sobre o Emprego do Teorema dos Trabalhos Virtuais na
Resolução de Estruturas Hiperestáticas: Treliças. 
A estrutura possui dois graus de liberdade e é duas vezes hiperestática. A finalidade deste item é a ilustração relativa aos conceitos expostos no quadro comparativo deste capítulo, o que conduz a resolução dessa treliça pelos Processos dos Esforços e dos Deslocamentos.

\subsubsection{Resolução da Treliça pelo Processo dos Esforços}

O primeiro passo é a obtenção da estrutura isostática fundamental, mostrada na Figura 6.1.

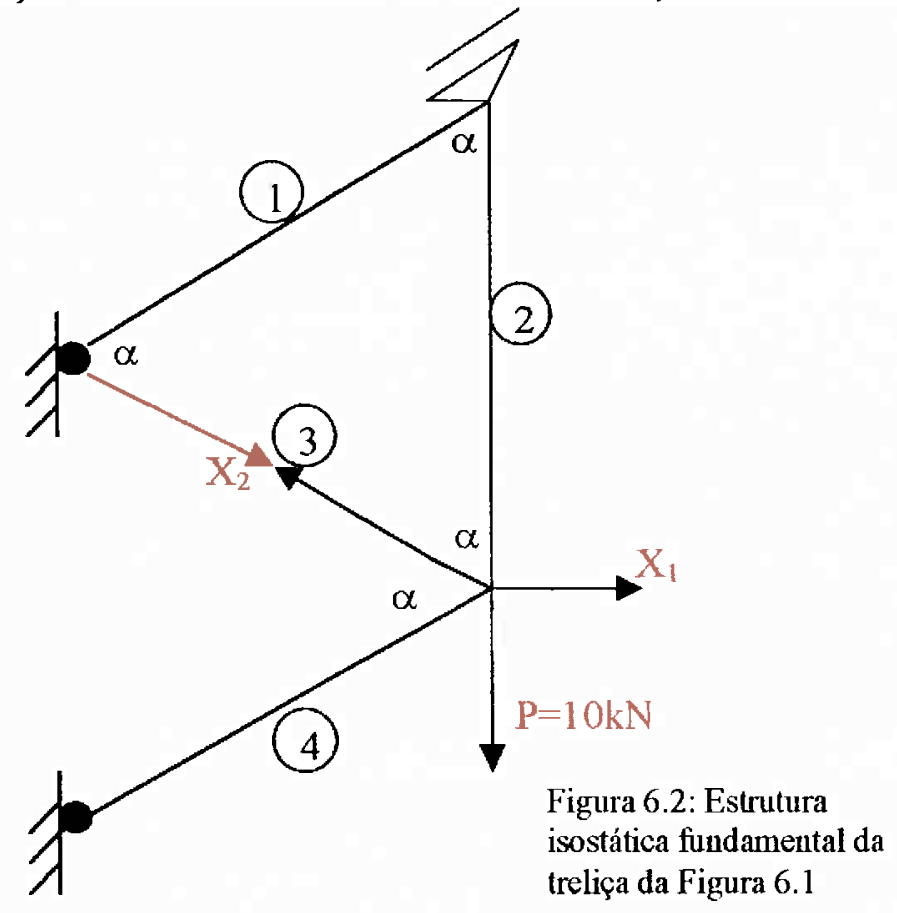

Sendo a estrutura duas vezes hiperestática, deverão ser obtidas duas equações de compatibilidade. Por conseqüência, os vetores $\{\delta\}$ e $\left\{\delta^{0}\right\}$ terão ordem $2 \times 1$, enquanto a matriz de flexibilidade, [F], terá ordem $2 \times 2$.

A seguir, obtém-se os mesmos vetores mencionados no parágrafo anterior. Como não há deslocamentos impostos nos apoios da estrutura, então o vetor $\{\delta\}$ é um vetor nulo, ou seja:

$$
\{\delta\}=\left\{\begin{array}{l}
0 \\
0
\end{array}\right\}
$$

Pode-se observar que o vetor $\{\delta\}$ é obtido em relação à estrutura original.

A seguir, deve ser obtido o vetor $\left\{\delta^{0}\right\}$, que representa os deslocamentos na estrutura isostática fundamental correspondentes às incógnitas hiperestáticas, em virtude das cargas que atuam na estrutura original. Esse vetor consideraria também os efeitos relativos à 
variação de temperatura, se houvesse. As componentes do vetor $\left\{\delta^{0}\right\}$ são calculadas através da aplicação do Método da Carga Unitária. Para tanto, são considerados os seguintes casos:

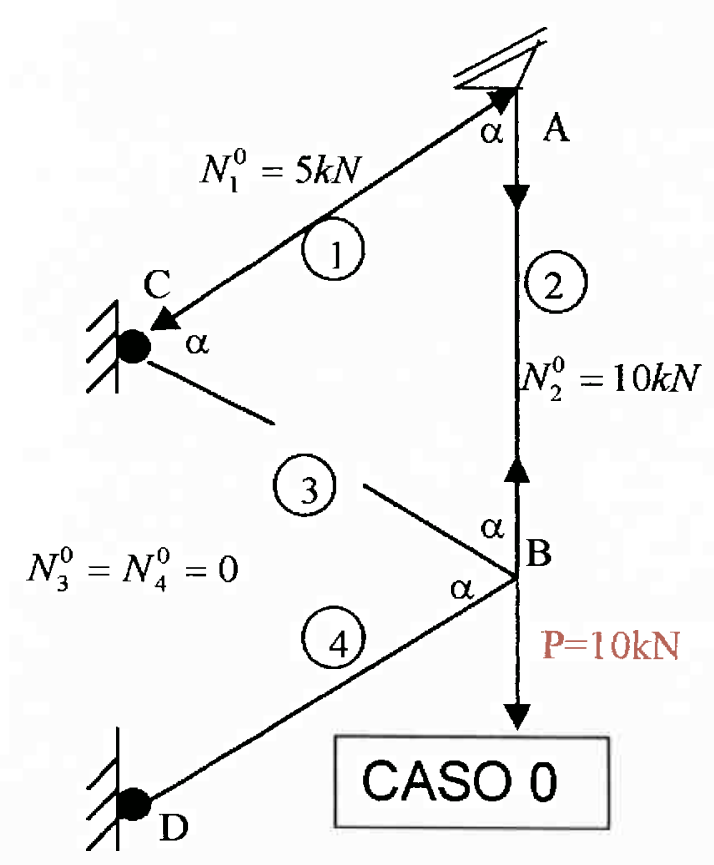

Figura 6.3: Estrutura isostática fundamental resolvida para o carregamento original.

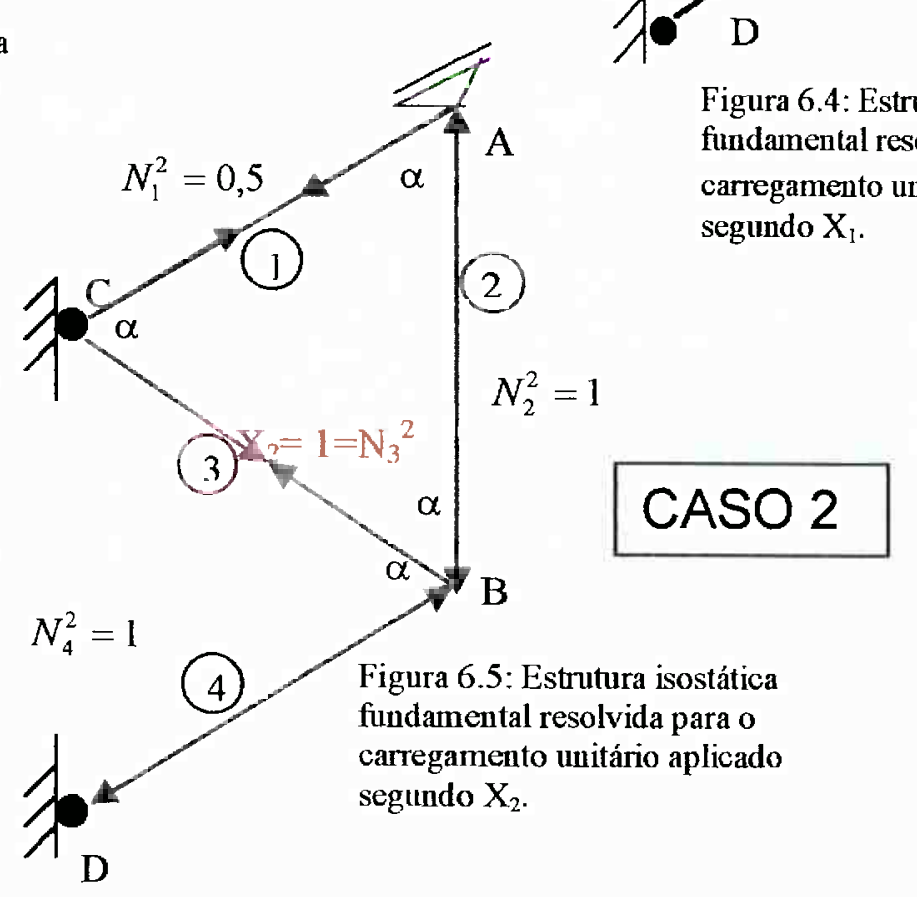

O esforço $N_{i}^{j}$ significa o esforço normal na barra i relativo ao carregamento do caso j.

Os cálculos relativos ao vetor $\left\{\delta^{0}\right\}$ e da matriz de flexibilidade [F] são baseados na tabela a seguir: 


\begin{tabular}{|c|c|c|c|c|c|c|c|c|c|c|}
\hline Barra & $\mathrm{N}_{\mathrm{i}}^{0}$ & $\mathrm{~N}_{\mathrm{i}}^{1}$ & $\mathrm{~N}_{i}^{2}$ & $L_{i} / E A_{i}$ & $\delta_{1}^{0}$ & $\delta_{2}^{0}$ & $\delta_{11}$ & $\delta_{21}$ & $\delta_{12}$ & $\delta_{22}$ \\
\hline 1 & -5 & $-0,289$ & 0,5 & $5.10^{-3}$ & $-7,23.10^{-3}$ & $-0,0125$ & $4,18 \cdot 10^{-4}$ & $-7,2.10^{-4}$ & $-7,2.10^{-4}$ & $1,25.10^{-3}$ \\
\hline 2 & 10 & 0,577 & $-1,0$ & $5.10^{-3}$ & 0,0289 & $-0,05$ & $1,665 \cdot 10^{-3}$ & $-2,89.10^{-3}$ & $-2,89.10^{-4}$ & $5.10^{-3}$ \\
\hline 3 & 0 & 0 & 1,0 & $5.10^{-3}$ & 0 & 0 & 0 & 0 & 0 & $5.10^{-3}$ \\
\hline 4 & 0 & 1,155 & $-1,0$ & $5.10^{-3}$ & 0 & 0 & $6,7.10^{-3}$ & $-5,78.10^{-3}$ & $-5,78.10^{-3}$ & $5.10^{-3}$ \\
\hline & & & & & 0,0361 & $-0,0625$ & $8,75.10^{-3}$ & $-9,38.10^{-3}$ & $-9,38.10^{-3}$ & 0,0163 \\
\hline
\end{tabular}

A componente $\delta^{0}{ }_{1}$ do vetor $\left\{\delta^{0}\right\}$ é obtida pelos valores relativos a $\mathrm{N}^{0}{ }_{\mathrm{i}}$ e $\mathrm{N}^{1}$ i por meio da seguinte relação:

$$
\delta_{1}^{0}=\sum_{i=1}^{4}\left(N_{i}^{0} N_{i}^{1} \frac{L_{i}}{E A_{i}}\right)
$$

Observando a tabela, tem-se:

$$
\delta_{1}^{0}=0,0361 m
$$

A componente $\delta^{0}{ }_{2}$ do vetor $\left\{\delta^{0}\right\}$ é obtida pelos valores relativos a $\mathrm{N}^{0}{ }_{\mathrm{i}}$ e $\mathrm{N}^{2}{ }_{\mathrm{i}}$, por meio da seguinte relação:

$$
\delta_{2}^{0}=\sum_{i=1}^{4}\left(N_{i}^{0} N_{i}^{2} \frac{L_{i}}{E A_{i}}\right)
$$

Observando a tabela, tem-se:

$$
\delta_{2}^{0}=-0,0625 m
$$

Com (6.3) e (6.5), o vetor $\left\{\delta^{0}\right\}$ é dado por:

$$
\left\{\delta^{0}\right\}=\left\{\begin{array}{c}
0,0361 \\
-0,0625
\end{array}\right\}
$$

A seguir, deve ser obtida a matriz de flexibilidade $[\mathrm{F}]$. 


\section{OBTENÇÃO DA PRIMEIRA COLUNA DA MATRIZ DE FLEXIBILIDADE}

$O$ termo $\delta_{11}$ da matriz de flexibilidade é obtido pelos valores relativos a $\mathrm{N}^{1}$, por meio da seguinte expressão:

$$
\delta_{11}=\sum_{i=1}^{4}\left(N_{i}^{1} N_{i}^{1} \frac{L_{i}}{E A_{i}}\right)
$$

Observando a tabela, tem-se:

$$
\delta_{11}=8,75 \cdot 10^{-3} \mathrm{~m}
$$

$\mathrm{O}$ termo $\delta_{21}$ da matriz de flexibilidade é obtido pelos valores relativos a $\mathrm{N}_{\mathrm{i}}{ }_{\mathrm{i}} \mathrm{e} \mathrm{N}^{2}{ }_{\mathrm{i}}$, por meio da seguinte expressão:

$$
\delta_{21}=\sum_{i=1}^{4}\left(N_{i}^{1} N_{i}^{2} \frac{L_{i}}{E A_{i}}\right)
$$

Observando a tabela, tem-se:

$$
\delta_{21}=-9,38 \cdot 10^{-3} \mathrm{~m}
$$

\section{OBTENÇÃO DA SEGUNDA COLUNA DA MATRIZ DE FLEXIBILIDADE}

O termo $\delta_{12}$ da matriz [F] é obtido pelos valores relativos a $\mathrm{N}_{\mathrm{i}}^{1}$ e $\mathrm{N}_{\mathrm{i}}^{2}$, por meio da seguinte relação:

$$
\delta_{12}=\sum_{I=1}^{4}\left(N_{i}^{1} N_{i}^{2} \frac{L_{i}}{E A_{i}}\right)
$$

Observando a tabela, tem-se:

$$
\delta_{12}=-9,38 \cdot 10^{-3} \mathrm{~m}
$$

O termo $\delta_{22}$ da matriz [F] é obtido pelos valores relativos a $\mathrm{N}^{2}$, por meio da seguinte relação:

$$
\delta_{22}=\sum_{i=1}^{4}\left(N_{i}^{2} N_{i}^{2} \frac{L_{i}}{E A_{i}}\right)
$$


Observando a tabela, tem-se:

$$
\delta_{22}=0,0163 m
$$

A matriz de flexibilidade é obtida a partir de (6.8), (6.10), (6.12) e (6.14), então:

$$
[F]=\left[\begin{array}{cc}
8,75 \cdot 10^{-3} & -9,38 \cdot 10^{-3} \\
-9,38 \cdot 10^{-3} & 0,0163
\end{array}\right]
$$

Assim, tem-se o sistema linear abaixo:

$$
\begin{aligned}
& \{\delta\}=\left\{\delta^{0}\right\}+[F]\{X\} \\
& {\left[\begin{array}{cc}
8,75 \cdot 10^{-3} & -9,38 \cdot 10^{-3} \\
-9,38 \cdot 10^{-3} & 0,0163
\end{array}\right]\left\{\begin{array}{l}
X_{1} \\
X_{2}
\end{array}\right\}=\left\{\begin{array}{c}
0,0361 \\
-0,0625
\end{array}\right\}}
\end{aligned}
$$

A solução é dada por:

$$
\begin{aligned}
& X_{1}=0 \\
& X_{2}=-3,85 k N
\end{aligned}
$$

\subsubsection{Resolução da Treliça pelo Processo dos Deslocamentos}

Considerando a mesma treliça do item 6.4.1. A primeira observação a ser feita é a visualização dos graus de liberdade conforme mostra a Figura 6.9.

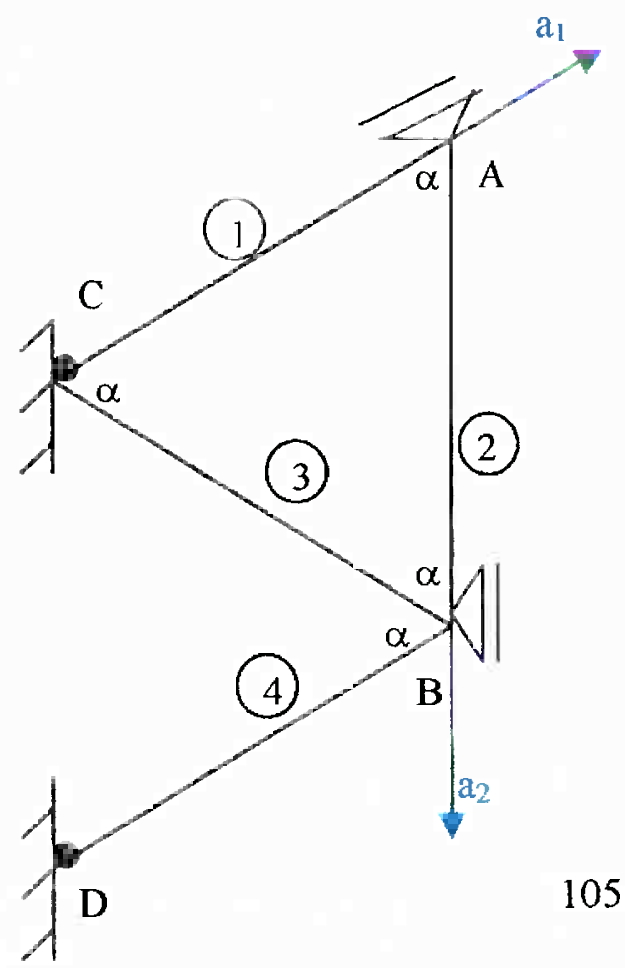

$$
\begin{aligned}
& \mathrm{L}_{1}=\mathrm{L}_{2}=\mathrm{L}_{3}=\mathrm{L}_{4}=5 \mathrm{~m} \\
& \mathrm{EA}=10^{3} \mathrm{kN}
\end{aligned}
$$

Figura 6.6: Graus de liberdade da treliça 
A seguir, deve ser obtida a estrutura bloqueada, mostrada na Figura 6.10:

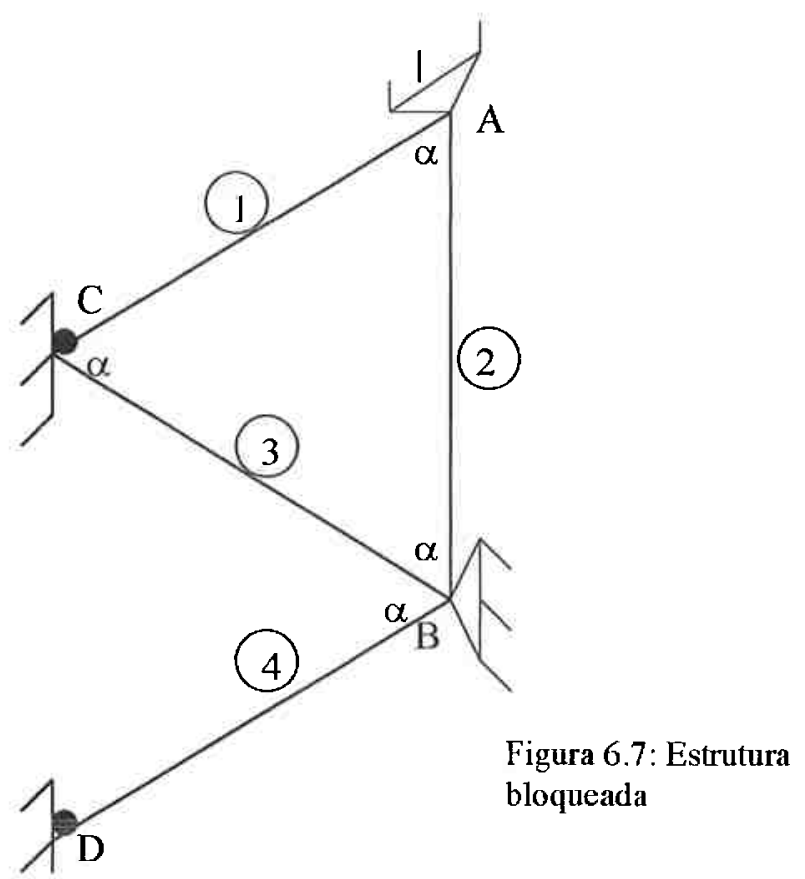

Havendo dois graus de liberdade, serão obtidas duas equações de equilíbrio. Conseqüentemente, os vetores $\{\mathrm{f}\}$ e $\left\{\mathrm{f}^{0}\right\}$ são de ordem $2 \times 1$, enquanto a matriz $[\mathrm{F}]$ é $2 \times 2$. A seguir são obtidos esses dois vetores.

$O$ vetor $\{f\}$ tem como suas componentes os esforços externos aplicados correspondentes aos graus de liberdade, então:

$$
\{f\}=\left\{\begin{array}{c}
0 \\
10
\end{array}\right\}
$$

Vale mencionar que ele é obtido a partir da estrutura original.

$O$ vetor $\left\{\mathrm{f}^{0}\right\}$ indica os esforços de engastamento perfeito. Como a estrutura em análise é uma treliça, apenas possui forças aplicadas aos nós. Sendo assim, é um vetor nulo, portanto:

$$
\left\{f^{0}\right\}=\left\{\begin{array}{l}
0 \\
0
\end{array}\right\}
$$

$O$ vetor $\left\{f^{0}\right\}$ é obtido em relação à estrutura bloqueada. 
A seguir, deve-se obter a matriz de rigidez da treliça. Este procedimento consiste em impor deslocamentos unitários segundo os graus de liberdade da estrutura. Cada deslocamento imposto irá fornecer uma coluna da matriz de rigidez, que é composta pelos esforços correspondentes a esses deslocamentos unitários, ou seja: impondo um deslocamento unitário segundo o grau de liberdade $a_{1}$, surge um esforço correspondente a esse grau, $K_{11}$, e outro correspondente ao grau de liberdade $a_{2}, K_{21}$. Analogamente, impondo um deslocamento unitário segundo $a_{2}$, obtêm-se $K_{22}$ na direção desse mesmo grau e $K_{21}$ na direção de $\mathbf{a}_{1}$.

\section{DETERMINAÇÃO DA PRIMEIRA COLUNA DA MATRIZ DE RIGIDEZ}

A determinação das colunas da matriz de rigidez deve seguir o seguinte procedimento:

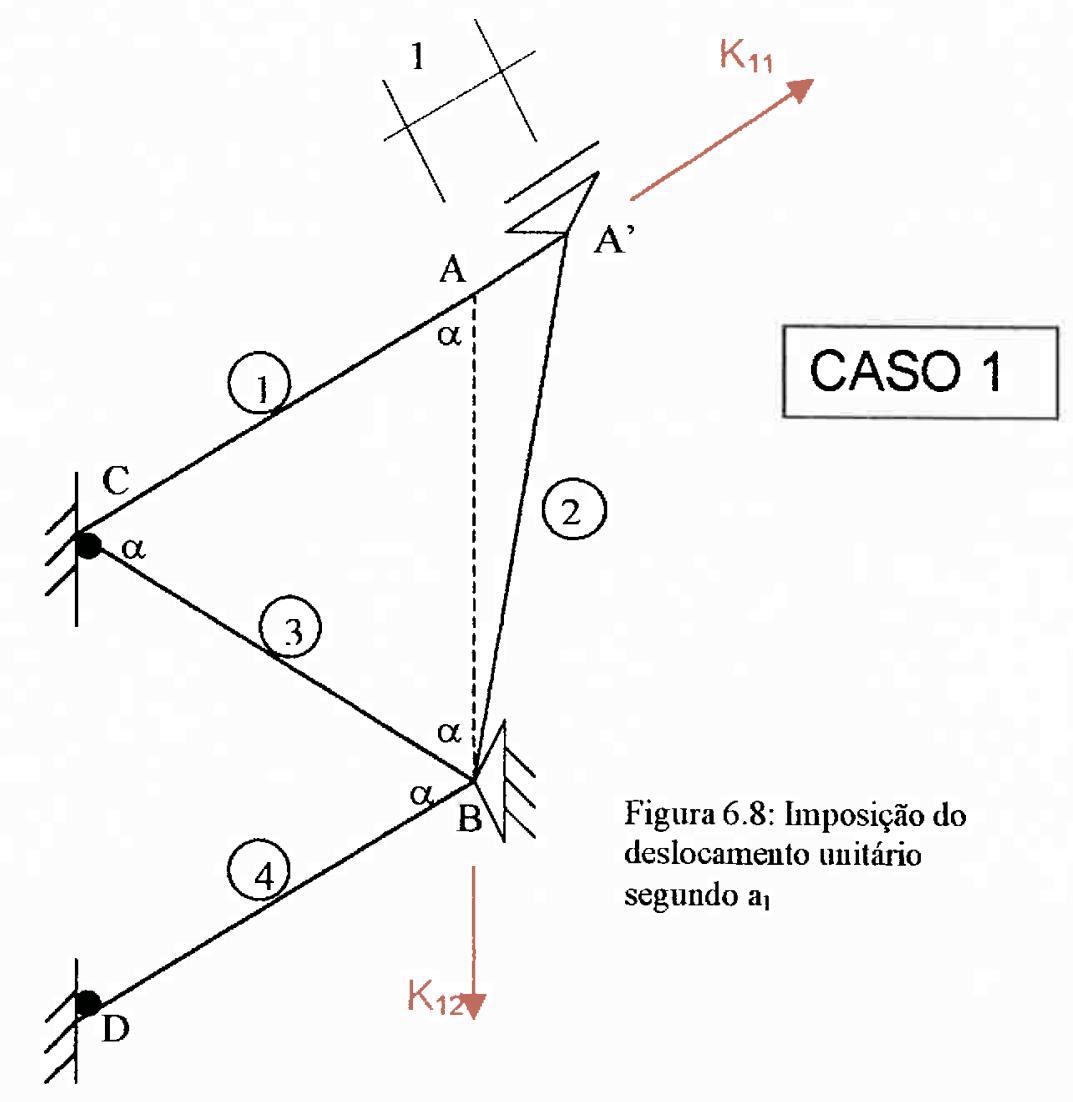

Deve-se impor um deslocamento unitário segundo o grau de liberdade $a_{1}$. Em seguida, devem ser seguidos os seguintes passos: 
1) IMPOSIÇÃO DA COMPATIBILIDADE ENTRE DESLOCAMENTOS E DEFORMAÇÕES

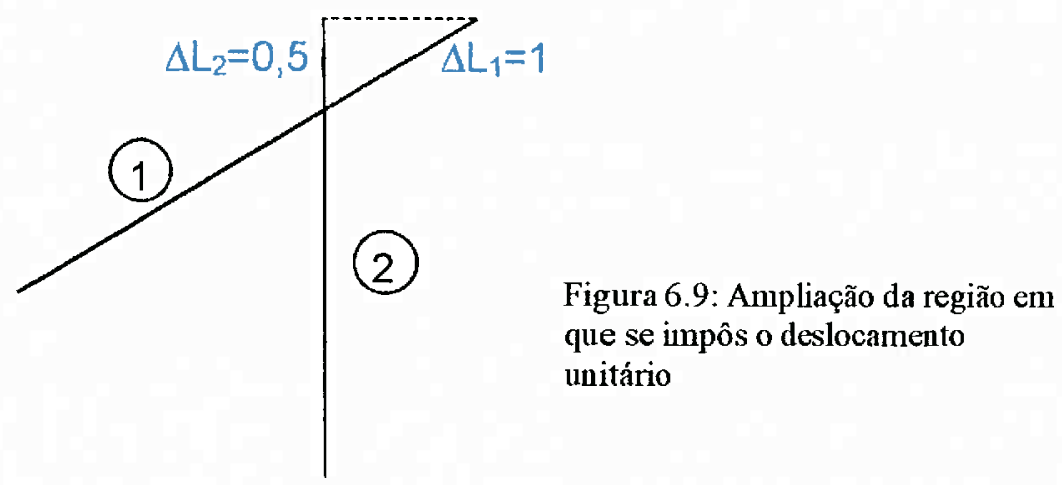

A variação de comprimento da barra 1 possui a mesma magnitude que o deslocamento imposto.

2) UTILIZAÇÃO DA LEI DE HOOKE

$$
\begin{aligned}
& N_{1}^{1}=E A_{1} \frac{\Delta L_{1}}{L_{1}}=200 k N \\
& N_{2}^{1}=E A_{2} \frac{\Delta L_{2}}{L_{2}}=100 k N
\end{aligned}
$$

\section{3) IMPOSIÇÃO DO EQUILÍBRIO}

Os termos $K_{11}$ e $K_{21}$ são obtidos através da imposição do equilíbrio nos nós A e B, então:

EQUILÍBRIO DO NÓ A:

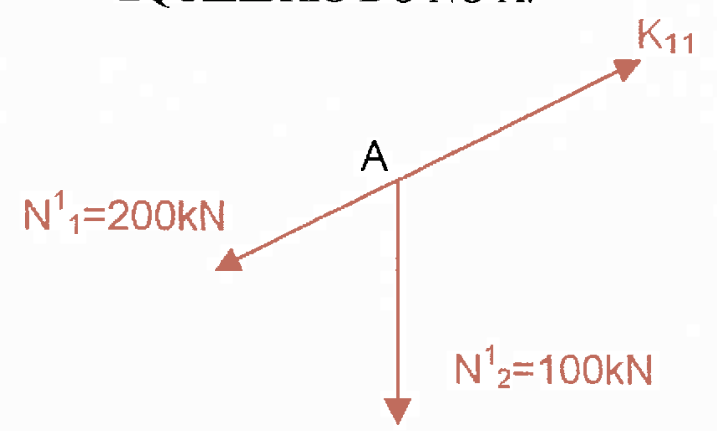

Figura 6.10: Forças atuantes no nó $\mathrm{A}$

Obtém-se:

$$
\mathrm{K}_{11}=250 \mathrm{kN} \text {. }
$$


EQUILÍBRIO DO NÓ B:

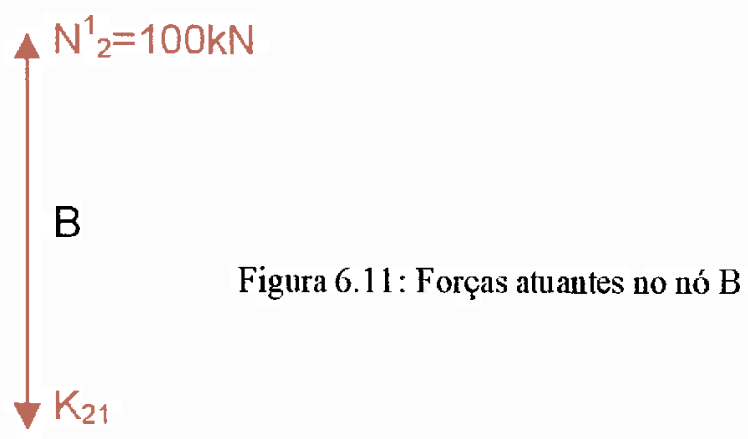

Obtém-se: $\quad K_{21}=100 \mathrm{kN}$

\section{DETERMINAÇÃO DA SEGUNDA COLUNA DA MATRIZ DE RIGIDEZ}

A obtenção da segunda coluna da matriz de rigidez se dá de maneira análoga, impondo-se um deslocamento unitário segundo o grau de liberdade $\mathrm{a}_{2}$.

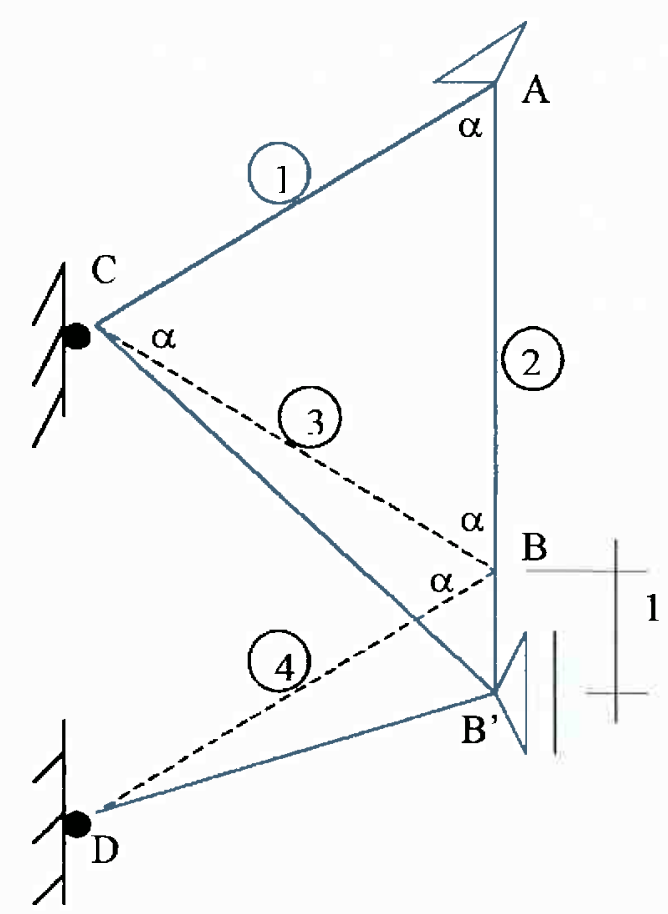

\section{CASO 2}

Figura 6.12: Imposição do deslocamento unitário segundo $\mathrm{a}_{2}$ 
1) IMPOSIÇÃO DA COMPATIBILIDADE ENTRE DESLOCAMENTOS E DEFORMAÇÃO

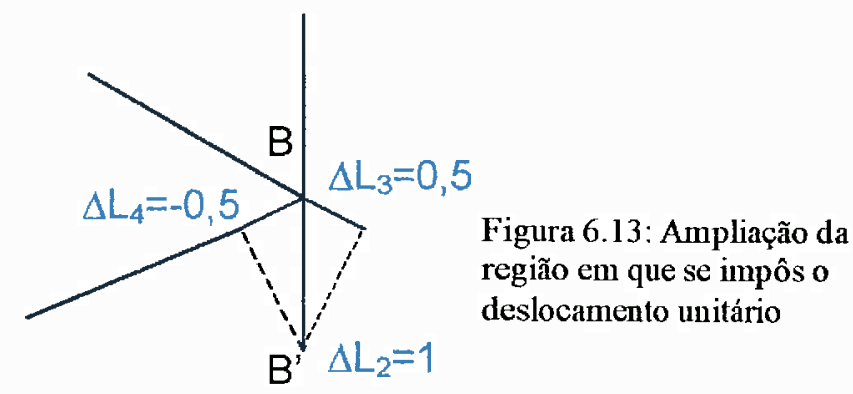

2) UTLIZAÇÃO DA LEI DE HOOKE

$$
\begin{aligned}
& N_{2}^{2}=E A_{2} \frac{\Delta L_{2}}{L_{2}}=200 k N \\
& N_{3}^{2}=E A_{3} \frac{\Delta L_{3}}{L_{3}}=100 k N \\
& N_{4}^{2}=E A_{4} \frac{\Delta L_{4}}{L_{4}}=-100 k N
\end{aligned}
$$

\section{3) IMPOSIÇÃO DO EQUILÍBRIO}

Os termos $K_{12}$ e $K_{22}$ são obtidos através da imposição do equilíbrio nos nós A e B, relativo aos graus de liberdade $a_{1}$ e $a_{2}$, então:

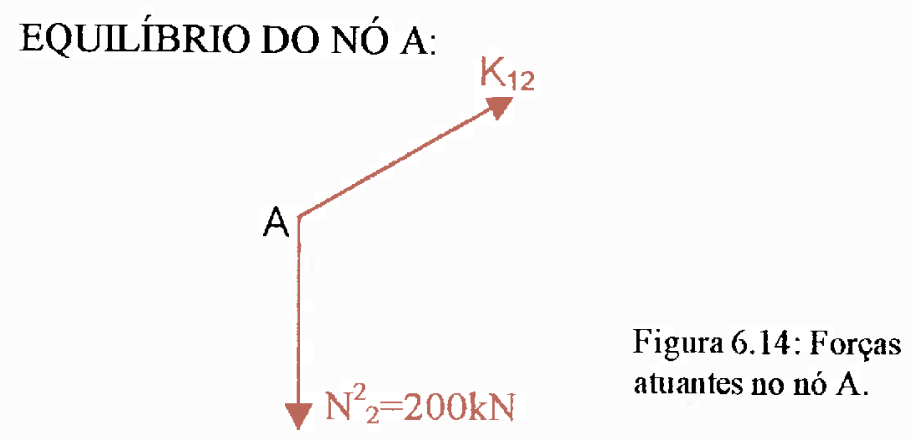

Tem-se: $\quad K_{12}=100 k N$. 


\section{EQUILÍBRIO DO NÓ B}

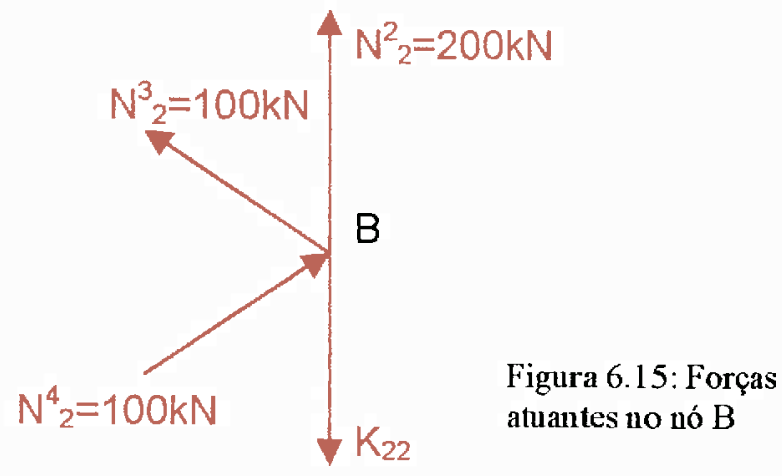

Tem-se: $\quad \mathrm{K}_{22}=300 \mathrm{kN}$.

Sendo assim, a matriz de rigidez é dada por:

$$
[K]=\left[\begin{array}{ll}
250 & 100 \\
100 & 300
\end{array}\right]
$$

Assim, pode-se estabelecer o sistema linear abaixo:

$$
[K]\{a\}=\{f\}-\left\{f^{0}\right\}
$$

Utilizando (6.17), (6.18) e (6.28), obtém-se:

$$
\left[\begin{array}{cc}
250 & 100 \\
100 & 300
\end{array}\right]\left\{\begin{array}{l}
a_{1} \\
a_{2}
\end{array}\right\}=\left\{\begin{array}{c}
0 \\
10
\end{array}\right\}
$$

A solução é dada por:

$$
\begin{aligned}
& a_{1}=0,0385 m \\
& a_{2}=-0,0154 m
\end{aligned}
$$




\section{Capítulo 7}

\section{Observações Finais}

\subsection{Introdução}

Até o presente capítulo, foram apresentados processos e conceitos que permitem realizar uma análise relativa aos processos que se situam dentro do Método Clássico: os Processos Direto, dos Esforços e dos Deslocamentos. Os dois últimos são apresentados tradicionalmente nos cursos de engenharia, enquanto que o primeiro tem pouca aplicação. De fato; o Processo Direto apresenta desvantagens que superam as vantagens oferecidas o que faz com que o mesmo não seja recomendável na resolução sistemática de estruturas, porém pode ser utilizado para mostrar a existência de um processo diverso dos tradicionais, ou seja, um processo misto alternativo.

\subsection{Análise e Conclusões}

Conforme afirmou-se na Capítulo 1, o método deve estar baseado na escolha de hipóteses fundamentais. O Método Clássico baseia-se no equilíbrio, na linearidade física e geométrica e na continuidade da estrutura. Já o processo está relacionado com o procedimento de cálculo através do qual se obtém a solução do problema. Dentro das hipóteses do Método Clássico, foram mencionados três processos:

a) O Processo dos Esforços

b) O Processo dos Deslocamentos

c) O Processo Direto

O primeiro processo é recomendável em relação ao segundo, quando uma estrutura apresentar seu grau de hiperestaticidade $(\mathrm{g})$ menor que o número de graus de liberdade $(\mathrm{h})$, pois a matriz de flexibilidade $[\mathrm{F}]$ será de ordem inferior à matriz de rigidez $[\mathrm{K}]$. $\mathrm{O}$ segundo processo é recomendável em relação ao primeiro quando a estrutura apresentar o número de graus de liberdade $(\mathrm{h})$ inferior ao grau de hiperestaticidade $(\mathrm{g})$, pois a matriz de rigidez $[\mathrm{K}]$ será de ordem inferior à matriz de flexibilidade $[\mathrm{F}]$. 
O Processo Direto é válido, pois leva aos mesmos resultados fornecidos pelos processos tradicionais. Eventuais diferenças são atribuídas a erros de arredondamento nas operações executadas. No entanto, o Processo Direto é menos eficiente que os outros dois processos, uma vez que sua matriz é de ordem $M \times M$, onde $M=g+h$, sendo $g$ o grau de hiperestaticidade da estrutura e h, o número de graus de liberdade da estrutura, portanto superior ao dos processos tradicionais, pois no Processo dos Esforços, a matriz de flexibilidade possui ordem gxg, enquanto no Processo dos Deslocamentos, a matriz de rigidez possui ordem hxh. Além disso, no Processo Direto a matriz não é simétrica, o que não ocorre nos outros dois processos. Tais razões indicam que o Processo Direto não é recomendável para a resolução de estruturas. No entanto, ele permite a introdução conceitual dos Processos dos Esforços e dos Deslocamentos. Os processos tradicionais são formulações irredutíveis. Segundo Zienkiewicz, o estabelecimento das equações diferenciais vai determinar se uma formulação será irredutivel ou mista e que é possível obter mais de uma formulação irredutível para uma dada situação física. Ele atribui a denominação irredutivel quando não é mais possível eliminar qualquer incógnita utilizada na solução do problema. Observando as ordens das matrizes de rigidez e flexibilidade e comparando-as com a matriz dos coeficientes do Processo Direto, percebe-se facilmente que este não se enquadra na definição de formulação irredutível enunciada por Zienkiewicz.

Pode-se notar que as matrizes de rigidez e flexibilidade não são de uso exclusivo dos Processos dos Deslocamentos e dos Esforços. Élas possuem aplicação mais abrangente conforme foi visto.

O Processo Direto pode fornecer esforços e deslocamentos: pode-se ter as equações constitutivas inseridas nas equações de equilíbrio, obtendo-se um sistema linear com incógnitas relativas às deformações nas barras (deformações axiais e curvaturas), ou podese proceder conforme foi realizado neste trabalho, inserindo as equações constitutivas nas equações de compatibilidade, obtendo-se os esforços de extremidade em cada barra.

Repete-se no Processo Direto a mesma dificuldade encontrada no Processo dos Esforços no que diz respeito à automação, pois ambos necessitam de uma estrutura isostática fundamental. $\mathrm{O}$ fato de haver várias estruturas isostáticas fundamentais torna o Processo dos Deslocamentos uma alternativa mais interessante para a automação, uma vez que só existe uma estrutura bloqueada. Além disso, o Processo Direto assim como o Processo dos Esforços tem o grau de complexidade da resolução do problema dependente da escolha da estrutura isostática fundamental: uma escolha inconveniente pode resultar em uma resolução mais trabalhosa.

A utilização dos Teoremas dos Deslocamentos e dos Esforços Virtuais caracterizaram meios de obtenção das equações de equilíbrio e compatibilidade, respectivamente: observou-se que as equações de equilíbrio são facilmente obtidas através do equilíbrio direto, enquanto as equações de compatibilidade têm como caminho mais fácil para sua obtenção a aplicação do Teorema dos Esforços Virtuais. Vale salientar que os Teoremas dos Deslocamentos e dos Esforços Virtuais constituem uma teoria mais abrangente e mais

${ }^{1}$ Zienkiewicz, O.C. The Finite Element Method - p.319 e 320. 
genérica que o Processo Direto: enquanto os primeiros possuem maior amplitude em sua aplicação, podendo ser aplicados em estruturas genéricas, sem mencionar as características do material, o Processo Direto apresenta, neste trabalho, seu uso mais restrito, encontrando suas fronteiras nas hipóteses do Método Clássico. 


\section{Bibliografia}

[1] Costa, H.B; Diogo, L. A. C. Considerações sobre o Emprego do Teorema dos Trabalhos Virtuais na Resolução de Estruturas Hiperestáticas: Treliças. BT/PEF-9007 (Boletim Técnico do Departamento de Engenharia de Estruturas e Fundações) EPUSP, São Paulo, 1990.

[2] Costa, H.B; Diogo, L. A. C. Considerações sobre o Emprego do Teorema dos Trabalhos Virtuais na Resolução de Estruturas Hiperestáticas: Pórticos. BT/PEF-9517 (Boletim Técnico do Departamento de Engenharia de Estruturas e Fundações) EPUSP, São Paulo, 1995.

[3] Costa, H.B. Notas de aula de PEF-212 - Resistência dos Materiais II. EPUSP, 1996.

[4] Gere, J. T; Weaver Jr., W. Análise de Estruturas Reticuladas. Editora Guanabara, 1987. Rio de Janeiro.

[5] Oden, J. T; Ripperger, E. A. Mechanics of Elastic Structures. Mc Graw Hill, $2^{\text {nd }}$ Ed.. New York.

[6] Langendonck, T. H. M. Van. Considerações sobre o Método Clássico de Resolução de Estruturas Hiperestáticas. São Paulo.

[7] Timoshenko, S.P; Gere, J. E. Mecânica dos Sólidos. Volumes I e II. LTC - Livros Técnicos e Científicos Editora, 1984. Rio de Janeiro.

[8] Notas de aula de PEF - 5740 - Elementos de Matemática Aplicada à Engenharia de Estruturas, 1996.

[9] Zienkiewicz, O. C. The Finite Element Method. Mc Graw Hill, $4^{\text {th }}$ Ed., 1989. London.

[10] Laursen, H. I. Structural Analysis. Mc Graw Hill Book Company $2^{\text {nd }}$ Ed. 1978. New York.

[11] Mazzilli, C. E. N; André, J. C; Bucalem, M; Cifu, S. Teoremas de Trabalhos Virtuais e Teorema de Energia. EPUSP, 2000.

[12] Langhaar, H. L. Energy Methods in Applied Mechanics. John Wiley \& Sons, Inc. New York, 1962.

[13] Lindenberg N., H. Introdução à Mecânica das Estruturas. EPUSP. 1996. 